\title{
Control-Oriented Thermal Network Models for Predictive Load Management in Canadian Houses with On-Site Solar Electricity Generation: Application to a Research House
}

\author{
Seyed Matin Abtahi \\ A Thesis \\ In the Department \\ of \\ Building, Civil, and Environmental Engineering \\ Presented in Partial Fulfillment of the Requirements \\ For the Degree of \\ Master of Applied Science (in Building Engineering) at \\ Concordia University \\ Montreal, Québec, Canada
}

May 2021

(C) Seyed Matin Abtahi, 2021 


\section{Concordia University}

\section{School of Graduate Studies}

This is to certify that the thesis prepared

By: Seyed Matin Abtahi

Entitled: Control-Oriented Thermal Network Models for Predictive Load Management in Canadian Houses with On-Site Solar Electricity Generation: Application to a Research House

and submitted in partial fulfillment of the requirements for the degree of Master of Applied Science (Building Engineering)

Signed by the final Examining Committee:

Chair

Dr. H. Ge

Examiner

Dr. B. Lee

Examiner

Dr. M. Ouf

Supervisor

Dr. A. Athienitis

Approved by Chair of Department or Graduate Program Director

Dr. Michelle Nokken

May 2021 Dean of Gina Cody School of Engineering and Computer Science Dr. Mourad Debbabi 


\section{Abstract \\ Control-Oriented Thermal Network Models for Predictive Load Management in Canadian Houses with On-Site Solar Electricity Generation: Application to a Research House}

Seyed Matin Abtahi

This study presents a methodology to develop suitable control-oriented thermal RC network models for optimized HVAC load management in typical electrically heated single-family detached houses. Using recurring parameter identification and model-reset, the building dynamics are represented by an explicit discrete time-varying state-space formulation.

Next, these models are applied in a predictive control framework in which the objective is to enhance energy efficiency and energy flexibility of the building by prioritizing the import from the most efficient energy source(s), storing energy in the building's thermal mass and/or a battery, and shifting the HVAC load to lower the stress on the local grid.

Finally, the benefits of predictive control strategies for HVAC load management, both for the building owners and the local grid, are studied through a seasonal simulation where the performance of the building subject to a reference reactive controller and a predictive controller are compared. Applying the predictive controller, the results show an average of $12.1 \%$ reduction in the daily heating load, $19.8 \%$ reduction in the total daily import, $68.1 \%$ reduction in the peak demand, $67.0 \%$ reduction in the daily energy cost, and $13.4 \%$ increase in the self-consumption of on-site generated solar electricity for the duration of January 1 st to March 31st (90 days), compared to the reactive controller. 


\section{Acknowledgments}

I would like to express my sincere gratitude to my supervisor, Dr. Athienitis for his support, expert guidance and understanding throughout my studies.

I would also like to thank my colleagues at the Centre for Zero Energy Building Studies for their helpful ideas, constructive feedback and friendship: Stratos Rounis, Jennifer Date, Vasken Dermardiros, Navid Morovat, Zissis Ioannidis, Harry Vallianos and Jiwu Rao.

I would like to acknowledge the technical and financial support from the NSERC/Hydro-Québec Industrial Research Chair and the Faculty of Gina Cody School of Engineering and Computer Science at Concordia University. The use of the Hydro- Québec Experimental Houses for Building Energetics data is greatly appreciated.

I am appreciative of unconditional love and support from my parents, Yousef and Reyhaneh, and my brother Moein; thank you for your endless support and encouragement. 


\section{Table of Contents}

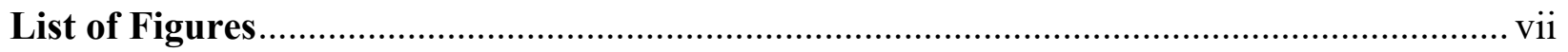

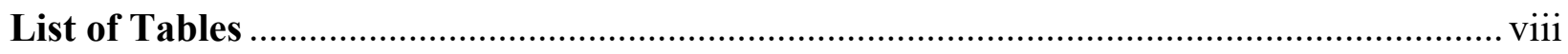

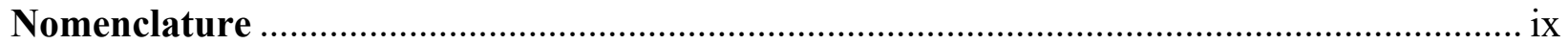

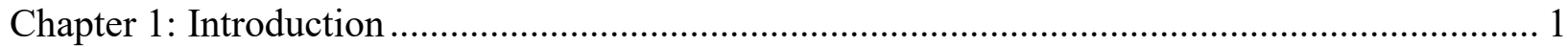

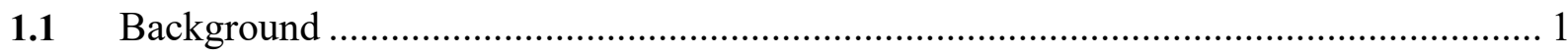

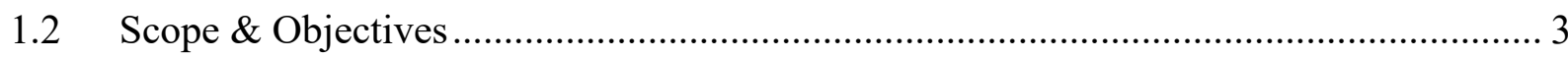

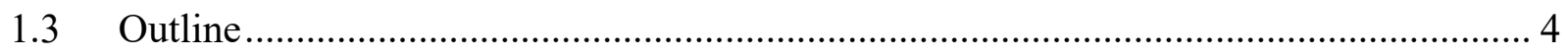

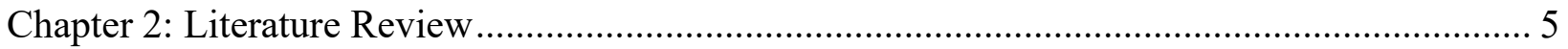

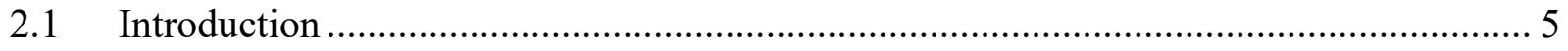

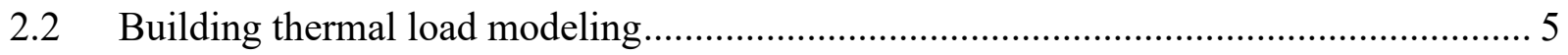

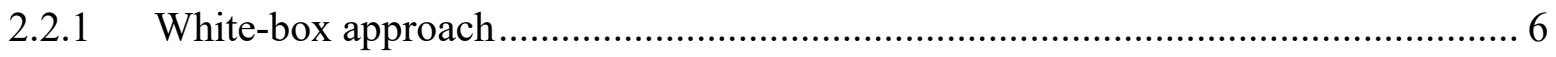

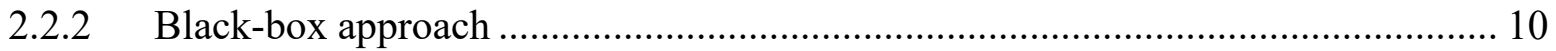

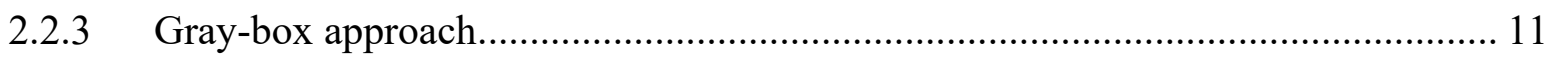

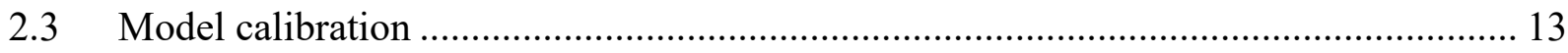

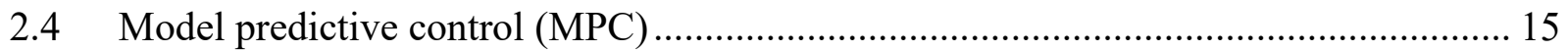

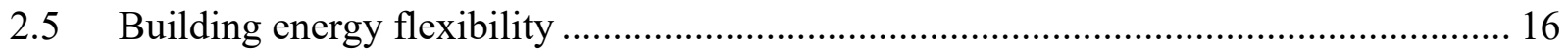

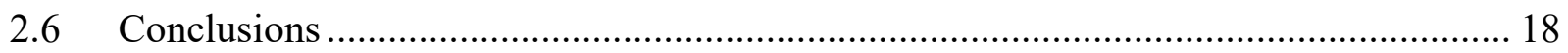

Chapter 3: Methodology and Evaluation' ............................................................................. 19

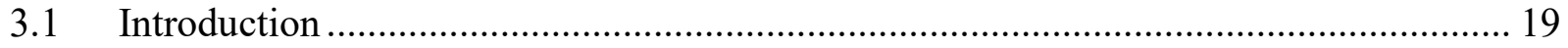

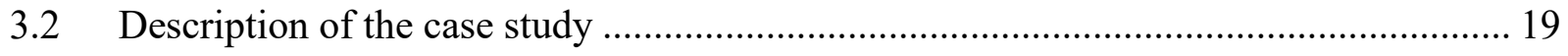

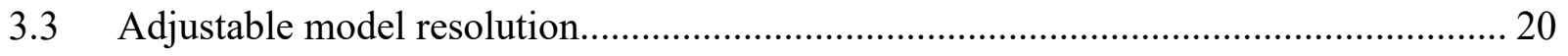

3.4 Sequential parameter identification............................................................... 21

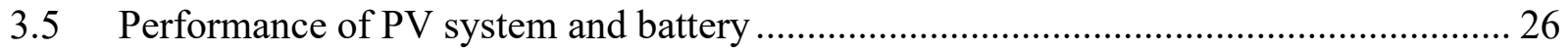

3.6 Predictive HVAC control ........................................................................... 27

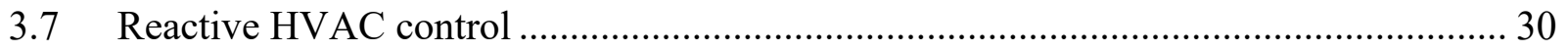




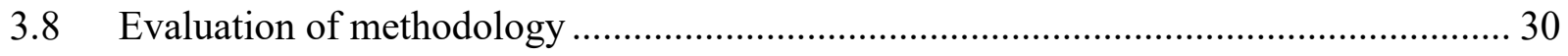

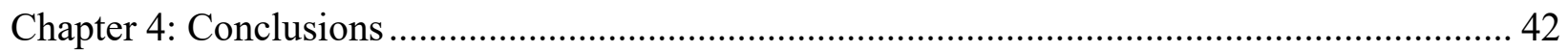

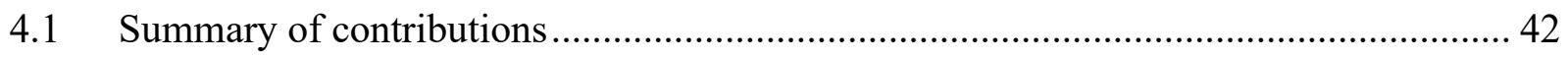

4.2 Recommendations for future work .............................................................. 42

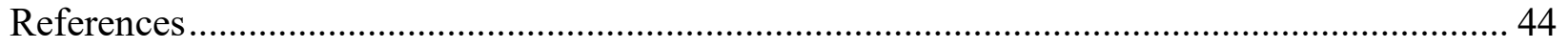

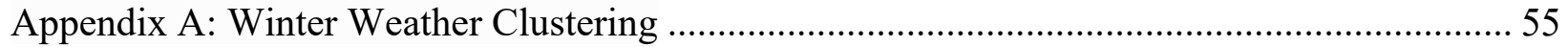

Appendix B: Photovoltaics System Performance Modelling …............................................. 57

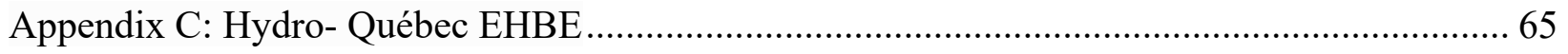

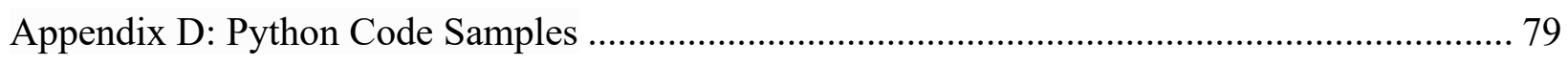

Appendix E: Model Selection and Over-Parameterization.................................................... 82 


\section{List of Figures}

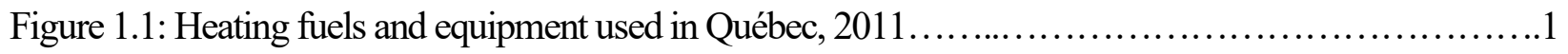

Figure 1.2: Normalized power demand of the grid in Québec on a typical very cold day of winter..........2

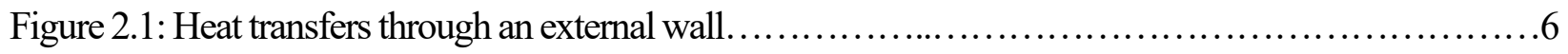

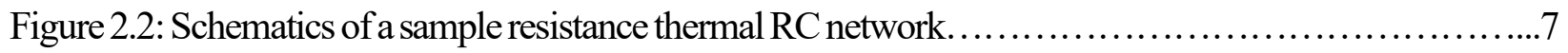

Figure 2.3: Explicit finite difference discretization. ........................................

Figure 2.4: Data science continuum and the concept of gray-box modeling .........................11

Figure 3.1: Hydro- Québec experimental house for building energetics, Shawinigan, Québec ...............20

Figure 3.2: 3C6R network model...................................................21

Figure 3.3: 3C7R network model....................................................22

Figure 3.4: Simulation reference: Price of electricity as per Hydro-Québec Rate Flex-D.................31

Figure 3.5: Simulation reference: Heating setpoints for the reactive controller and allowable zone air temperature range for the predictive controller................................................ 31

Figure 3.6: Forecast of outside ambient air temperature for March $27^{\text {th }}$ and March $28^{\text {th }} \ldots \ldots \ldots \ldots \ldots \ldots \ldots . . . . . .32$

Figure 3.7: Results of the 3C7R network model training and testing for simulation on March $27^{\text {th }}$ -

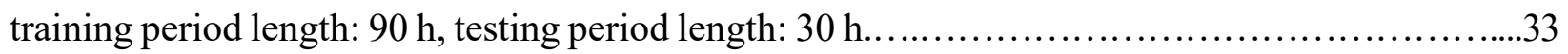

Figure 3.8: Electrical demand and generation subject to the predictive controller and the reactive controller-

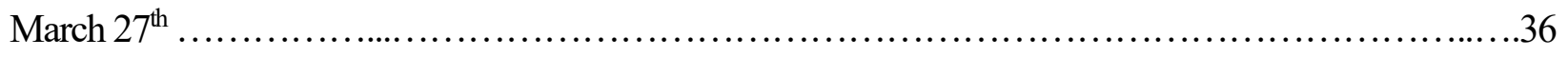

Figure 3.9: Zone air temperature subject to the predictive controller and the reactive controller $\operatorname{March} 27^{\text {th }}$ .36

Figure 3.10: : Battery state of charge subject to the predictive controller and the reactive controller

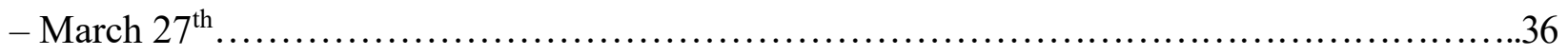

Figure 3.11: Electrical demand and generation subject to the predictive controller and the reactive controller - March $28^{\text {th }}$ 37

Figure 3.12: Zone air temperature subject to the predictive controller and the reactive controllerMarch $28^{\text {th }}$.... .37

Figure 3.13: Battery state of charge subject to the predictive controller and the reactive controller March $28^{\text {th }}$ .37

Figure 3.14: Building's net electrical demand subject to both controllers on March $27^{\text {th }}$ and March $28^{\text {th }}$ 


\section{List of Tables}

Table 3.1: Assumptions for calculation of initial values...............................22

Table 3.2: Initial values of proposed models......................................23

Table 3.3: Results of the 3C7R network model re-calibration for simulation on March $27^{\text {th }}$ -

Identification period: March $22^{\text {nd }}$ to March $26^{\text {th }} ; 75 \%$ train and $25 \%$ test $\ldots \ldots \ldots \ldots \ldots \ldots \ldots . . . .33$

Table 3.4: Building's daily measures subject to both controllers on March $27^{\text {th }}$ and March $28^{\text {th }}$. 39

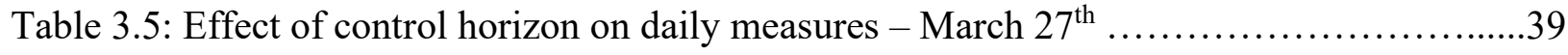

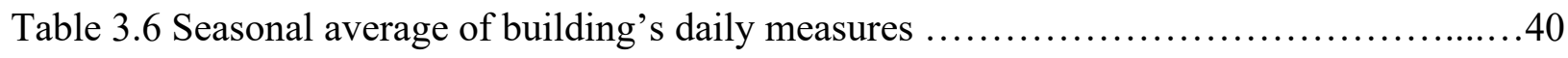




\section{Nomenclature}

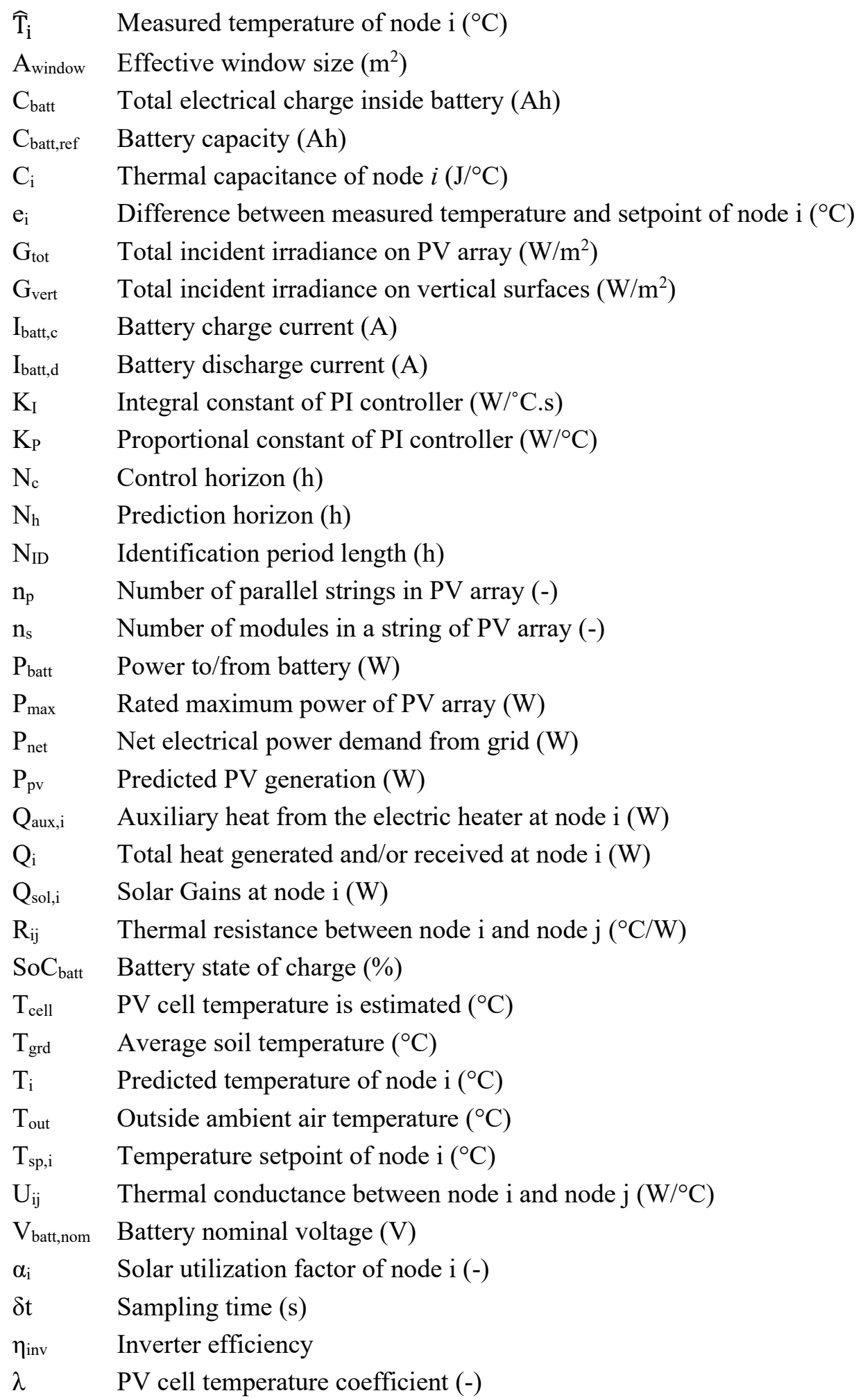




\section{Chapter 1: Introduction}

\subsection{Background}

In the province of Québec, $94 \%$ of generated electricity comes from hydroelectric plants (Le Bel \& Gelinas, 2012). Québec primary electricity generation was 170,260 GWh in 2011 (Statistics Canada, 2011b), while household energy use of electricity was 56,272 GWh, 33\% of total electricity generation.

Fig. 1.1 shows that $82 \%$ of Québec's households reported electricity as their main heating fuel (Statistics Canada, 2011a). This figure also shows 66\% of houses in Québec reported using baseboards as the main heating equipment and $9 \%$ reported electric radiant heating. It is expected that the installation of electric space heating will increase over the coming years due to their low initial and operating cost. The shape of the region's demand profile is strongly coincident with the demand profile of residential sector.
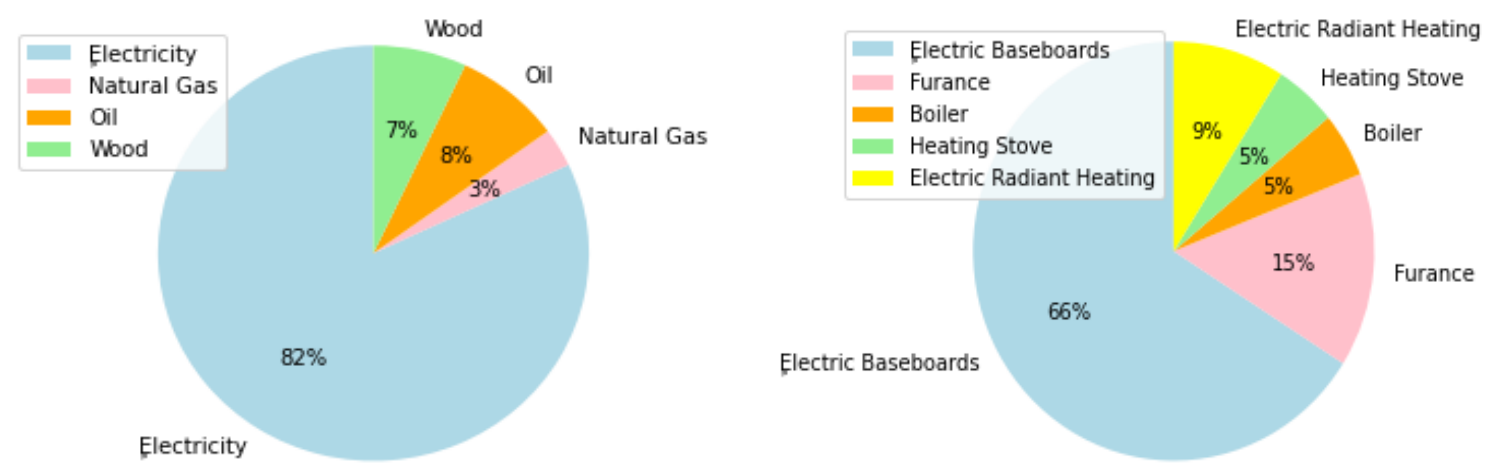

Figure 1.1: Heating fuels (left) and equipment (right) used in Québec, 2011

Due to its cold winter weather, Québec has a high space heating demand. In the winter, the peak demand periods typically occur on very cold weekday mornings between 6:00 and 9:00, and/or evenings between 16:00 and 20:00 (Fig. 1.2) during which space heating represents up to $80 \%$ of the total demand of the households (Le Bel \& Handfield, 2008) and effectively puts the grid under stress.

The total generating capacity of the Québec's grid from 87 stations which are operated by Hydro- Québec is $37.3 \mathrm{GW}$ (Belanger, 2018). In January 2013 there was a reported peak demand of 39.1 GW (Hydro- Québec, 2013). Therefore, in Québec, electric space heating 
in residential sector is a relevant load for demand response in the winter. Finding practical ways to shift and/or shave the load during the peak period can significantly reduce the stress on the grid. The newly-introduced dynamic tariff (Rate Flex-D) in combination with tailored instructions from a Hydro-Québec subsidiary (Hilo) gives the residential customers the opportunity to actively reduce the pressure on the grid and save money during the peak periods, by shifting the load to the off-peak periods when electricity is cheaper.

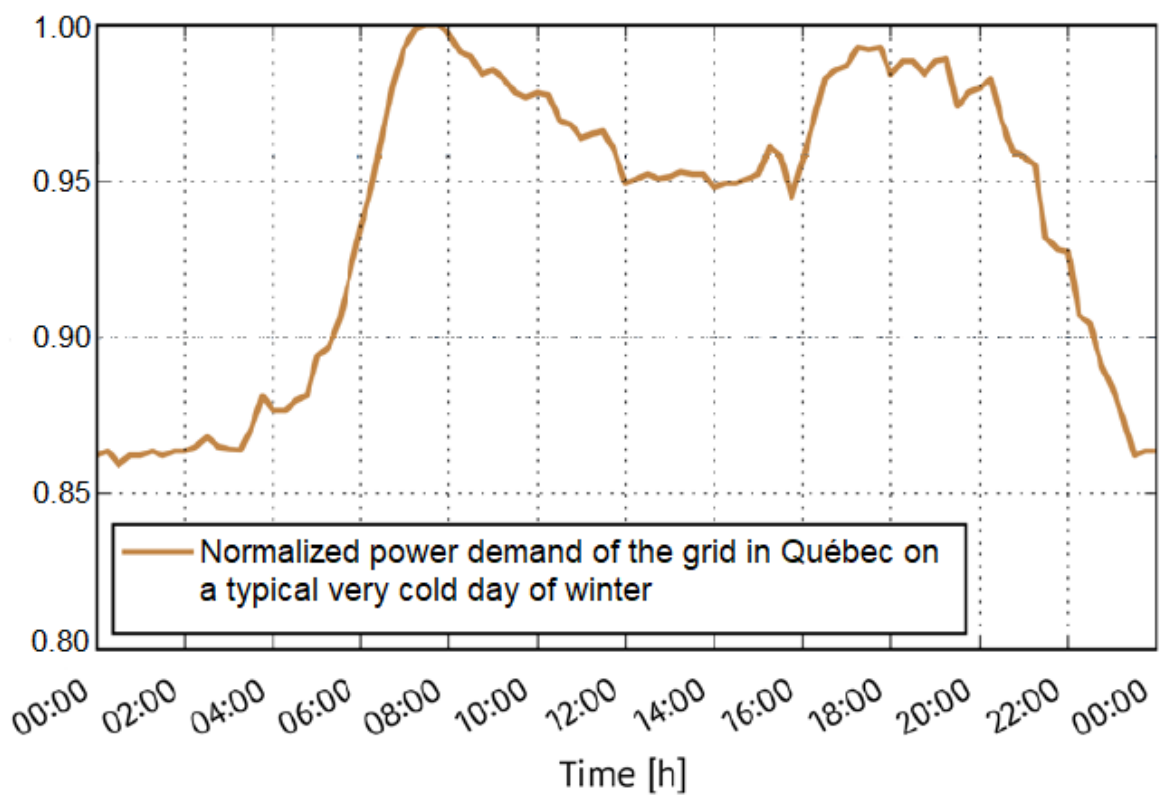

Figure 1.2: Normalized power demand of the grid in Québec on a typical very cold day of winter (Team MTL engineering narratives for Solar Decathlon China, 2018)

Even though it has been repeatedly reported that advanced control strategies significantly improve the operation of HVAC systems and reduce their carbon footprint, still the majority of buildings adopt simple on/off control or PID controllers with limited capacity for energy savings (Afram et al., 2014). Reactive approaches attempt to maintain a predefined profile of setpoint for different variables (e.g., inside air temperature, humidity and state of charge (SoC) of energy storage devices), with no regard to future weather conditions and energy price. Relatively large oscillation from the temperature setpoint when adopting on/off control and improper performance of untuned PID controllers are other drawbacks of rule-based control (RBC) techniques (Kuboth, Heberle, Konig-Haagen \& Brüggemann, 2019). 
On the other hand, buildings are also expected to play a major role in the high penetration of decentralized renewable energy. Solar electricity appears to have the greatest potential for renewable integration due to the significant drop in the price of photovoltaic (PV) technologies and also, the unutilized roof spaces (Mavromatidis et al., 2015); However, a major challenge associated with the integration of intermittent solar electricity generation and the building is the mismatch between the period of maximum solar generation and the peak consumption and/or high energy price periods (Date et al., 2020).

High-accuracy weather forecasts and digitalization facilitate the adoption of advanced control strategies using dynamic programming (DP) such as model predictive control (MPC), in buildings. MPC uses a mathematical model of the building to predict its future behaviour, based on which optimal control actions are implemented to systematically satisfy the occupants' thermal comfort while ensuring energy savings, grid flexibility services and/or maximization of self-consumption (Drgona et al., 2020).

\subsection{Scope \& Objectives}

The main objectives of this study are:

1. To develop suitable control-oriented thermal network models for optimal HVAC load management in an experimental house for building energetics (EHBE) which represents typical Canadian single-family detached houses. The building dynamics are represented by an explicit discrete time-varying state-space model through recurring parameter identification considering the uncertainty of parameters.

2. To apply the developed models in an MPC framework for day-ahead operation planning that enhances energy efficiency and energy flexibility of the building by storing energy in the building's thermal mass and/or a battery, and shifting the load to reduce the demand for electricity as needed/incentivized by the grid.

3. To compare the performance of the HVAC system subject to a reference reactive controller and a predictive controller within seasonal simulations to quantify the benefits of MPC for HVAC load management in the Canadian residential context, both for the building owners and the local grid. 


\subsection{Outline}

The following list summarizes the content of each chapter in this thesis:

Chapter 1) Introduction: Presents the motivation, the scope and the objectives of the research as well as the thesis outline.

Chapter 2) Literature Review: Presents a review on different building's thermal load modelling approaches with focus on gray-box modelling and proceeds by reviewing the literature and previous works in application of MPC, mostly in residential context.

Chapter 3) Methodology: Starts with a description of the Hydro-Québec Experimental House for Building Energetics (EHBE) and explains the methodology used to develop and calibrate the low-order RC thermal network and PV/battery performance models. Next, the application of developed models in an MPC framework where the objective is to enhance energy efficiency and energy flexibility of the building is presented. Finally, the benefits of predictive control strategies for HVAC load management are showcased through a seasonal simulation where the performance of the heating system subject to a reference reactive controller and a predictive controller are compared.

Chapter 4) Conclusions: Includes a summary of the main contributions and the recommendations for future work. 


\section{Chapter 2: Literature Review}

\subsection{Introduction}

This chapter reviews the literature related to the building thermal load modeling and discusses different approaches in section 2.2. This review will also provide an overview of building thermal load model calibration in section 2.3 , with specific attention to frequently used statistical indices. Another topic presented in section 2.4 is the literature and previous works in application of predictive control in the buildings, mainly in the residential context. Finally, section 2.5 reviews the definitions and drivers of energy flexibility in buildings.

\subsection{Building thermal load modeling}

The most common purpose of thermal load modeling is to study different design options and respective energy profiles and carbon footprint. To slow down the demand growth and reduce the amount of energy used within existing buildings, it is crucial to understand the energy distribution throughout a building and how each parameter contributes to the demand (Langner et al, 2012). Energy consumption analysis of buildings is an effortful task as it requires detailed knowledge of interactions among the building, the HVAC system and the surroundings or external factors such as weather, as well as obtaining mathematical and physical models that effectively characterize each of those items. The dynamic behaviour of weather conditions, building operations and occupant behaviour, and the presence of multiple variables, require computer simulations in the design and operation of high-performance buildings.

Building thermal modeling involves three main research approaches (Foucquier et al., 2013). First, the white-box modelling approach, based on the principles of heat transfer and conservation of energy and mass with physically meaningful parameters that are identified from geometry, material properties and equipment specifications. Second, the black-box modelling approach, based on machine learning (ML) techniques with parameters that are identified from the measured data with no assumption regarding the building geometry, envelope and equipment. And finally, a hybrid approach (gray-box), 
based on simplified physical relationships with parameters identified from the measured data.

\subsubsection{White-box approach}

The physics-based approach to building thermal modeling is based on the solving of equations describing the physical behaviour of heat transfer throughout the building. The principal thermal fluxes are conduction through the walls, convection, long wave and shortwave radiation and the ventilation.

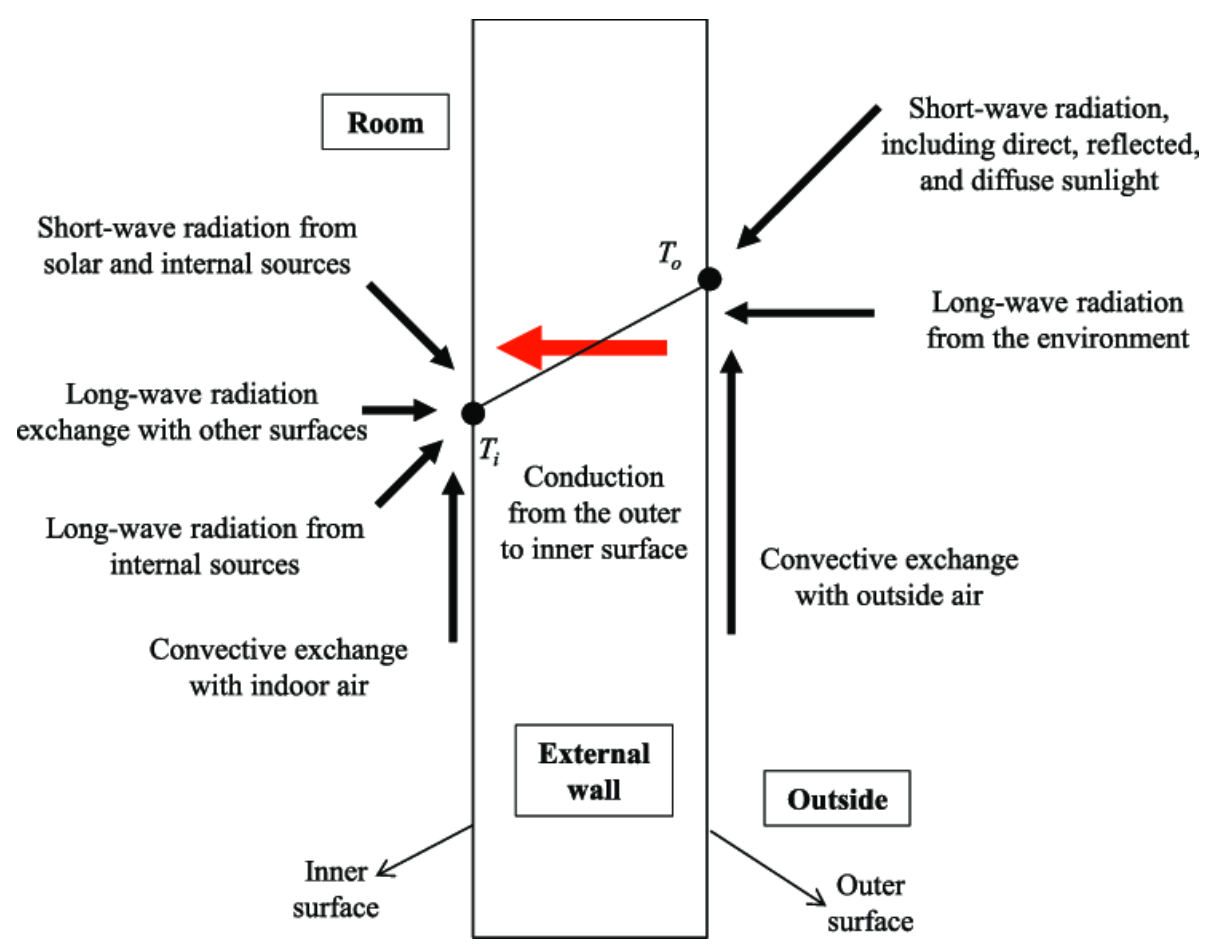

Figure 2.1: Heat transfers through an external wall (Yan et al., 2017)

Heat storage capacity and heat transmissibility are the fundamental thermal properties of building elements. Walls, ceilings, floors and the air inside enclosures are building components that can store energy. The capacity of these elements in storing energy is a function of their mass and their specific heat capacity. Heat is not only stored, but it can be transmitted through building elements in different ways.

Due to the perfect analogy between diffusion of heat and electrical charge, a useful representation of a thermal network utilizes an RC circuit analogue where heat storage is 
represented by capacitors and heat transmission by resistors. Lumped element approach further simplifies the description of spatially distributed $\mathrm{RC}$ networks into a topology consisting of discrete entities and approximates dynamics of the network, assuming that all the elements of the network are concentrated into idealized components. This approach reduces a thermal $\mathrm{RC}$ network to several discrete control volumes $(\mathrm{CV})$ and assumes that the temperature difference within each $\mathrm{CV}$ is negligible. Thus, it is a common simplifying approximation in transient conduction, which can be employed whenever heat conduction within a CV is much faster than heat transfer across its boundaries. From this scheme it is possible to derive the equations that govern the thermal dynamics of the building with finite-difference (FD) (Athienitis et al., 1985; Goyal \& Barooah, 2012; Hazyuk et al., 2012; Date et al., 2015), state-space (SS) (Athienitis et al., 1990; Candanedo et al., $2011 \& 2015$ ) or conduction transfer function (CTF) (Armstrong, Leeb \& Norford, 2006; Zakula, Armstrong \& Norford, 2014; Blum, Xu \& Norford, 2016) formulation.

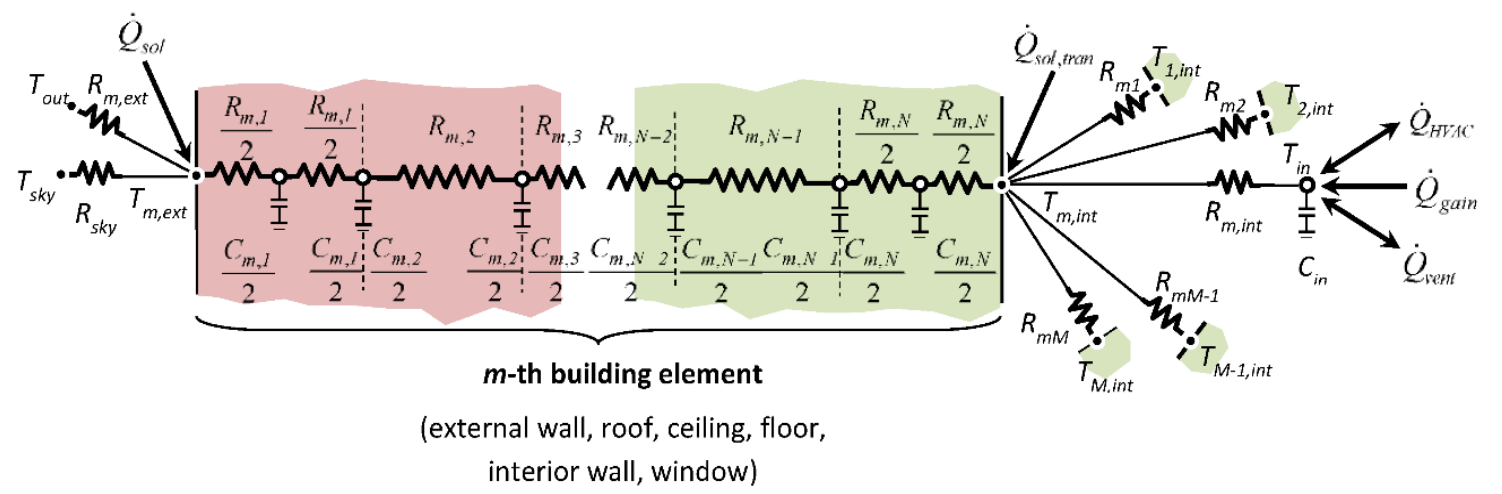

Figure 2.2: Schematics of a sample resistance thermal RC network (Buonomano, 2016)

Goyal \& Barooah (2012) used the lumped parameter RC analogy to predict the temperature and the humidity in multi-zone buildings from outside temperature and humidity, heat gains from occupants and solar radiation, supply air flow rates and supply air temperatures. Their objective was to decrease the order of this model by testing several reduction methods. Hazyuk et al. (2012) developed multi zone model using lumped parameter RC analogy and proposed a description of the walls and the floor by two identical resistances and one capacity. The thermal mass is characterized by a single capacity and windows by single resistances. Athienitis et al. (1985) used the same approach to model multi-zone passive solar buildings. The main advantage of the state-space 
formulation is the facilitated integration of design and control (Chen et al., 2013) and the main disadvantage is the difficulty of accommodating non-linearity, such as temperature dependent heat transfer coefficients. However, in practice, linearization of heat transfer phenomena is often an acceptable compromise (Shou, 1991).

Athienitis \& O'Brien (2015) state that commonly introduced assumptions in mathematical models to facilitate representation of the building thermal behaviour are:

1. Linearization of heat transfer: Convective and radiative heat transfer are nonlinear processes and the respective heat transfer coefficients are usually linearized so that the system energy balance equations can be solved by direct linear algebra techniques and, if desired, represented by a linear thermal network. Linearization generally introduces less error for long-wave radiant exchanges between surfaces than convection between surfaces and room air. A linear lumped parameter system can be represented by a set of ordinary differential equations and thermal networks. An important subset of linear systems is those with time varying coefficients, an important case in building energy analysis, where we can often represent thermal conductances as known variable level of natural ventilation or time-varying infiltration.

2. Spatial and/or temporal discretization: Transient heat conduction is described by a parabolic, diffusion type partial differential equation. Thus, when using finite difference methods, a conducting medium with significant thermal capacity such as concrete or brick must be discretized into a number of CVs which may be modelled by lumped network elements. Also, time domain discretization is required in which an appropriate time step is employed.

3. Approximations for appropriate model resolution: These approximations are employed in order to reduce the number of simultaneous equations to be solved and the required data input or to enable the derivation of analytical solutions. Combining radiative and convective heat transfer coefficients, assuming that surfaces are at the same temperature, or considering certain heat exchanges as negligible are some examples.

The one-dimensional heat transfer process for a section is governed by the following parabolic, diffusion-type partial differential equation:

$$
\frac{\partial T}{\partial t}=\alpha \frac{\partial^{2} T}{\partial x^{2}}
$$

where: 
$\alpha=k / \rho c=$ thermal diffusivity

$k=$ thermal conductivity

$\rho=$ density

$c=$ thermal capacitance

In explicit finite difference schemes, the temperature at time $\mathrm{n}+1$ depends explicitly on the temperature at time n. The explicit finite difference discretization of Eq. 2.1 is: ( $\alpha$ and $\Delta \mathrm{x}^{2}$ are assumed to be the same on all sides of the node i)

$$
\frac{T_{i}^{n+1}-T_{i}^{n}}{\Delta t}=\alpha \frac{T_{i+1}{ }^{n}-2 T_{i}{ }^{n}+T_{i-1}{ }^{n}}{\Delta x^{2}}
$$

This can be rearranged in the following manner:

$$
T_{i}^{n+1}=T_{i}^{n}+\alpha \Delta t \frac{T_{i+1}^{n}-2 T_{i}{ }^{n}+T_{i-1}{ }^{n}}{\Delta x^{2}}
$$

$T_{i+1}{ }^{n}, T_{i}^{n}$ and $T_{i-1}{ }^{n}$ are all known, thus $T_{i}^{n+1}$ is computable. This is schematically shown on Fig. 2.3. The main advantage of explicit finite difference method is its relative simplicity which makes this method computationally fast. However, the main drawback is that stable solutions are obtained only when the following condition is satisfied:

$$
0<\frac{\alpha \Delta t}{\Delta x^{2}}<0.5
$$

If this condition is not satisfied, the solution becomes unstable and starts to wildly oscillate. The explicit finite difference method is particularly suitable for modeling of nonlinear heat diffusion problems such as heat transfer through a section. It can easily accommodate non-linear heat transfer coefficients and control actions.

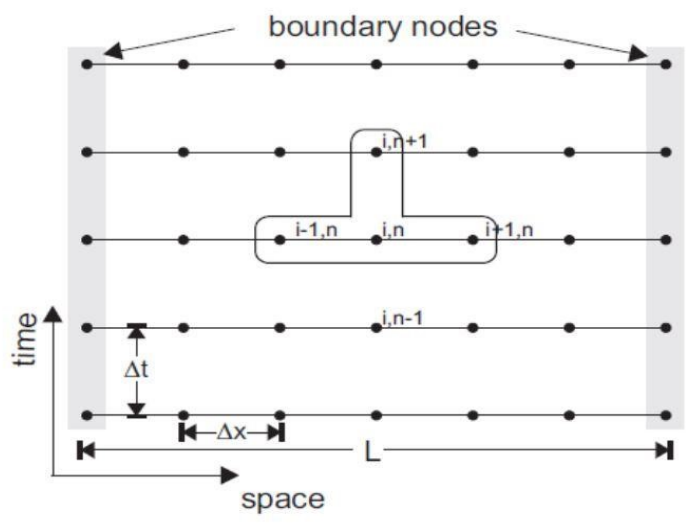

Figure 2.3: Explicit finite difference discretization (Jennifer Date, 2015) 
In the transient one-dimensional finite difference thermal network, a node with a thermal capacitance, $\mathrm{C}$, connected to two thermal resistances, $\mathrm{R}$, each equal to half the RValue of the layer, forms a T-section that represents each sub-layer of the section. For a multi-layered section, an energy balance is applied at each node at regular time intervals to obtain the temperature of the nodes as a function of time. These equations may be solved with implicit method as a set of simultaneous equations or with the explicit method, in which we march forward in time from a set of initial conditions. The general form of the explicit finite difference formulation corresponding to node $i$ and time interval $\mathrm{n}$ is:

$$
T_{i}^{n+1}=T_{i}{ }^{n}+\frac{\delta t}{C_{i}}\left(Q_{i}{ }^{n}+\sum_{j} \frac{T_{j}{ }^{n}-T_{i}{ }^{n}}{R_{i, j}}\right)
$$

where $n+1$ indicates the next time step, $j$ is all the nodes connected to the node $i$ and $Q$ is the heat sources at the node $i$. When the thermal capacitance $C$ can be negligible, the equation is as follows:

$$
T_{i}^{n+1}=\left(Q_{i}+\sum_{j} \frac{T_{j}^{n}}{R_{i, j}}\right) / \sum_{j} \frac{1}{R_{i, j}}
$$

A proportional-integral (PI) control algorithm can approximate the auxiliary heat by the heating system. The relationships for thermal energy satisfied by the heating system and the corresponding power demand are expressed, respectively, as:

$$
\begin{aligned}
& Q_{\text {aux }}{ }^{n+1}=k_{p}\left(T_{\text {sp }}{ }^{n}-T_{\text {air }}{ }^{n}\right)+k_{i} \sum_{k=0}^{n}\left(T_{s p}{ }^{k}-T_{\text {air }}{ }^{k}\right) \cdot \delta t \\
& P_{\text {Load }}=Q_{\text {aux }} / \text { cop }
\end{aligned}
$$

where:

$k_{p}=$ Proportional control constant

$k_{i}=$ Integral control constant

$s p=$ Air temperature setpoint

$T_{\text {air }}=$ Actual measured air temperature

$c o p=$ Heating system's coefficient of performance

\subsubsection{Black-box approach}

Problems in which there is no insight into the physical properties or prior knowledge of the process under study are dealt with differently; a data-driven approach that mathematically connects the system input(s) to its output(s) without including any physical 
meaning in the equation parameters is useful for solving such problems. Black-box models are built using data gathered from the system responses to disturbances and/or controlled inputs.

In building energy analysis, multiple linear regression (MLR) and artificial neural networks (ANN) are usually used for the prediction of the energy consumption or the forecasting of energy use as the cooling or heating demand without knowing the geometry or the thermal properties of the building.

\subsubsection{Gray-box approach}

A large amount of measured data is required to identify the parameters used for complex models that represent multi-zone buildings; thus, it is crucial to consider reduced-order models with a simpler structure and fewer parameters for the ease of parameter estimation and data fitting. In practice, there is a trade-off between the model accuracy and its computational complexity that can be addressed by choosing an appropriate order of reduction.

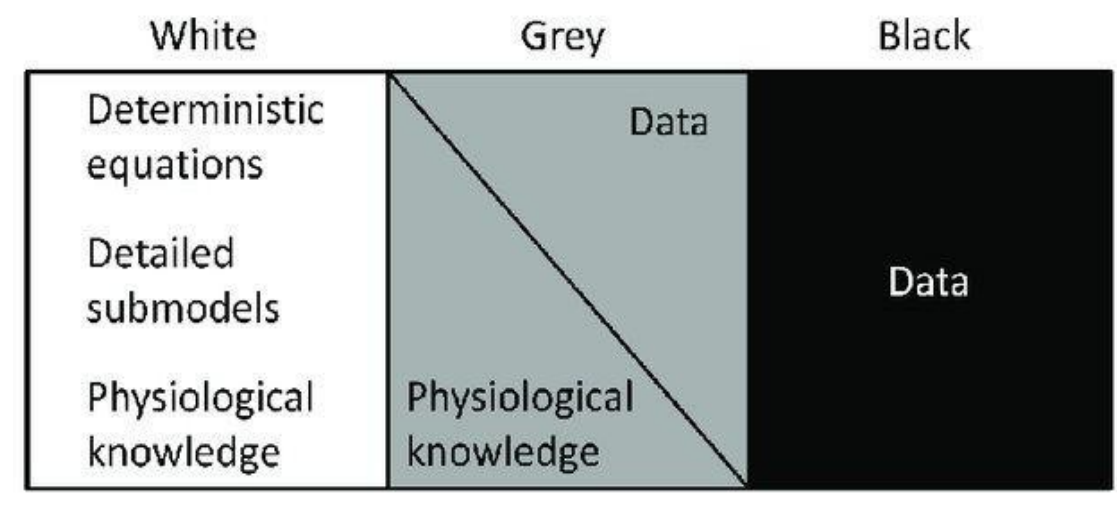

\section{Traditional Statistics}

\section{Machine Learning}

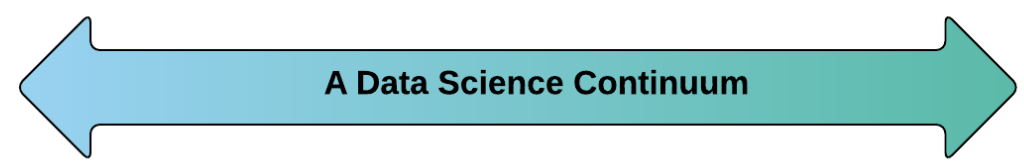

White-box modelling simpler computation, emphasis on introspection, form, causal effects and processes, finding a 'correct' model

\section{Black-box modelling} high computational complexity, emphasis on speed and quality of prediction, finding a 'performant' model

Figure 2.4: Data science continuum and the concept of gray-box modeling (Top: DuunHenriksen, 2013 - Bottom: Sedar, 2016) 
The principle of gray-box (hybrid) approach is based on coupling of physics-based and mathematics-based approaches, where a combination of prior physical knowledge and data-driven modelling is utilized. Gray-box modeling is a comprehensive and accurate method to model dynamic systems and obtain knowledge of the building's thermal properties. A sufficient gray-box model is the smallest model that describes all the useful information embedded in the data (Bacher \& Madsen, 2011).

Detailed building models that are commonly used to optimize building designs require thousands of parameters, which makes them unsuitable for classical parameter identification techniques. Models with fewer parameters facilitate setting-up initial states, also reduce the number of calculations required by the optimization algorithm. Simplified models have been applied to the study of advanced building controls, but a systematic methodology to generate simplified models for control applications is still needed.

Robust parameter identification is the main challenge related to the development of gray-box models. The parameters of gray-box models have physical meaning and offline or online mathematical techniques are implemented to identify their values. The offline approach identifies the values by minimizing the model error over a specific period, once or frequently; however, a global optimization such as the multi-start technique (De Coninck et al., 2016) is required due to various local optima (Drgona et al., 2020). The online approach can be formed for example based on Bayesian calibration techniques (Rouchier, Jimenez, \& Castano, 2019; Shi \& O’Brien, 2019) or re-initializing the optimization within the "model-reset" approach (Date et al., 2020). In contrast to black-box models that achieve higher accuracy if trained on more data, gray-box models' accuracy tends to decline if the training period is too long relative to the involved thermal mass. Braun and Chaturvedi (2002) showed one to two weeks of data is sufficient to train a reduced-order thermal RC network model to predict transient cooling load accurately. Arendt et al. (2018) showed value identification in a reduced-order thermal RC network model may result in an overestimation of the thermal mass if the training period is unreasonably long. Blum et al. (2019) concluded that the optimal training period length depends on the horizon of the optimal control problem and suggested that regular re-calibration is necessary. 


\subsection{Model calibration}

Calibration of a model is the process of obtaining outputs from that model, which are very close to the measured data. Generally, calibrating a model implies adjustment of the model parameters within a reasonable range to achieve a representation of the reality that produces reliable outputs. Reddy (2006) states that the followings are the main sources of uncertainties, which cause error:

1. Improper model assumptions and simplifications due to use of semi-empirical models and/or inaccuracies in the physical model

2. Improper input parameters due to user's lack of experience (they often have to assume or predict certain input parameters like air infiltration) and/or inaccurate specification of material properties and systems structures (mainly HVAC)

3. Inaccurate numerical algorithms, mathematical model limitations and errors in simulation code

The match between the predicted and the measured values can be assessed and minimized using different statistical indices. Some of the most used indices for this matter are:

1. The root mean squared error (RMSE), which estimates the magnitude of the error. In other words, RMSE shows how much spread exists in the difference between measured and predicted values:

$R M S E=\sqrt{\sum(M-P)^{2} / N}$

where:

$R S M E=$ Root mean squared error;

$P=$ Predicted value;

$M=$ Measured value;

$N=$ Number of values

2. The dimensionless quantity called the coefficient of variation of the root mean squared error (CVRMSE), which quantifies the relative error and is a normalized measure:

$C V R M S E=R M S E / \mu$

where:

$\mu=$ Mean measured value 
3. The mean bias error (MBE), which represents the average difference between the measured values and predicted values:

$$
M B E=\sum(M-P) / N
$$

ASHRAE Guideline 14 (Reddy, 2006) suggests that when comparing the whole building energy consumption, CVRMSE of maximum $15 \%$ and MBE of maximum 5\%, on a monthly basis, or CVRMSE of maximum $30 \%$ and MBE of maximum $10 \%$, on an hourly basis guarantee a calibrated model. The International Performance Measurement \& Verification Protocol (IPMVP-Committee, 2002) suggests that when comparing the whole building energy consumption, CVRMSE of maximum $5 \%$ on a monthly basis, or CVRMSE of maximum $20 \%$ on an hourly basis guarantee a calibrated model.

Calibration can be done manually, through trial and error. Varying inputs and observing the changes to the outputs, identifies which parameters have a significant impact on the output. It is a straight-forward procedure; however, according to Troncoso (1997), a major problem with manual calibration of a model is that the analyst has to adjust the input data without sufficient evidence on which data should be modified or to what extent.

Troncoso (1997) presented a methodology to perform a manual calibration of building simulation. This calibration methodology is composed of following stages:

1. Definition of power and schedule of constant loads

2. Simulation of design days for thermal loads analysis

3. Sensitivity analysis over input parameters related to significant gain/loss

4. Adjustment of input values of high level of influence and uncertainty

5. Whole year simulation and final results

Another way to calibrate a model is an automatic iterative optimization process, which determines the optimal values of all model parameters, given a proper objective function and the desired threshold. There are two major problems when performing this automatic approach:

1. It is highly possible that the optimization algorithm finds values, which mathematically result in the best possible match but do not have physical meaning. To tackle this problem, experience is needed to set up proper initial values and to limit the boundaries in which the initial values can change. 
2. The result of the optimization depends on the objective function and the threshold. Practically, there are several possible objective functions to be minimized for calibrating a model, any of which converge a set of values for the parameters.

Candanedo et al. (2013) suggests that the Euclidean distance between the predicted and the measured values is a useful objective function for model calibration. The Euclidean distance between points $P$ and $Q$ is the length of the line segment connecting them $(\overline{P Q})$. In Cartesian coordinates, if $P=\left(P_{1}, P_{2}, \ldots, P_{n}\right)$ and $Q=\left(Q_{1}, Q_{2}, \ldots, Q_{n}\right)$ are two points in Euclidean n-dimensional space, then the Euclidean distance from $P$ to $Q$, or from $Q$ to $P$ is given by the Pythagorean formula:

$$
\overline{P Q}=\sqrt{\left(P_{1}-Q_{1}\right)^{2}+\cdots+\left(P_{n}-Q_{n}\right)^{2}}=\sqrt{\sum_{i=1}^{n}\left(P_{i}-Q_{i}\right)^{2}}
$$

\subsection{Model predictive control (MPC)}

Accurate live weather forecasts and decreasing costs in sensing and computation facilitate the adoption of predictive control strategies based on a simplified building model. MPC is an optimal control strategy that employs a mathematical model of the system to solve a constrained optimization problem and estimates the optimal set of future actions which minimizes (maximizes) a certain objective function with regards to weather forecast and price of energy. Constraints of the problem include the physical limitations of the system and occupants' comfort (Winn \& Wins, 1985; Kintner-Meyer \& Emery, 1995; Henze et al., 1997; Henze et al., 2005; Kummert et al., 2006).

Minimizing the total energy use (Picard \& Helsen, 2018; Jorissen, 2018) and cost (Bianchini, Casini, Vicino \& Zarrilli, 2016; Avci, Erkoc, Rahmani \& Asfour, 2013; Vrettos, Lai, Oldewurtel \& Andersson, 2013) are the most frequent motivations for MPC in buildings. Economic MPC could be applied to effectively reduce the peak electricity demand (Oldewurtel, Ulbig, Parisio, Andersson \& Morari, 2010) or to increase the building energy flexibility (Patteeuw, Henze \& Helsen, 2016). Cutsem, Kayal, Blum \& Pritoni (2019) concluded that economic MPC formulation under commercial time-of-use (ToU) energy prices could provide services such as load shifting to the grid with the same energy cost as conventional control.

Another well-studied objective is the maximization of the share of renewable energy sources (RES) by incorporating energy storage and advanced control. Tarragona, 
Fernandez \& de Gracia (2020) applied MPC to minimize annual energy costs of a heat pump integrated with thermal energy storage (TES) and PV in a detached house located in Spain and showed up to $58 \%$ savings can be achieved compared to the same system with conventional control strategies. Kuboth, Heberle, Konig-Haagen \& Brüggemann (2019) investigated economic MPC for a residential building with combined thermal and electric supply and air source heat pump and reported an $11.6 \%$ reduction in operational costs and $3.5 \%$ increase in self-consumption of photovoltaic energy. Cao, Du \& Soleymanzadeh (2019) concluded employing TES in a commercial building could maintain the occupants' comfort level and increase the flexibility to take part in demand-response (DR) programs, and consequently, reduction in energy costs and demand charge. Toradmal et al. (2018) investigated boosting the PV self-consumption by optimized scheduling of a heat pump and incorporating thermal mass in a residential building and reported considerable improvements. Fischer et al. (2017) reported effective cost reduction and increase in PV self-consumption when applying MPC to variable-speed air source heat pumps. Salpakari \& Lund (2016) investigated optimal control strategies for energy flexibility in residential buildings with PV, battery and ground source heat pump, and reported a $13-25 \%$ reduction in energy costs compared to a reference $\mathrm{RBC}$ control with a constant price of energy.

\subsection{Building energy flexibility}

To reduce greenhouse gas (GHG) emissions, the integration of renewable energy sources (RES) to the power grid is vital; however, due to the intermittent nature of these sources, this may associate problems such as instability, congestion, and curtailment. To mitigate this serious risk, a transition in the perception of energy availability is necessary. The production-on-demand principle where energy is thought of as unlimited should be replaced by the consumption-on-demand principle where demand management helps to minimize the stress on the grid. Demand-side flexibility enables demand-side management, which results in reduction of mismatch between demand and supply.

The International Energy Agency Energy in Buildings and Communities (IEAEBC) Annex 67 program defines an "Energy Flexible Building" as "A building which is able to manage its demand and generation according to the local climate conditions, user needs and grid requirements without jeopardizing indoor comfort and technical requirements of 
the building and heating, ventilation and cooling systems." (Jensen et al., 2017). Buildings' energy flexibility can be utilized to respond to the grid's requirements and lower the stress on it when needed.

Athienitis et al. (2020) states that energy flexibility may be enhanced by actions ahead of the peak periods, and is enabled through 1) building's thermal mass and modification of zone setpoints, 2) thermal storage in HVAC systems, 3) specific active mass systems like a radiant slab, 4) integrated operation of heat pumps, possible on-site renewable energy generators and thermal storage and 5) battery storage/electric vehicle and controllable appliance and lighting.

Two major applications of demand-side energy flexibility are: (Hydro- Québec, 2019)

1. Reserve: Thermostatically-controlled and other fast-responsive loads in the residential sector may serve as contingency (non-spinning) reserve upon a short notice from the grid's operator, which practically leaves the end users with no time for preparation.

2. Peak load shifting/shaving: Energy flexible end users can shift/cancel the operation of equipment and/or appliances during the peak demand period. They possibly can discharge a thermal storage medium to maintain the comfort and consume less power for air conditioning or discharge an electrical storage to reduce the power demand directly. An early notification from the grid's operator gives them enough time to charge their thermal and/or electrical storage mediums.

Buildings may potentially support other grid ancillary services, such as spinning reserves, frequency stability or voltage regulation; but only if responsive and reliable at short notice.

Two of the most referred performance indicators for buildings with PV system are selfgeneration and self-consumption (Salom et al., 2014; Baetens et al., 2010; De Coninck et al., 2014; Vanhoudt et al., 2014; and Klein et al., 2015). Self-generation is the proportion of electrical demand met by on-site generation and self-consumption is defined as the proportion of on-site generation consumed by building. Alternative design options such as generators, storage mediums and control strategies can be simulated and compared in terms of self-generation and self-consumption over a desired period of time which helps building owners to effectively manage their financial resources. 


\subsection{Conclusions}

Control-oriented models in combination with advanced control strategies make the buildings' energy flexibility available to the grid. Control-oriented models are computationally simple as they are developed to be implemented in real controllers or building automation systems (BAS); they are not an oversimplification of the system, but an acutely understood selection of relevant system information. Normally, parameters of these models have physical meaning and mathematical techniques are implemented to identify the value of parameters. The development and application of control-oriented models require a good understanding of all the involved phenomena, a coherent choice of significant parameters and variables, and much care and thinking when analyzing and interpreting the data (Lachal, 1992). 


\section{Chapter 3: Methodology and Evaluation ${ }^{1,2}$}

\subsection{Introduction}

This study presents a methodology to develop suitable control-oriented thermal RC network models for optimized heating, ventilation and air conditioning (HVAC) load management in typical electrically heated single-family detached houses, with optional photovoltaics system and battery storage, based on detailed measured data from a research house of Hydro-Québec LTE. Using recurring parameter identification and model-reset, the building dynamics are represented by an explicit discrete time-varying thermal network model with state-space formulation (sections 3.3 and 3.4).

Next (section 3.6), these models are applied in a model predictive control MPC framework in which the objective is to enhance energy efficiency and energy flexibility of the building by storing energy in the building's thermal mass and/or a battery, and shifting the HVAC load to lower the stress on the local grid.

Finally in section 3.8, the benefits of predictive control strategies for HVAC load management, both for the building owners and the local grid, are studied through a seasonal simulation for months of January, February and March where the performance of the heating system subject to a reference traditional reactive controller and a predictive controller are compared.

\subsection{Description of the case study ${ }^{3}$}

The case study is an experimental house for building energetics, located in Shawinigan, Québec, Canada. This test bench is a two-storey detached house with an excavated basement. The house has outer dimensions of $7.6 \mathrm{~m} \times 7.9 \mathrm{~m}$ and $60 \mathrm{~m}^{2}$ footprint. It has three bedrooms and a bathroom on the second floor, while the kitchen, the living room, the dining room and a small washroom are on the ground (first) floor. The wall assemblies of the building represent the typical lightweight wood-framed house in Canada. The total fenestration area is $19 \mathrm{~m}^{2}$, consisting of vinyl framed double-glazing windows with an air

\footnotetext{
${ }^{1}$ A paper based on this chapter is submitted to the Journal of Building Performance Simulation.

${ }^{2}$ A paper based on this chapter is accepted at the conference of IBPSA-Canada, eSim 2021 Vancouver.

${ }^{3}$ Appendix $\mathrm{C}$ presents a comprehensive description of the case study.
} 
gap. The building is oriented $35^{\circ}$ west of the south. It is heated with baseboard heaters in each room with individual electronic room thermostats. The total installed capacity of baseboard heaters is $15 \mathrm{~kW}$. A $36000 \mathrm{Btu} / \mathrm{h}$ air-to-air heat pump, also delivers heat to the building when required.
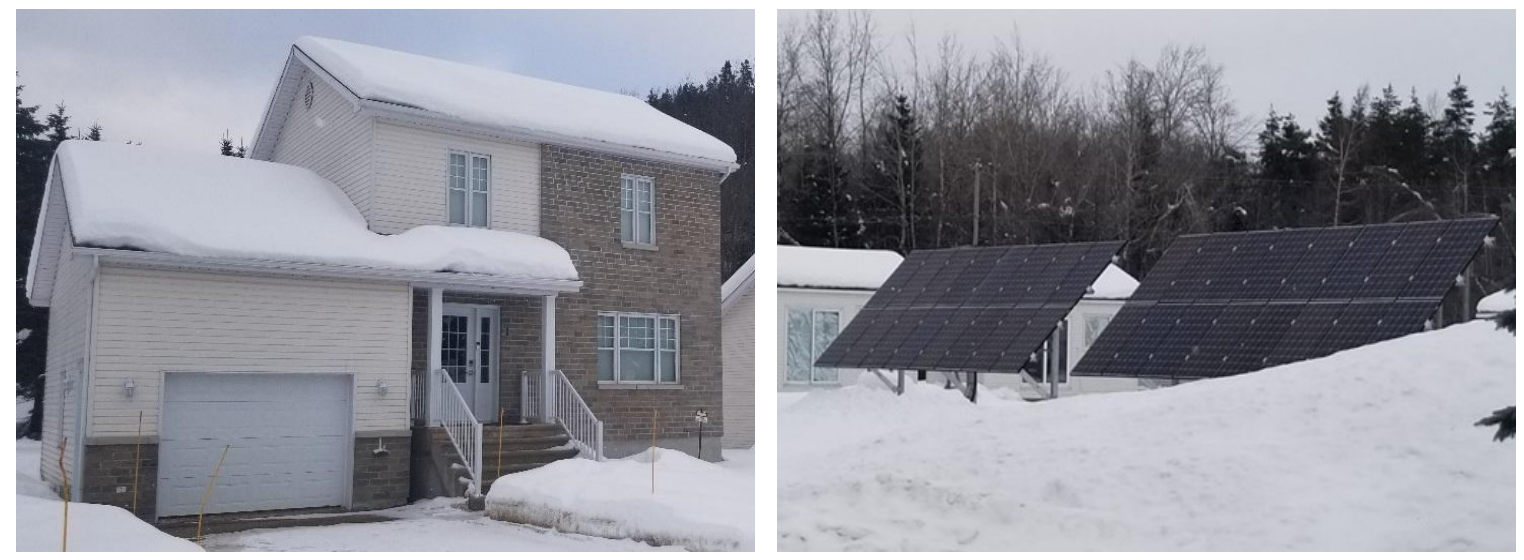

Figure 3.1: Hydro- Québec experimental house for building energetics, Shawinigan, Québec

There are many sensors in the building and the soil around it. The recordings include 15-minute average observations of zone-by-zone heating, plug and lighting loads plus instant observations of solar irradiance on vertical and horizontal planes, outside ambient air temperature, soil temperature, and zone-by-zone air and surface temperature at every 15 minutes. The available dataset for this study includes all the aforementioned observations for the period of 2019-01-01 to 2019-03-31. ${ }^{4}$

\subsection{Adjustable model resolution ${ }^{5}$}

In gray-box models, there is a trade-off between robust parameter identification and complexity. As the model grows in order, meaning it is describing the thermal dynamics of the building with higher resolution, it becomes more difficult to minimize the model's error and identify the parameters with reasonable uncertainty. The motivations to develop models with higher resolution than a simple first-order model, which looks at the building as one lumped thermal capacitance, are 1) to be able to identify the optimal set of predictive control actions for different zones of the building while maintaining the acceptable thermal

\footnotetext{
${ }^{4}$ Appendix A presents an unsupervised analysis of weather data as a part of data preparation process.

${ }^{5}$ Appendix E presents an explanation on resolution selection in gray-box models and the issue of over-parametrization.
} 
comfort, and 2) to be able to investigate the impact of model resolution on the convergence of parameter identification and MPC algorithms. Choosing an appropriate order of reduction requires analysis of the building's past behaviour.

Two third-order thermal RC network models are proposed in this study: 1) The 3C6R network (Fig. 3.2), in which $\mathrm{C}_{1}$ represents the first floor, $\mathrm{C}_{2}$ represents the second floor, and $\mathrm{C}_{3}$ represents the basement; and 2) The 3C7R network (Fig. 3.3), in which $\mathrm{C}_{1}$ represents the southern zone of the above-grade space, $\mathrm{C}_{2}$ represents the northern zone of the above-grade space, and $\mathrm{C}_{3}$ represents the basement.

\subsection{Sequential parameter identification}

Robust calibration of model parameters helps quantify the expected cost savings and zone temperatures, with a sufficient accuracy. Therefore, a systematic sequential approach is employed to reduce the number of parameters being calibrated simultaneously:

1. First, a theoretical set of values for parameters and their bounds is estimated from simplified geometry and material properties, under certain assumptions about infiltration.

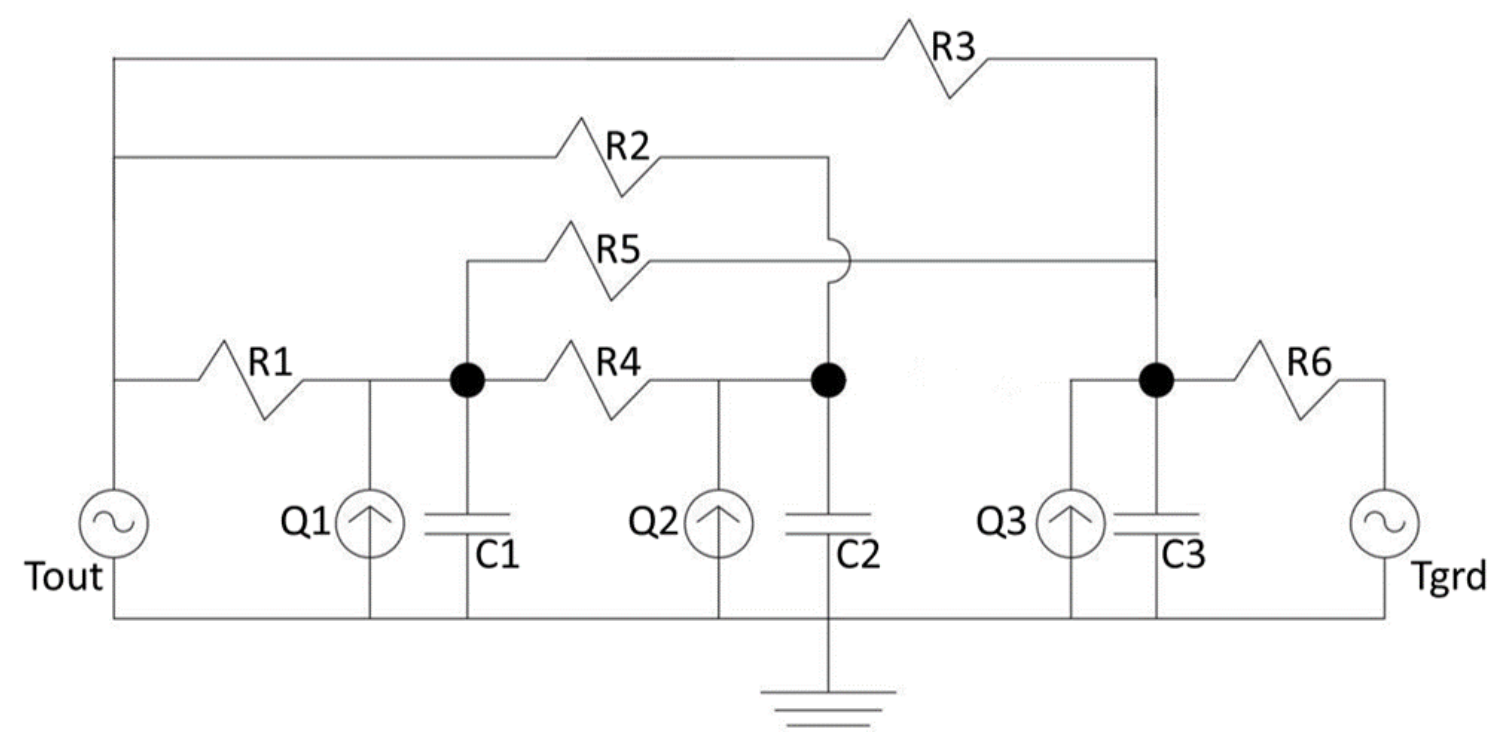

Figure 3.2: 3C6R network model

2. Next, an identification period, chosen from immediate past data, is split into the train (70-80\%) and test (20-30\%) sets and an inclusive preliminary algorithm updates all the theoretical values by minimizing the model error. The length of the identification period depends on control horizon of the optimal strategy. 


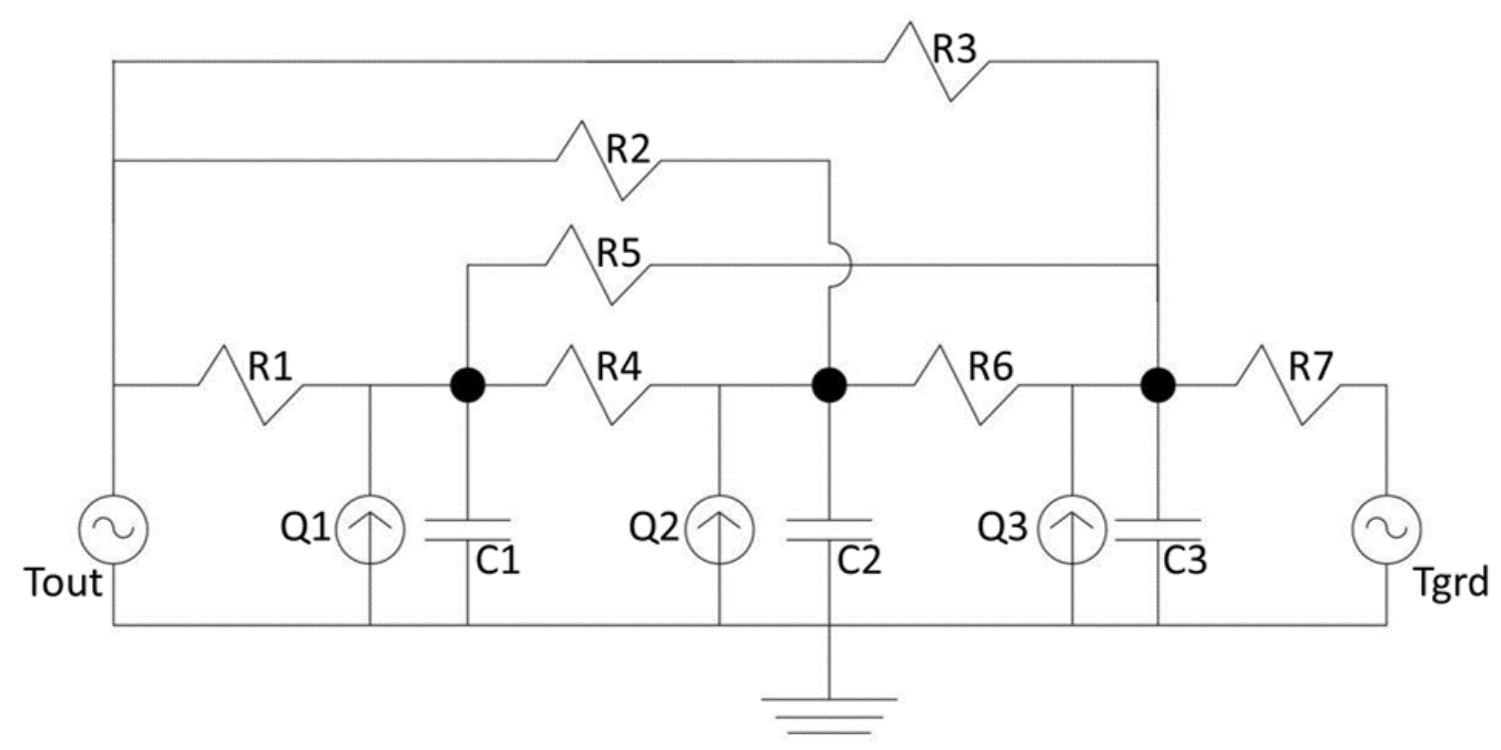

Figure 3.3: 3C7R network model

3. Finally, a series of exclusive complementary algorithms over sub-periods of the identification period are used to calibrate the parameters. To be able to estimate the uncertainty associated with each parameter, it is recommended to concurrently calibrate as few parameters as possible in the final step.

The assumptions used in calculation of initial values are tabled below:

Table 3.1: Assumptions for calculation of initial values

\begin{tabular}{|l|l|}
\hline Parameters & Assumptions for calculation of initial values \\
\hline Above-grade space capacitances & $\begin{array}{l}\text { Gypsum board with } 10 \mathrm{~mm} \text { depth of } \\
\text { penetration in the exterior walls }\end{array}$ \\
$\qquad \begin{array}{l}\text { Gypsum board with } 10 \mathrm{~mm} \text { depth of } \\
\text { penetration in the roof }\end{array}$ \\
- $\begin{array}{l}\text { Plywood with } 10 \mathrm{~mm} \text { depth of penetration in } \\
\text { the floor }\end{array}$ \\
\hline Basement capacitance & $\begin{array}{l}\text { Air multiplier }=10 \\
\text { Gypsum board with } 10 \mathrm{~mm} \text { depth of } \\
\text { penetration in the foundation walls }\end{array}$ \\
\hline
\end{tabular}




\begin{tabular}{|c|c|}
\hline & $\begin{array}{l}\text { - Gypsum board with } 5 \mathrm{~mm} \text { depth of penetration } \\
\text { in the ceiling } \\
\text { - Concrete with } 25 \mathrm{~mm} \text { depth of penetration in } \\
\text { the slab } \\
\text { - Air multiplier }=10\end{array}$ \\
\hline $\begin{array}{l}\text { Resistances connecting capacitances to } \\
\text { the outside ambient air }\end{array}$ & - $\quad$ Air change $=1 / \mathrm{hr}$ \\
\hline $\begin{array}{l}\text { Resistances connecting basement to the } \\
\text { ground }\end{array}$ & - $\quad$ Air change $=1 / \mathrm{hr}$ \\
\hline $\begin{array}{l}\text { Resistances connecting above-grade } \\
\text { space capacitances }\end{array}$ & $\begin{array}{l}\text { - Modelled as an infiltration resistance } \\
\text { - } \quad \text { Air change }=5 / \mathrm{hr}\end{array}$ \\
\hline
\end{tabular}

Table 3.2: Initial values of proposed models

\begin{tabular}{|c|c|c|}
\hline \multirow[t]{2}{*}{ Parameters } & \multicolumn{2}{|l|}{ Initial Magnitude } \\
\hline & 3C6R network model & 3C7R network model \\
\hline$\alpha_{1}$ & 0.40 & 0.60 \\
\hline$\alpha_{2}$ & 0.50 & 0.30 \\
\hline$\alpha_{3}$ & 0.05 & 0.05 \\
\hline $\mathrm{C}_{1}$ & $6.75 \times 10^{6} \mathrm{~J} /{ }^{\circ} \mathrm{C}$ & $6.60 \times 10^{6} \mathrm{~J} /{ }^{\circ} \mathrm{C}$ \\
\hline $\mathrm{C}_{2}$ & $6.25 \times 10^{6} \mathrm{~J} /{ }^{\circ} \mathrm{C}$ & $6.40 \times 10^{6} \mathrm{~J} /{ }^{\circ} \mathrm{C}$ \\
\hline $\mathrm{C}_{3}$ & $7.45 \times 10^{6} \mathrm{~J} /{ }^{\circ} \mathrm{C}$ & $7.45 \times 10^{6} \mathrm{~J} /{ }^{\circ} \mathrm{C}$ \\
\hline $\mathrm{R}_{1}$ & $0.016^{\circ} \mathrm{C} / \mathrm{W}$ & $0.015^{\circ} \mathrm{C} / \mathrm{W}$ \\
\hline $\mathrm{R}_{2}$ & $0.014{ }^{\circ} \mathrm{C} / \mathrm{W}$ & $0.015^{\circ} \mathrm{C} / \mathrm{W}$ \\
\hline $\mathrm{R}_{3}$ & $0.019^{\circ} \mathrm{C} / \mathrm{W}$ & $0.019^{\circ} \mathrm{C} / \mathrm{W}$ \\
\hline
\end{tabular}




\begin{tabular}{|l|l|l|}
\hline $\mathrm{R}_{4}$ & $0.002{ }^{\circ} \mathrm{C} / \mathrm{W}$ & $0.002^{\circ} \mathrm{C} / \mathrm{W}$ \\
\hline $\mathrm{R}_{5}$ & $0.006{ }^{\circ} \mathrm{C} / \mathrm{W}$ & $0.014^{\circ} \mathrm{C} / \mathrm{W}$ \\
\hline $\mathrm{R}_{6}$ & $0.036^{\circ} \mathrm{C} / \mathrm{W}$ & $0.014^{\circ} \mathrm{C} / \mathrm{W}$ \\
\hline $\mathrm{R}_{7}$ & & $0.036^{\circ} \mathrm{C} / \mathrm{W}$ \\
\hline
\end{tabular}

Algorithm $1{ }^{6}$ presents the general parameter identification procedure in this study:

\section{Algorithm 1: Parameter Identification}

\section{Input:}

Indoor air temperature observations $\left(\mathrm{T}_{\mathrm{i}}\right.$ in $\left.{ }^{\circ} \mathrm{C}\right)$

Heating demand observations ( $\mathrm{Q}_{\text {aux,i }}$ in $\left.\mathrm{W}\right)$

Outdoor air temperature observations $\left(\mathrm{T}_{\mathrm{ext}}\right.$ in $\left.{ }^{\circ} \mathrm{C}\right)$

Soil temperature observations $\left(\mathrm{T}_{\text {grd }}\right.$ in $\left.{ }^{\circ} \mathrm{C}\right)$

Irradiance on the vertical plane observations $\left(\mathrm{G}\right.$ in $\left.\mathrm{W} / \mathrm{m}^{2}\right)$

\section{Output:}

Calibrated values of model parameters

\section{Steps:}

1 Split the identification period into train and test periods.

2 Select the training dataset.

3 Form the vector of indoor air temperature prediction and initialize.

$T_{i}=[0]_{1 \times \text { length of train dataset }}$

$T_{i}{ }^{0}=\widehat{T}_{i}^{0}$

${ }^{6}$ Appendix D presents a sample python code for training the 3C7R network model using SciPy.optimize package. 
4 Calculate a theoretical set of values for parameters and define their boundaries.

5 Define an objective function that properly represents the model error.

6 Minimize the objective function subject to the system dynamics, the initial value set and the boundaries on the values using a least-square solver.

$$
\begin{aligned}
& \min _{R_{i, j}, C_{i}, \alpha_{i}} \sum_{i=1}^{N I} \omega_{i} \sqrt{\sum_{k=1}^{N_{\text {train }}} \omega_{k}\left(T_{i}^{k}-\widehat{T}_{i}^{k}\right)^{2} / N_{\text {train }}} \\
& \text { s.t: } \\
& \operatorname{Param}_{0}=\left[U_{i j, 0}, C_{i, 0}, \alpha_{i, 0}\right] \\
& \text { Param }_{\text {min }}<\text { Param }<\text { Param }_{\text {max }} \\
& T_{i}{ }^{k+1}=T_{i}{ }^{k}+\left(\frac{\delta t}{C_{i}}\right)\left(Q_{a u x, i}{ }^{k}+\alpha Q_{s o l, i}{ }^{k}+\sum_{j} U_{i j}\left(T_{j}{ }^{k}-T_{i}{ }^{k}\right)\right) k \in N_{0}{ }^{N_{\text {train }}-1}
\end{aligned}
$$

7 Calculate fit metrics (RMSE and MBE).

\section{If fit metrics do not satisfy the predefined thresholds:}

Change the identification period and spatial/temporal weights in the objective function; Repeat steps 1-7.

\section{If fit metrics satisfy the predefined thresholds:}

Validate the training and proceed to the next step.

8 Select the test dataset.

9 Form the vector of indoor air temperature prediction and initialize

$T_{i}=[0]_{1 \times \text { length of test dataset }}$

$T_{i}^{0}=\widehat{T}_{i}^{0}$

10 Predict the indoor air temperature for duration of the test dataset, using the calibrated parameters from the training.

$$
\begin{aligned}
& \text { Param }=\left[U_{i j, \text { train }}, C_{i, \text { train }}, \alpha_{i, \text { train }}\right] \\
& T_{i}{ }^{k+1}=T_{i}{ }^{k}+\left(\frac{\delta t}{C_{i}}\right)\left(Q_{a u x, i}{ }^{k}+\alpha Q_{s o l, i}{ }^{k}+\sum_{j} U_{i j}\left(T_{j}{ }^{k}-T_{i}{ }^{k}\right)\right) k \in N_{0}{ }^{N_{\text {test }}-1}
\end{aligned}
$$


13 Calculate fit metrics (RMSE and MBE).

14 If fit metrics do not satisfy the predefined thresholds:

Change the train-test ratio; Repeat steps 1-13

If fit metrics satisfy the predefined thresholds:

Validate the testing; Print calibrated values of model parameters

\subsection{Performance of PV system and battery ${ }^{7}$}

A simplified model is used to predict the output of the PV system, using weather forecast together with the module's specifications. (Evans \& Florschuetz, 1977; Luque \& Hegedus, 2003). In Eq. 3.1, where the PV cell temperature is estimated, $T_{\text {cell }}, T_{\text {out }}, T_{\text {cell,nom }}$ and $T_{\text {out,nom }}$ are the cell temperature, the outside air temperature, the nominal operative cell temperature and the outside air temperature at nominal operative conditions, respectively. Also, $G_{t o t}$ and $G_{t o t, n o m}$ are the total plane of array (POA) irradiance at any given instance and nominal operative conditions, respectively. Nominal operative conditions are predefined test conditions defined by manufacturers. Eq. 3.2 calculates the PV system; $P_{\max , s t c}, G_{t o t, s t c}$ and $T_{c e l l, s t c}$ are the rated maximum power of the array, the total POA irradiance and the cell temperature at standard testing conditions (STC), respectively; $\lambda$ is the cell temperature coefficient at maximum power point (MPP) and reflects the effect of cell's technology. Also, $n_{p}$ is the number of strings in parallel and $n_{s}$ is the number of modules in each string set in series. Finally, $\eta_{i n v}$ is the efficiency of the inverter. $\left(P_{\max , s t c}=280\right.$ Watt, $G_{t o t, s t c}=1000$ Watt $/ \mathrm{m}^{2}, T_{\text {cell,stc }}=25{ }^{\circ} \mathrm{C}, \lambda=0.00431 /{ }^{\circ} \mathrm{C}, T_{\text {cell,nom }}=45^{\circ} \mathrm{C}, G_{\text {tot,nom }}=800 \mathrm{Watt} / \mathrm{m}^{2}, T_{\text {out }, \text { nom }}$ $=20{ }^{\circ} \mathrm{C}, n_{p}=2, n_{s}=8, \eta_{\text {inv }}=0.96$ )

$$
\begin{aligned}
& T_{\text {cell }}{ }^{k}=T_{\text {out }}{ }^{k}+\frac{G_{\text {tot }}{ }^{k}}{G_{\text {tot }, \text { nom }}}\left(T_{\text {cell,nom }}-T_{\text {out }, \text { nom }}\right) \\
& P_{p v}{ }^{k}=\eta_{i n v} \cdot n_{s} \cdot n_{p}\left(P_{\text {max }, \text { stc }} \cdot \frac{G_{\text {tot }}{ }^{k}}{G_{\text {tot }, s t c}}\left(1-\lambda\left(T_{\text {cell }}{ }^{k}-T_{\text {cell,stc }}\right)\right)\right)
\end{aligned}
$$

In Eq. 3.3, an explicit mathematical correlation estimates the total electrical charge inside the battery. As per this correlation, the electrical charge left inside the battery at the

\footnotetext{
${ }^{7}$ Appendix B provides a review on different approaches to PV system performance modeling.
} 
end of the $k$-th time step equals the charge left at the beginning of the time step (at the end of the (k-1)-th time step) plus the net charge which is transferred to/from the battery during that time step. Here, $C_{b a t t}$ is the total charge inside the battery and, $I_{b a t t, c}$ and $I_{b a t t, d}$ are the charge and the discharge current, respectively. Eq. 3.4 calculates the SoC of battery, where $C_{\text {batt, }, \text { ef }}$ is the battery capacity in Ampere-hour (Ah) $\left(V_{\text {batt,nom }}=50 \mathrm{~V}, C_{\text {batt, ref }}=200 \mathrm{Ah}\right)$.

$$
\begin{aligned}
& C_{\text {batt }}{ }^{k}=C_{\text {batt }}{ }^{k-1}+\delta t\left(I_{\text {batt }, c}{ }^{k}-I_{\text {batt }, d}{ }^{k}\right) \\
& \text { So } C_{\text {batt }}{ }^{k}=C_{\text {batt }}{ }^{k} / C_{\text {batt }, \text { ref }} \\
& P_{\text {batt }}{ }^{k}=I_{\text {batt }}{ }^{k} \cdot V_{\text {batt nom }}
\end{aligned}
$$

\subsection{Predictive HVAC control}

The MPC algorithm uses an explicit discrete time-varying state-space formulation, in which the model parameters are periodically re-calibrated at certain reset intervals. The model is expressed in Eq. 3.6, where $x^{k}, u^{k}, d^{k}$ and wk denote the values of states, inputs, disturbances and model uncertainty at the k-th time step of the prediction horizon $N_{h}$ with a sampling time of $\delta t$, respectively.

$$
\begin{aligned}
& x^{k+1}=A^{k} x^{k}+B^{k} u^{k}+C^{k} d^{k}+w^{k} \\
& x^{k}=\left[T_{1}{ }^{k}, T_{2}{ }^{k}, T_{3}{ }^{k}, S_{o} C_{\text {batt }}{ }^{k}\right] \\
& u^{k}=\left[Q_{\text {aux }, 1}{ }^{k}, Q_{\text {aux }, 2}{ }^{k}, Q_{\text {aux }, 3}{ }^{k}, I_{\text {batt }}{ }^{k}\right] \\
& d^{k}=\left[T_{\text {out }}{ }^{k}, T_{\text {grd }}{ }^{k}, Q_{\text {sol }}{ }^{k}, P_{\text {pv }}{ }^{k}\right] \\
& Q_{\text {sol }}{ }^{k}=G_{\text {vert }}{ }^{k} \cdot A_{\text {window }} \\
& P_{\text {load }}{ }^{k}=Q_{\text {aux }, 1}{ }^{k}+Q_{\text {aux }, 2}{ }^{k}+Q_{\text {aux }, 3}{ }^{k} \\
& P_{\text {net }}{ }^{k}=P_{\text {load }}{ }^{k}+P_{\text {batt }}{ }^{k}-P_{\text {pv }}{ }^{k}
\end{aligned}
$$

The states in Eq. 3.7, represent dynamics of energy storage elements in the system and are as follows: the temperature of $\mathrm{C}_{1}\left(T_{1}\right)$, the temperature of $\mathrm{C}_{2}\left(T_{2}\right)$, the temperature of $\mathrm{C}_{3}$ $\left(T_{3}\right)$, and the SoC of the battery $\left(S o C_{b a t t}\right)$. The inputs in Eq. 3.8, are the optimal actions corresponding to each of the states, which are computed by solving the optimal control problem and are as follows: the auxiliary heat to $\mathrm{C}_{1}\left(Q_{a u x, 1}\right)$, the auxiliary heat to $\mathrm{C}_{2}\left(Q_{a u x, 2}\right)$, the auxiliary heat to $\mathrm{C}_{3}\left(Q_{a u x, 3}\right)$, and the current to/from the battery $\left(I_{b a t t}\right)$. The disturbances (Eq. 3.9) are the predictions of outside ambient air temperature $\left(T_{\text {out }}\right)$, average ground temperature $\left(T_{g r d}\right)$, solar gains $\left(Q_{s o l}\right)$ and PV generation $\left(P_{p v}\right)$. Propagation of the 
uncertainty associated with parameters and weather forecast throughout the state estimation process results in the process noise $(w)$. All the measurements are assumed to be perfect (zero uncertainty). Matrices $A, B$ and $C$ are the products of the parameter identification process.

Using the weather forecast, Eq. 3.10 estimates the solar gains through the fenestration on the vertical walls $\left(G_{\text {vert }}=\right.$ total irradiance on the vertical walls, $\left.A_{\text {window }}=5.5 \mathrm{~m}^{2}\right)$. Eq. 3.11 calculates the total heating demand at each time step, simply by summing the auxiliary heat to all the zones; and considering the on-site solar electricity and the power to/from the battery, Eq. 3.12 calculates the net demand of the building at each time step.

The MPC algorithm solves a constrained optimization problem and computes the optimal set of future actions. The constraints on the states include the occupants' thermal comfort (here, soft constraint with a linear penalty associated to its violation) and the predefined bounds on the battery state of charge (Eq. 3.13), which are normally set to maintain its health $\left(S o C_{\text {batt,min }}=10 \%, S o C_{\text {batt,max }}=90 \%\right)$. The inputs are constrained by the size of the heating system in each zone (Eq. 3.14), and the maximum possible C-rate of the battery (Eq. 3.15).

$$
\begin{aligned}
& \operatorname{SoC}_{\text {batt,min }} \leq \operatorname{SoC}_{\text {batt }}{ }^{k} \leq S o C_{\text {batt,max }} \\
& 0 \leq Q_{\text {aux }, i}{ }^{k} \leq Q_{\text {aux }, \text {,max }} \\
& 0 \leq I_{\text {batt }}{ }^{k} \leq I_{\text {batt,max }}
\end{aligned}
$$

The MPC algorithm minimizes the multi-goal objective function $l\left(x^{k}, u^{k}, d^{k}, w^{k}, r^{k}\right)$ in Eq. 3.22, that associates a certain cost to the selection of a particular set of future actions, given the estimated states and disturbances. The objective function accommodates 1) minimization of heating energy cost (Eq. 3.16), 2) maximization of self-consumption (Eq. 3.17), 3) minimization of inputs' slew rate to avoid intense cycling (Eq. 3.18 \& 3.19), 4) penalization of thermal comfort violation (Eq. 3.20), and 5) penalization of peak demand (Eq. 3.21):

$$
\begin{aligned}
& l_{1}=\left(\sum_{k=0}^{N S-1} P_{\text {load }}{ }^{k} \cdot \text { price }^{k}\right) \cdot \omega_{1} \\
& l_{2}=\left(\sum_{k=0}^{N S-1}\left\|P_{\text {net }}{ }^{k}\right\|_{2}\right) \cdot \omega_{2} \\
& l_{3}=\left(\sum_{k=0}^{N S-1}\left(\sum_{i=1}^{3}\left\|Q_{\text {aux }, i}{ }^{k}-Q_{a u x, i}{ }^{k-1}\right\|_{2}\right)\right) \cdot \omega_{3}
\end{aligned}
$$




$$
\begin{aligned}
& l_{4}=\left(\sum_{k=0}^{N S-1}\left\|I_{\text {batt }}{ }^{k}-I_{\text {batt }}{ }^{k-1}\right\|_{2}\right) \cdot \omega_{4} \\
& l_{5}=\left(\sum_{k=0}^{N S-1}\left(\sum_{i=1}^{3} \max \left(T_{i, \min }{ }^{k}-T_{i}{ }^{k}, 0, T_{i}{ }^{k}-T_{i, \text { max }}{ }^{k}\right) \cdot \pi_{\text {comfort }, i}{ }^{k}\right)\right) \cdot \omega_{5} \\
& l_{6}=\left(\sum_{i=1}^{3}\left\|Q_{\text {aux }, i}\right\|_{\infty} \cdot \pi_{\text {peak }, i}{ }^{k}\right) \cdot \omega_{6} \\
& l\left(x^{k}, u^{k}, d^{k}, w^{k}, r^{k}\right)=\sum_{v=1}^{6} l_{v}
\end{aligned}
$$

Where the comfort violation and peak demand penalty factors are the results of problem fine-tuning $\left(\pi_{\mathrm{comfort}, 1}=\pi_{\mathrm{comfort}, 2}=20000, \pi_{\mathrm{comfort}, 3}=10000, \pi_{\text {peak }, i}=100\right)$. Each cost component $\left(l_{1}, l_{2}, \ldots, l_{6}\right)$ is scaled and weighted before it contributes to the objective function. Here, all the components are equally weighted $\left(\omega_{1}=\omega_{2}=\omega_{3}=\omega_{4}=\omega_{5}=\omega_{6}=\right.$ $1)$.

Algorithm 2 presents the general MPC procedure in this study:

Algorithm 2: Model predictive control

\section{Input:}

Building thermal model

PV system and battery performance models

Weather forecast

Price of electricity and other references

\section{Output:}

Optimal operation plan of HVAC system and battery

\section{Steps:}

1 Define the prediction horizon $\left(N_{h}\right)$ and the control horizon $\left(N_{c}\right)$.

2 Estimate the current states of the system.

3 Collect the disturbances $\left\{d^{0}, d^{l}, \ldots, d^{N h-1}\right\}$.

4 Collect the references $\left\{r^{0}, r^{1}, \ldots, r^{N h-1}\right\}$.

5 Compute the sequence of optimal inputs $\left\{u^{0}, u^{l}, \ldots, u^{N c}\right\}$ by solving the general MPC problem through a convex optimizer. 
$\min _{u^{0}, u^{1}, \ldots, u^{N c-1}} l\left(x^{k}, u^{k}, d^{k}, w^{k}, r^{k}\right)$

s.t:

$x^{k+1}=A^{k} x^{k}+B^{k} u^{k}+C^{k} d^{k}+w^{k}$

$f\left(x^{k}, u^{k}, d^{k}, r^{k}\right)=0$

$g\left(x^{k}, u^{k}, d^{k}, r^{k}\right)>0$

$x^{0}=$ current states

6 Implement the first optimal input $\left(u^{0}\right)$ over the sampling time $\delta t$.

7 Update; Repeat steps 2-6.

\subsection{Reactive HVAC control}

The reference controller to which the performance of the predictive controller is compared, reactively provides heat to the building to maintain the inside air temperature at a predefined setpoint, with no regard to weather forecast and energy price. Eq. 25 and 26 explain how the PI controller works. In Eq. $3.23 T_{s p, i}{ }^{k}$ is the heating setpoint at the $k$-th time step, $T_{i}^{k}$ is the sensed inside air temperature at that time step, and $e_{i}^{k}$ is the residual. The Eq. 3.24 calculates the auxiliary heat provided to the zone at the $(k+1)$-th setpoint based on residual of last time step, where $K_{P}=3000 \mathrm{Watt} /{ }^{\circ} \mathrm{C}, K_{I}=5 \mathrm{Watt} /{ }^{\circ} \mathrm{C}$.s. These constants are computed through a constrained minimization within a reasonable range for tuned PI control constants, where the error between the model's predictions and observations is minimized over 72 hours of data during which the heating setpoint is constantly $21{ }^{\circ} \mathrm{C}$.

$$
\begin{aligned}
& e_{i}{ }^{k}=T_{s p, i}{ }^{k}-T_{i}{ }^{k} \\
& Q_{\text {aux }, i}{ }^{k+1}=K_{P} \cdot e_{i}{ }^{k}+K_{I} \sum_{j=0}^{k} e_{i}{ }^{j} \cdot \delta t
\end{aligned}
$$

\subsection{Evaluation of methodology}

The methodology is evaluated through a seasonal simulation from January $1^{\text {st }}$ to March $31^{\text {st }}$ for optimal day-ahead heating load management, in which the objective is to minimize the energy costs by importing from the most efficient energy source(s) and storing energy in the building's thermal mass and/or a battery for later use. Within this simulation the prediction horizon $\left(N_{h}\right)$ is 24 hours and the control horizon $\left(N_{c}\right)$ is 6 hours. The identification period length is set to 120 hours $\left(N_{I D} / N_{h}=5\right)$, and the reset interval is also 
set to 24 hours, meaning the parameters are re-calibrated every 24 hours, at the beginning of each day. The sampling time $(\delta t)$ is 15 minutes. The forecast of the outside air temperature for the next control horizon (next 6 hours) is assumed to be perfect (no uncertainty) and the uncertainty of the irradiance for the next control horizon is $12.8 \%$ (Voyant et al., 2017). All the measurements are also assumed to be perfect. The references of the simulation include the price of electricity (Fig. 3.4), the heating setpoints for the reactive controller and the allowable zone temperature range for the predictive controller (Fig 3.5) which are identical for every day in the simulation. Starting with the price of electricity, it is constantly $4.33 \propto / \mathrm{kWh}$ except for the peak demand periods when it is 50.65 $\notin / \mathrm{kWh}$.

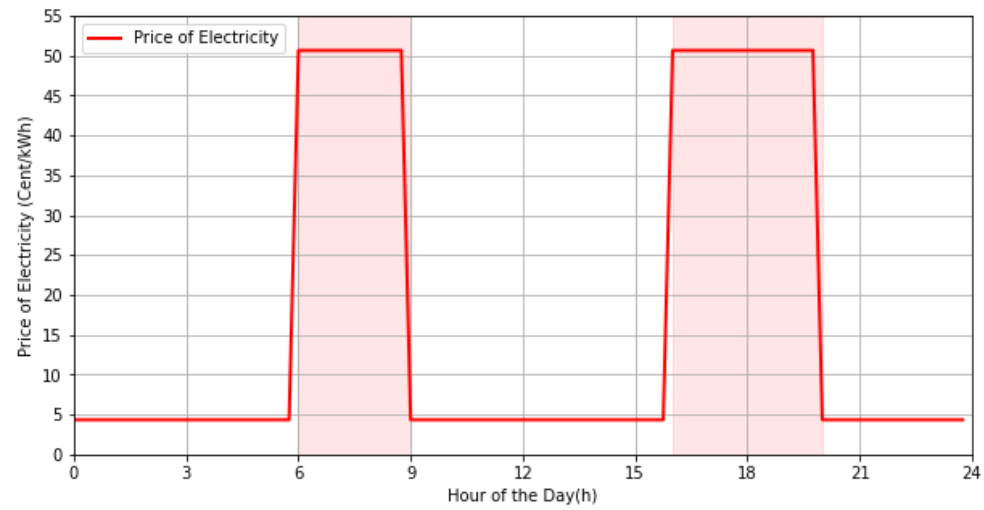

Figure 3.4: Simulation reference: Price of electricity as per Hydro-Québec Rate Flex-D

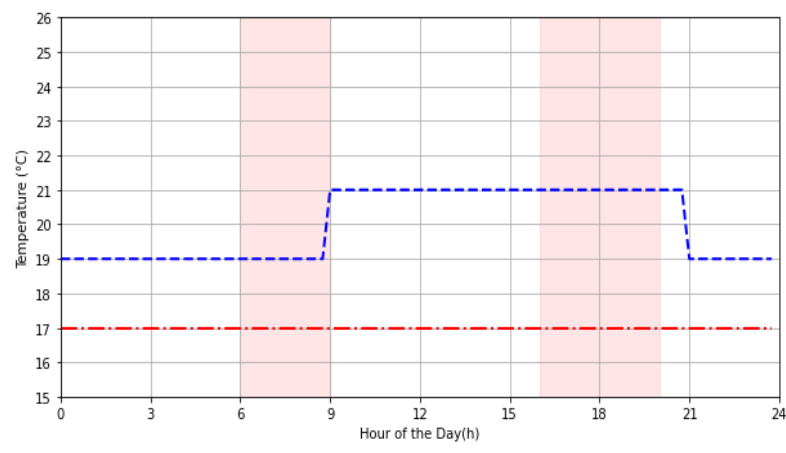

-- Above-Grade Space Setpoint - - Basement Setpoint

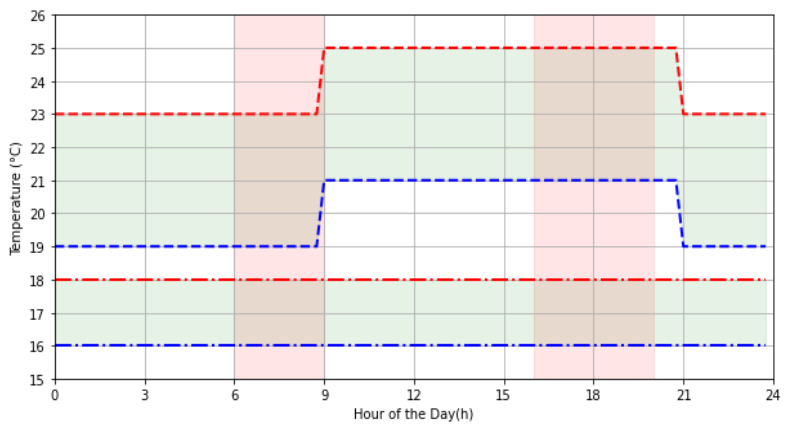

-- Room Air Temperature Higher Bound - - Basement Air Temperature Higher Bound -- Room Air Temperature Lower Bound _ _. Basement Air Temperature Lower Bound

Figure 3.5: Simulation reference: Heating setpoints for the reactive controller (left) and allowable zone air temperature range for the predictive controller (right)

The room heating setpoint is $21{ }^{\circ} \mathrm{C}$ from 9:00 to 21:00, otherwise, it is $19{ }^{\circ} \mathrm{C}$. The morning set-up and the night set-back represent a typical practice in Canadian houses (lower inside air temperature when people sleep). The basement heating setpoint is 
constantly $17^{\circ} \mathrm{C}$, naturally lower than the room setpoint. Applying the predictive control strategies, thermal comfort is a soft constraint with linear penalty associated to its violation. In fact, there is no penalty if the inside air temperature is in the comfort (allowable) range; however, the further it gets from the allowable range, the more penalty is associated to the control strategy. The higher bound for room air temperature is $25^{\circ} \mathrm{C}$ from 9:00 to 21:00, otherwise, it is $23{ }^{\circ} \mathrm{C}$. The lower bound for room air temperature is $21{ }^{\circ} \mathrm{C}$ from 9:00 to 21:00, otherwise, it is $19^{\circ} \mathrm{C}$. The area in between the bounds is assumed to be the allowable room air temperature range. For basement air temperature, the higher and lower bounds are $18{ }^{\circ} \mathrm{C}$ and $16^{\circ} \mathrm{C}$, respectively. The area in between the bounds is assumed to be the allowable basement air temperature range. Naturally, the basement is kept cooler than the above-grade space.

For the sake of brevity, the visualized and discussed results correspond only to the $3 \mathrm{C} 7 \mathrm{R}$ network model on two random consecutive days in late March 2019, $27^{\text {th }}$ and $28^{\text {th }}$. According to the weather forecasts, March $27^{\text {th }}$ is a sunny day with approximately $26 \mathrm{kWh}$ PV generation where the minimum and maximum of the outside air temperature are -13.5 ${ }^{\circ} \mathrm{C}$ and $4.9^{\circ} \mathrm{C}$, respectively. March $28^{\text {th }}$, is a warmer day with a smaller difference between the minimum and maximum of the outside air temperature. Being covered by passing clouds, the PV system is predicted to only generate about $6 \mathrm{kWh}$ throughout the day. Fig. 3.6 displays the forecast of outside ambient air temperature for both days.
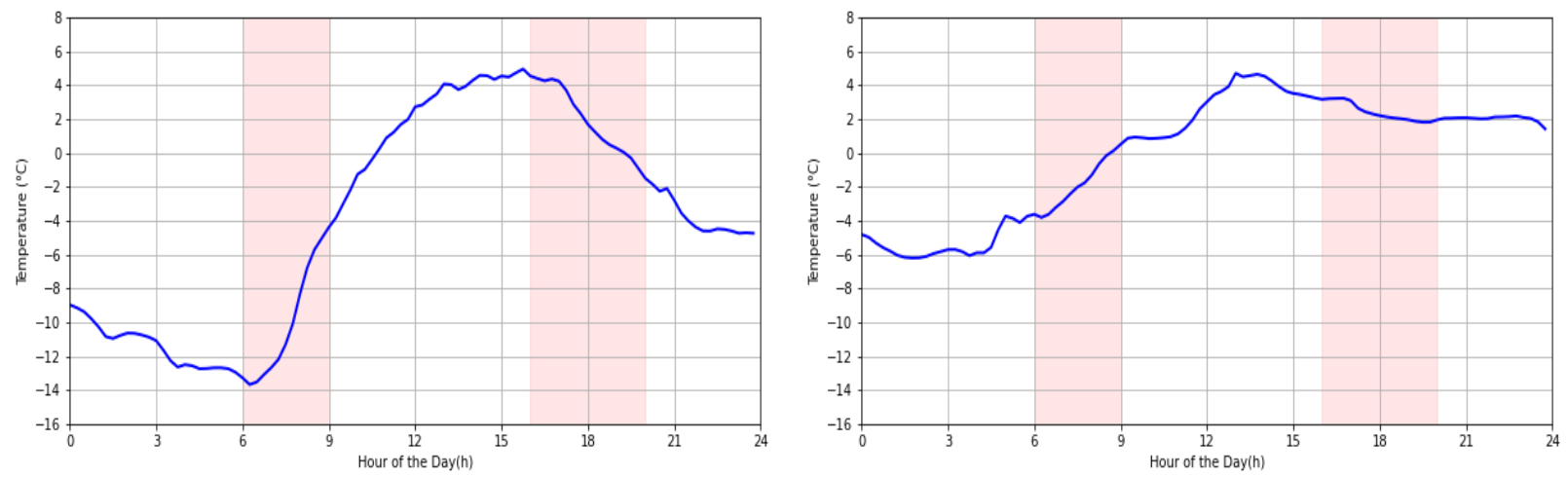

Figure 3.6: Forecast of outside ambient air temperature for March $27^{\text {th }}$ (left) and March $28^{\text {th }}$ (right)

The model is re-calibrated at the beginning of the day (March $27^{\text {th }}, 00: 00$ ) using the observations of the last 120 hours (March $22^{\text {nd }}$ to March $26^{\text {th }}$ ) as the identification period. The identification period is split into 75\% (90 hours) for training and 25\% (30 hours) for 
testing. Fig. 3.7 illustrates a comparison between the predictions and the observations of zones air temperature over the train and test periods; the residual is also plotted.
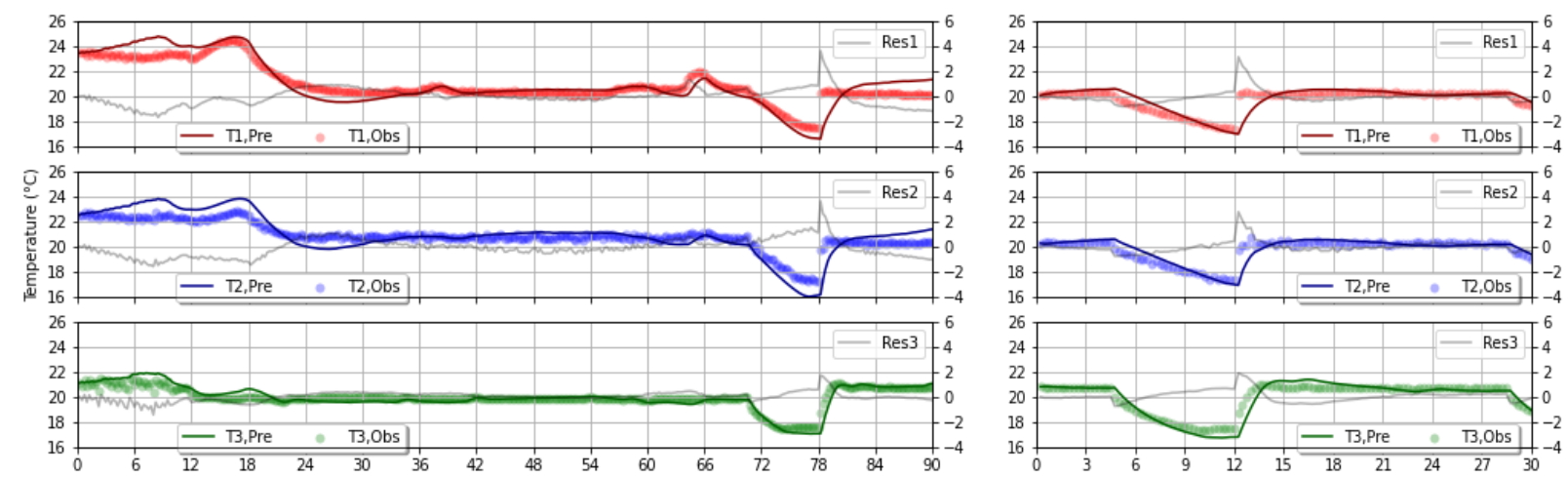

Figure 3.7: Results of the 3C7R network model training (left) and testing (right) for simulation on March $27^{\text {th }}$ - training period length: $90 \mathrm{~h}$, testing period length: $30 \mathrm{~h}$

Parameters are identified using Algorithm 1 and their uncertainty is calculated. The results of the parameter identification are summarized in Table 3.3, where the theoretical values, estimated from simplified geometry and material properties, and the calibrated values for March $27^{\text {th }}$ together with their uncertainty (95.45\% confidence) are listed. The simulation uses equal weights for all the zones and all the time steps by default; however, it is possible to manipulate the spatial/temporal weights in the objective function to emphasize certain zone(s) or period(s). The model's performance is evaluated with RMSE and MBE as fit metrics. The calibrated values are assumed to be validated if RMSE $E_{\text {test }} \leq$ $0.5^{\circ} \mathrm{C}$ and $\mathrm{MBE}_{\text {test }} \leq 0.25^{\circ} \mathrm{C}$.

Table 3.3: Results of the 3C7R network model re-calibration for simulation on March 27 $7^{\text {th }}$ Identification period: March $22^{\text {nd }}$ to March $26^{\text {th }} ; 75 \%$ train and $25 \%$ test

\begin{tabular}{|l|l|l|l|}
\hline Parameters & Theoretical values & Calibrated values for March $26^{\text {th }}$ & Calibrated values for March $27^{\text {th }}$ \\
\hline$\alpha_{1}$ & 0.60 & 0.59 & $0.51 \pm 6.1 \%$ \\
\hline$\alpha_{2}$ & 0.30 & 0.37 & $0.34 \pm 9.0 \%$ \\
\hline$\alpha_{3}$ & 0.05 & 0.02 & $0.02 \pm 25.0 \%$ \\
\hline $\mathrm{C}_{1}$ & $6.75 \mathrm{M} \mathrm{J} /{ }^{\circ} \mathrm{C}$ & $4.81 \mathrm{M} \mathrm{J} /{ }^{\circ} \mathrm{C}$ & $4.73 \mathrm{M} \mathrm{J} /{ }^{\circ} \mathrm{C} \pm 1.1 \%$ \\
\hline
\end{tabular}




\begin{tabular}{|c|c|c|c|}
\hline $\mathrm{C}_{2}$ & $6.25 \mathrm{MJ} /{ }^{\circ} \mathrm{C}$ & $4.25 \mathrm{M} \mathrm{J} /{ }^{\circ} \mathrm{C}$ & $4.28 \mathrm{M} \mathrm{J} /{ }^{\circ} \mathrm{C} \pm 4.6 \%$ \\
\hline $\mathrm{C}_{3}$ & $7.45 \mathrm{MJ} /{ }^{\circ} \mathrm{C}$ & $5.05 \mathrm{M} \mathrm{J} /{ }^{\circ} \mathrm{C}$ & $5.01 \mathrm{M} \mathrm{J} /{ }^{\circ} \mathrm{C} \pm 8.3 \%$ \\
\hline $\mathrm{R}_{1}$ & $0.015^{\circ} \mathrm{C} / \mathrm{W}$ & $0.055^{\circ} \mathrm{C} / \mathrm{W}$ & $0.053^{\circ} \mathrm{C} / \mathrm{W} \pm 0.8 \%$ \\
\hline $\mathrm{R}_{2}$ & $0.015^{\circ} \mathrm{C} / \mathrm{W}$ & $0.045^{\circ} \mathrm{C} / \mathrm{W}$ & $0.045^{\circ} \mathrm{C} / \mathrm{W} \pm 1.9 \%$ \\
\hline $\mathrm{R}_{3}$ & $0.019^{\circ} \mathrm{C} / \mathrm{W}$ & $0.027^{\circ} \mathrm{C} / \mathrm{W}$ & $0.029^{\circ} \mathrm{C} / \mathrm{W} \pm 4.8 \%$ \\
\hline $\mathrm{R}_{4}$ & $0.005^{\circ} \mathrm{C} / \mathrm{W}$ & $0.002{ }^{\circ} \mathrm{C} / \mathrm{W}$ & $0.002{ }^{\circ} \mathrm{C} / \mathrm{W} \pm 19.6 \%$ \\
\hline $\mathrm{R}_{5}$ & $0.014{ }^{\circ} \mathrm{C} / \mathrm{W}$ & $0.044^{\circ} \mathrm{C} / \mathrm{W}$ & $0.039^{\circ} \mathrm{C} / \mathrm{W} \pm 7.0 \%$ \\
\hline $\mathrm{R}_{6}$ & $0.014^{\circ} \mathrm{C} / \mathrm{W}$ & $0.003{ }^{\circ} \mathrm{C} / \mathrm{W}$ & $0.002{ }^{\circ} \mathrm{C} / \mathrm{W} \pm 41.4 \%$ \\
\hline $\mathrm{R}_{7}$ & $0.036^{\circ} \mathrm{C} / \mathrm{W}$ & $0.004{ }^{\circ} \mathrm{C} / \mathrm{W}$ & $0.004^{\circ} \mathrm{C} / \mathrm{W} \pm 27.1 \%$ \\
\hline \multicolumn{4}{|l|}{ Fit metrics } \\
\hline States & $\operatorname{RMSE}\left({ }^{\circ} \mathrm{C}\right)$ & & $\operatorname{MBE}\left({ }^{\circ} \mathrm{C}\right)$ \\
\hline $\mathrm{T}_{1}-$ Train & 0.624 & & 0.023 \\
\hline $\mathrm{T}_{2}-$ Train & 0.637 & & 0.071 \\
\hline $\mathrm{T}_{3}-$ Train & 0.393 & & -0.014 \\
\hline $\mathrm{T}_{1}-\mathrm{Test}$ & 0.435 & & 0.052 \\
\hline $\mathrm{T}_{2}-$ Test & 0.389 & & 0.027 \\
\hline $\mathrm{T}_{3}-$ Test & 0.464 & & -0.062 \\
\hline
\end{tabular}

Fig. 3.8 (left) displays the optimal operation plan of the heating system and the battery for March $27^{\text {th }}$, applying the predictive control. Knowing that at 6:00 the high energy price period starts, the predictive controller constantly stores energy in the above-grade space thermal mass and maintains the basement air temperature at a comfortable level with 
minimum energy consumption from 00:00 to 6:00. During this time, as shown in Fig. 3.9 (left), the temperature of the above-grade space air is optimally increased; however, the basement air temperature continuously stays within its boundaries. Letting the air temperature float in all the zones with no auxiliary heating from 6:00 to 9:00, the building is able to have no demand during this period. According to the forecast of solar radiation, the PV system is predicted to generate about $22 \mathrm{kWh}$ from 9:00 to 16:00. Aiming for maximized self-consumption and also knowing that at 16:00 another high energy price period starts, the predictive controller consumes the PV generation for maintaining the thermal comfort and charging the battery with minimum cost, first. As long as the comfort is satisfied, the excess solar electricity is exported. In a sunny day such as March 27 ${ }^{\text {th }}$, solar gains can effectively reduce the need for auxiliary heating between the two high energy price periods, which allows for charging the storage and/or exporting. The linear increase in the battery state of charge, shown in Fig. 3.10 (left), is the result of charging the battery at a constant C-rate. During the evening high energy price period (16:00 to 20:00), there is no auxiliary heating demand as the predictive controller prioritizes the minimization of energy cost over the penalization of thermal comfort violation and lets the air temperature float, even though it receives comfort violation penalty. Also, the battery discharges at a constant C-rate, partly during this period. The night set-back causes the auxiliary heating to be very small from 21:00 to 24:00.

The reactive PI controller, on the other hand, attempts to maintain the zone air temperature at the pre-defined heating setpoint, disregarding the energy price. Having no insight about the future, the PI controller covers as much heating load as possible with the PV generation at any time, and if there is excess, it first charges the battery and then exports to the grid. The results of controlling the heating system with a PI controller are shown in Fig. 3.8, 3.9 and 3.10 (right). During the period of maximum solar gains, when the inside air temperature is above the heating setpoint, the reactive controller stores approximately $8 \mathrm{kWh}$ in the battery and exports more than 1.5 times of that to the grid. 

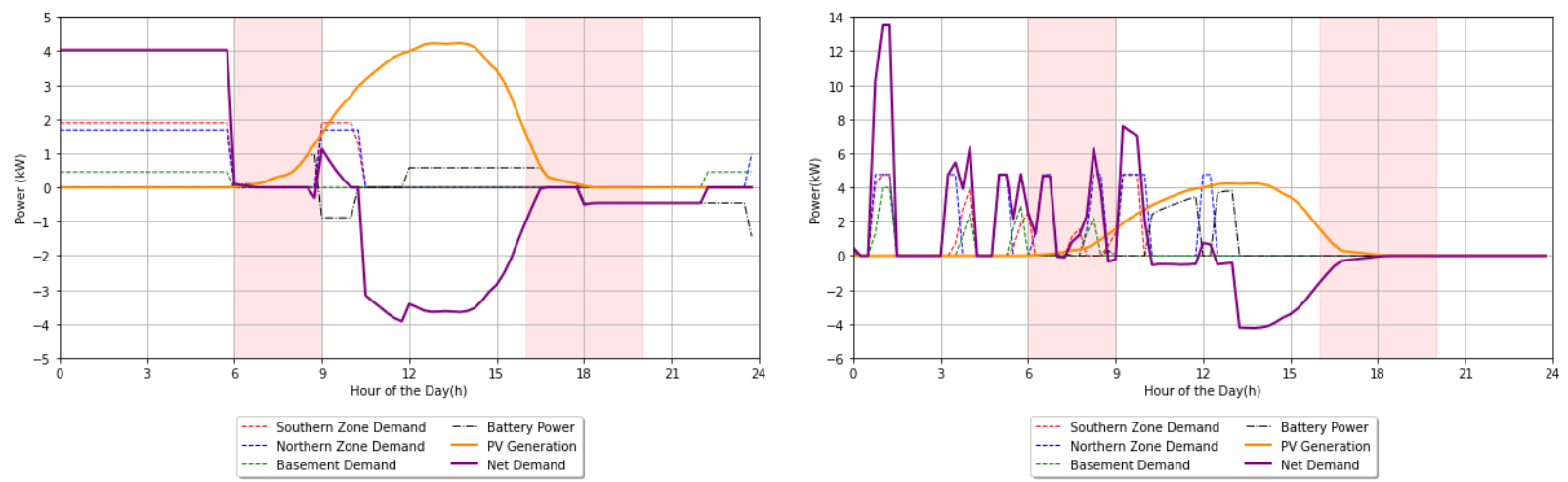

Figure 3.8: Electrical demand and generation subject to the predictive controller (left) and the reactive controller (right) - March $27^{\text {th }}$
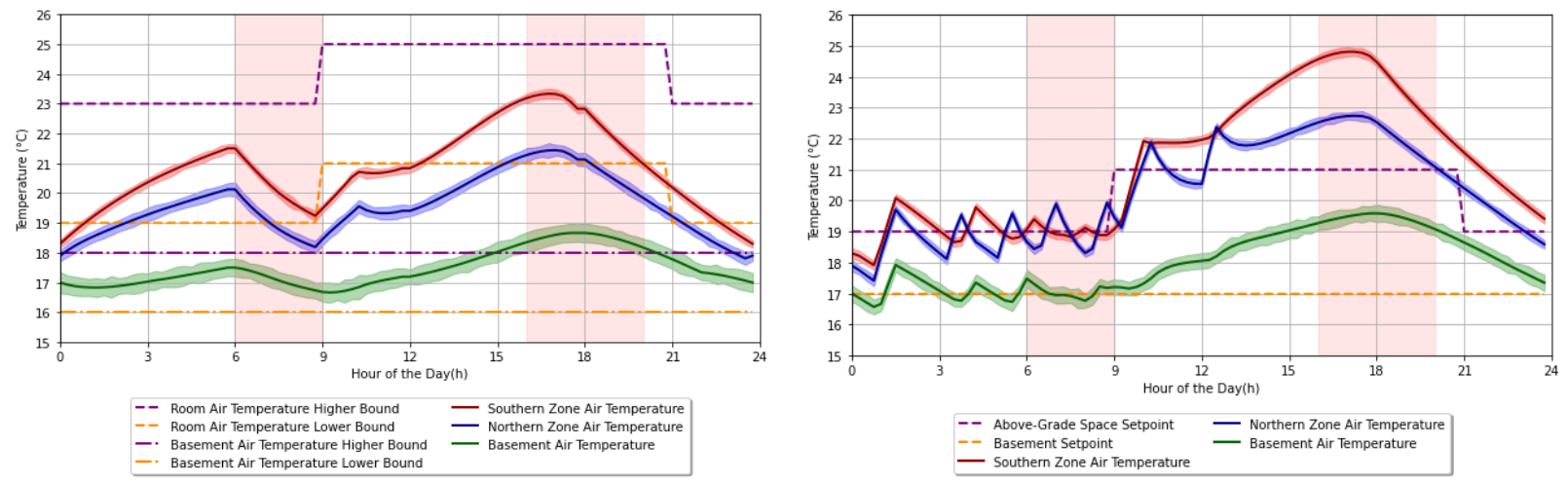

Figure 3.9: Zone air temperature subject to the predictive controller (left) and the reactive controller (right) - March $27^{\text {th }}$
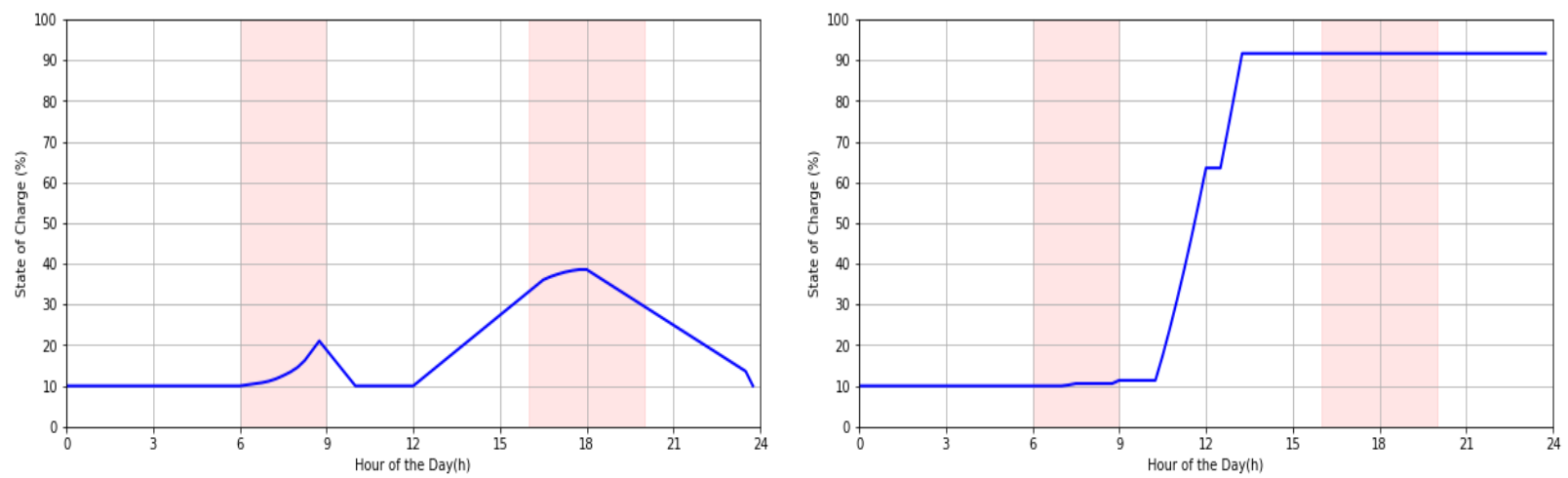

Figure 3.10: Battery state of charge subject to the predictive controller (left) and the reactive controller (right) - March $27^{\text {th }}$

For simulation on March $28^{\text {th }}$, the model is re-calibrated at the beginning of the day using the observations of the last 5 days (March $23^{\text {nd }}$ to March $27^{\text {th }}$ ) as the identification 
period, with train to test ratio (TTR) of 3.0. The same procedure explained for March 2 $7^{\text {th }}$, updates all the model parameters.
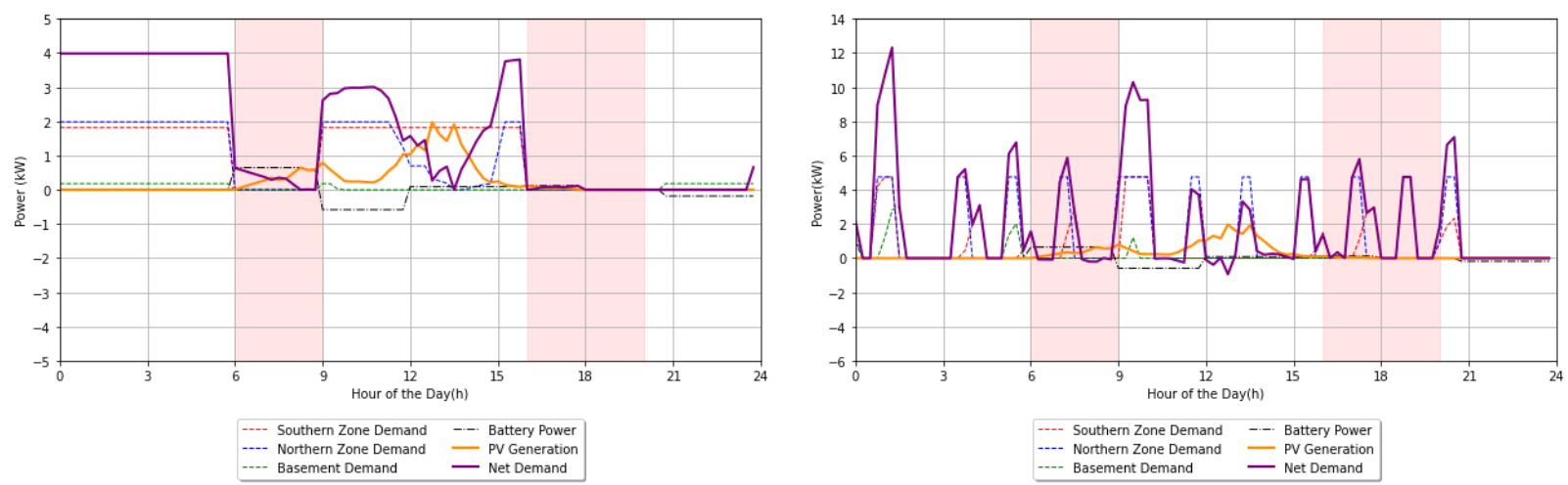

Figure 3.11: Electrical demand and generation subject to the predictive controller (left) and the reactive controller (right) - March $28^{\text {th }}$
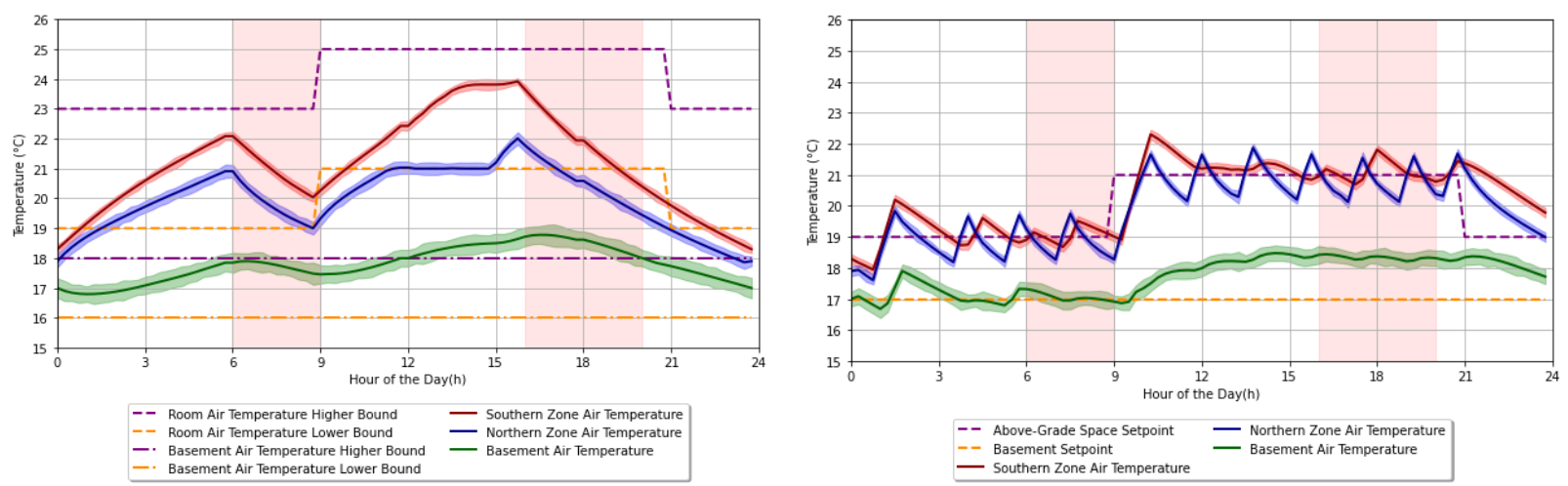

Figure 3.12: Zone air temperature subject to the predictive controller (left) and the reactive controller (right) - March $28^{\text {th }}$
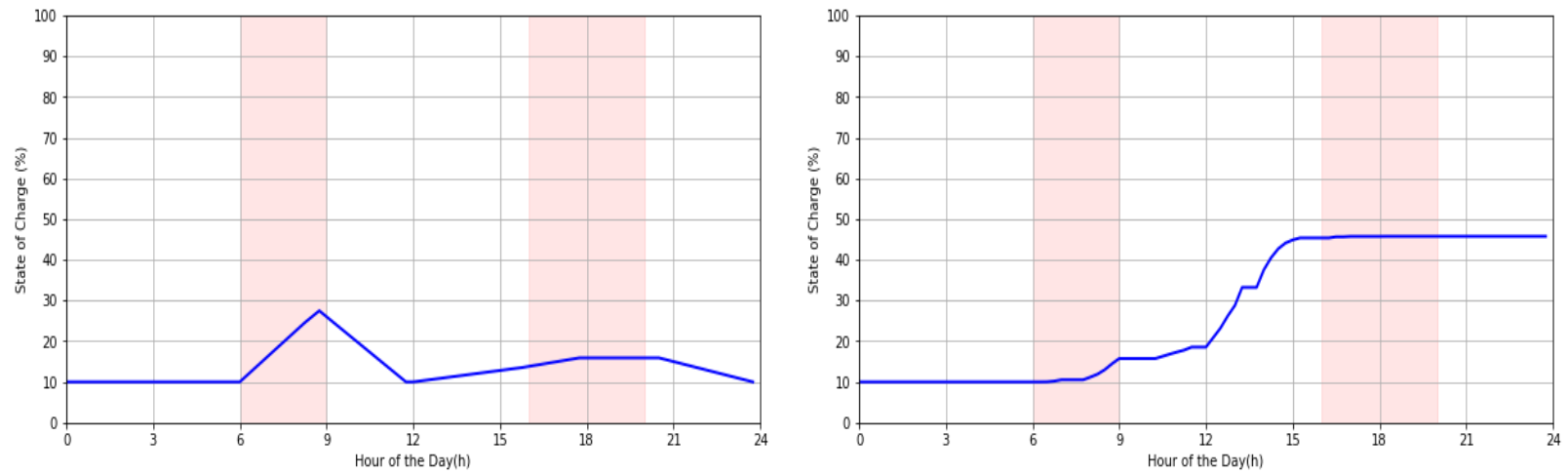

Figure 3.13: Battery state of charge subject to the predictive controller (left) and the reactive controller - March $28^{\text {th }}$ 
Optimal increase in the temperature of the above-grade space air and maintenance of the basement air temperature with minimal auxiliary heating are obvious from 00:00 to 6:00, in Fig. 3.11 and 3.12 (left). With the start of the morning high price period, the predictive controller stops heating and lets the building thermal mass discharge, which results in the air temperature float during this period. The PV system is predicted to generate a small amount of energy due to passing clouds or snow which is forecasted for March $28^{\text {th }}$. Therefore, all the PV generation from 9:00 to 16:00 is consumed for heating the building to help demand shaving during the evening high price period. Like the previous day, the night set-back effectively lowers the need for auxiliary heating from 21:00 to 24:00. The results of controlling the heating system with the reactive PI controller on March $28^{\text {th }}$ are shown in Fig. 3.11, 3.12 and 3.13 (right). The inside air temperature oscillates around the heating setpoint at the cost of $12.3 \mathrm{~kW}$ peak demand and roughly 7 $\mathrm{kWh}$ consumption of the high price energy.

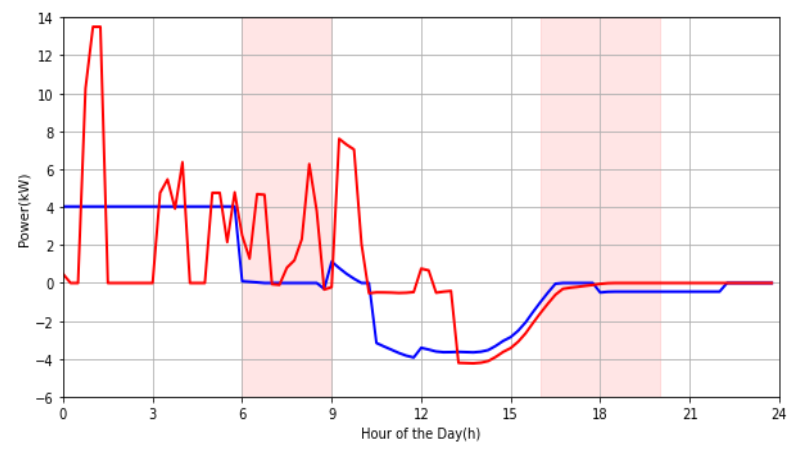

— Predictive Net Demand — Reactive Net Demand

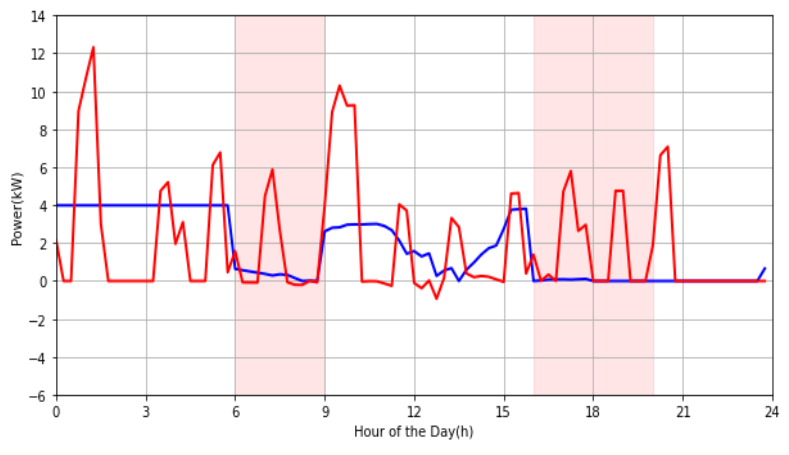

— Predictive Net Demand - Reactive Net Demand

Figure 3.14: Building's net electrical demand subject to both controllers on March $27^{\text {th }}$ (left) and March $28^{\text {th }}$ (right)

Fig. 3.14 and Table 3.4 compare the building performance subject to both controllers on March $27^{\text {th }}$ and $28^{\text {th }}$. The building's net electrical demand is plotted in Fig. 3.14, and the building's daily measures are presented in Table 3.4. On March $27^{\text {th }}$ (sunny day), $21.2 \%$ reduction in the total heating load, $24.8 \%$ reduction in the total import, $70.4 \%$ reduction in the peak demand, and the smooth profiles of auxiliary heating and battery charge/discharge clearly demonstrate the effectiveness of the predictive control. 8.0\% reduction in the total heating load, $17.3 \%$ reduction in the total import, and $67.5 \%$ reduction in the peak demand show the advantages of applying the predictive controller over the reactive controller also on partly-cloudy days such as March $28^{\text {th }}$. Actively attempting to maximize the selfconsumption, the predictive controller utilizes the on-site solar electricity approximately $11 \%$ more than the reactive controller. 
Table 3.4: Building's daily measures subject to both controllers on March $27^{\text {th }}$ and March $28^{\text {th }}$

\begin{tabular}{|l|l|l|l|l|}
\hline \multicolumn{2}{|l|}{ Day } & \multicolumn{2}{l|}{ March 27 } & \multicolumn{2}{l|}{ March 28 } \\
\hline Control & Reactive & Predictive & Reactive & Predictive \\
\hline PV Generation (kWh/Day) & 26.2 & 6.1 & \multicolumn{2}{l|}{} \\
\hline Auxiliary heating (kWh/Day) & 37.3 & 29.4 & 48.7 & 44.8 \\
\hline Total import (kWh/Day) & 31.8 & 23.9 & 46.9 & 38.8 \\
\hline Total export (kWh/Day) & 12.4 & 20.6 & 0.7 & 0.0 \\
\hline Net load (kWh/Day) & 19.4 & 3.3 & 46.2 & 38.8 \\
\hline Self-cons. (kWh/Day) & 13.8 & 5.6 & 5.5 & 6.1 \\
\hline Self-cons. (\%/Day) & 5.25 & 21.4 & 89.2 & 100 \\
\hline Peak demand (kW) & 13.5 & 4.0 & 12.3 & 4.0 \\
\hline
\end{tabular}

Table 3.5: Effect of control horizon on daily measures - March $27^{\text {th }}$

\begin{tabular}{|l|l|l|l|}
\hline Control horizon $\left(N_{c}\right)$ & $6 \mathrm{~h}$ & $12 \mathrm{~h}$ & $24 \mathrm{~h}$ \\
\hline Auxiliary heating (kWh/Day) & 29.4 & 32.4 & 32.8 \\
\hline Total import (kWh/Day) & 23.9 & 27.7 & 28.7 \\
\hline Total export (kWh/Day) & 20.6 & 21.5 & 22.1 \\
\hline Self-consumption (kWh/Day) & 5.6 & 4.7 & 4.1 \\
\hline Self-consumption (\%/Day) & 21.4 & 18.0 & 15.6 \\
\hline Peak demand (kWh/Day) & 4.0 & 4.6 & 5.1 \\
\hline
\end{tabular}


The selection of an appropriate control horizon requires analysis and tuning. Normally, a large control horizon leads to more heating load, higher peak demand and more battery cycles, which are not desirable. On the other hand, reducing the control horizon (increasing the $N_{h} / N_{c}$ ratio in general) puts the convergence of the optimization at risk. Therefore, there is an optimal control horizon within the feasible range. Table 3.5 compares how different control horizons influence the performance of the predictive controller on March $27^{\text {th }}$. The predictive controller with $N_{c}=12$ or $24 \mathrm{~h}$ cycles the battery more and stores approximately $10 \%$ more energy in the thermal mass during the low-price period to ensure the minimization of energy cost. The reason is that as per step 5 of Algorithm 2, the controller computes the sequence of optimal inputs for a longer period, which results in exploitation of the thermal mass and battery. According to this analysis, the 6-hour control horizon is selected for the seasonal simulation of optimal day-ahead heating load management.

Table 3.6: Seasonal average of building's daily measures

\begin{tabular}{|l|l|l|l|l|}
\hline Control & \multicolumn{2}{l|}{ Reactive } & \multicolumn{2}{l}{ Predictive } \\
\hline Model & 3 C6R & $3 \mathrm{C} 7 \mathrm{R}$ & $3 \mathrm{C} 6 \mathrm{R}$ & $3 \mathrm{C} 7 \mathrm{R}$ \\
\hline PV Generation (kWh/Day) & \multicolumn{2}{l}{11.2} & \multicolumn{2}{l|}{} \\
\hline Auxiliary heating (kWh/Day) & 50.5 & 45.9 & 43.8 & 40.9 \\
\hline Total import (kWh/Day) & 47.5 & 43.2 & 37.6 & 35.1 \\
\hline Total export (kWh/Day) & 2.9 & 3.6 & 10.9 & 11.8 \\
\hline Self-cons. (kWh/Day) & 3.1 & 3.7 & 4.6 & 5.2 \\
\hline Self-cons. (\%/Day) & 27.7 & 33.0 & 41.1 & 46.4 \\
\hline Peak demand (kW) & 13.5 & 13.5 & 4.6 & 4.0 \\
\hline Energy cost (\$/Day) & 4.8 & 4.6 & 1.6 & 1.5 \\
\hline
\end{tabular}


Table 3.6 compares the building performance subject to both controllers based on seasonal average of daily measures. Applying the predictive controller, the results show an average of $12.1 \%$ reduction in the daily heating load, $19.8 \%$ reduction in the total daily import, $68.1 \%$ reduction in the peak demand, $67.0 \%$ reduction in the daily energy cost, and $13.4 \%$ increase in the self-consumption of on-site generated solar electricity for the duration of January $1^{\text {st }}$ to March $31^{\text {st }}$ (90 days), compared to the reactive controller. This table also presents a comparison between the two thermal RC network models. Generally, the $3 \mathrm{C} 7 \mathrm{R}$ network model performs more advantageously, as it systematically reduces the above-grade space auxiliary heating due to better anticipation of the effective solar gains. In other words, during sunny days the predictive controller with the 3C6R model consumes more auxiliary heating in the above-grade space [than the predictive controller with the $3 \mathrm{C} 7 \mathrm{R}$ model], as it underestimates the solar gains.

The simulation is written and performed in the Google CoLaboratory ${ }^{\mathrm{TM}}$ environment using various packages and libraries. NumPy and pandas are used for data preparation; SciPy.optimize, Imfit and Scikit-learn are used for parameter identification; CVXPY and uncertainties are used for implementation of MPC; And finally, Matplotlib is used for visualization of the results. 


\section{Chapter 4: Conclusions}

\subsection{Summary of contributions}

Suitable low-order control-oriented models for optimal heating load management in typical Canadian single-family detached houses were developed, calibrated and employed in a predictive framework for day-ahead operation planning, in which the objective is to enhance energy efficiency and energy flexibility of the building. The building dynamics are represented by a discrete time-varying state-space formulation with recurring parameter identification.

The effectiveness of the predictive control strategies is demonstrated within a seasonal simulation from January $1^{\text {st }}$ to March $31^{\text {st }}$, where the performance of the heating system subject to a reference reactive PI controller and a predictive controller are compared. The results show an average of $12.1 \%$ reduction in the daily heating load, $19.8 \%$ reduction in the total daily import, $68.1 \%$ reduction in the peak demand, $67.0 \%$ reduction in the daily energy cost, and $13.4 \%$ increase in the self-consumption of on-site generated solar electricity for the period of simulation.

To investigate the impact of model resolution on the convergence of parameter identification and MPC algorithms, two third-order thermal RC network models with different resolutions are developed. The first one divides the above-grade space to the southern and northern zones and the second one divides this space to the first and second floors. The simulation shows that due to more accurate anticipation of the effective passive solar gains, using the $3 \mathrm{C} 7 \mathrm{R}$ network model results in $6.6 \%$ less auxiliary heating load, $6.3 \%$ less energy costs and $5.3 \%$ more self-consumption of on-site generated solar electricity, compared to the 3C6R network model.

\subsection{Recommendations for future work}

The following are recommended topics for future research:

1. Continue studies on control-oriented RC thermal network models for predictive control applications and establish a systematic way for order selection. 
2. Develop an online systematic approach for parameter identification of the $\mathrm{RC}$ thermal network models, using Bayesian approach.

3. Conduct experimental research for investigation of the energy flexibility provided by different control strategies and system configurations.

4. Perform statistical analysis on large raw datasets consisting the consumption and onsite generation data of various prosumers in order to produce classified datasets for machine learning purposes.

5. Investigate the predictive control strategies effectiveness within a cluster of prosumers. 


\section{References}

Afram A, Janabi-Sharifi F. Theory and applications of HVAC control systems - A review of model predictive control (MPC). Building and Environment 2014;72:343-55.

Afroz Z, Shafiullah G. M, Urmee T, Higgins G. Modeling techniques used in building HVAC control systems: A review. Renewable and Sustainable Energy Reviews 2018;83:64-84.

Arendt K, Jradi M, Shaker H. R, Veje C. Comparative analysis of white, gray and black-box models for thermal simulation of indoor environment: Teaching building case study. Proceedings of the 2018 building performance modelling conference and simbuild co-organized by ASHRAE and IBPSA-USA;173-180.

Armstrong P. R, Leeb S. B, Norford L. K. Control with building mass-part I: Thermal response model. ASHRAE Transactions 2006;112:449.

Athienitis A. K, Chandrashekar M, Sullivan H. Modeling and analysis of thermal networks through subnetworks for multizone passive solar buildings. Applied Mathematical Modelling 1985;9:109-16.

Athienitis A. K, O’Brien W. Modeling, Design, and Optimization of Net-Zero Energy Buildings. Wiley 2015.

Athienitis A. K, Stylianou M, Shou J. Methodology for building thermal dynamics studies and control applications. ASHRAE Transactions 1990;(pt 2):839-48.

Athienitis, A., \& O’Brien, W. (2015). Modeling, Design, and Optimization of Net-Zero Energy Buildings. Wiley.

Athienitis, A., Chandrashekar, M., \& Sullivan, H. (1985). Modeling and analysis of thermal networks through subnetworks for multizone passive solar buildings. Applied Mathematical Modelling, 9 (2), $109-116$.

Athienitis, A., Stylianou, M., \& Shou, J. (1990). Methodology for building thermal dynamics studies and control applications. ASHRAE Transactions, (pt 2), 839 - 848.

Avci M, Erkoc M, Rahmani A, Asfour S. Model predictive HVAC load control in buildings using real-time electricity pricing. Energy and Buildings 2013;60:199-209. 
B. Kroposki, W. Marion, D. King, W. Boyson, and J. Kratochvil, "Comparison of Module Performance Characterization Methods," 28th IEEE PV Specialists Conference, 2000, pp. 1407- 1411.

B. Lachal, O. G., W. U. Weber (1992). Simplified methods for the thermal analysis of multifamily and administrative buildings. GA (USA)

Bacher P, Madsen H. Identifying suitable models for the heat dynamics of buildings. Energy and Buildings 2011;43:1511-22.

Bacher, P., \& Madsen, H. (2011). Identifying suitable models for the heat dynamics of buildings. Energy and Buildings, 43 (7), $1511-1522$.

Baetens, R., De Coninck, R., Helsen, L., and Saelens, D. (2010). The Impact of Load Profile on the Grid-Interaction of Building Integrated Photovoltaic (BIPV) Systems in Low-Energy Dwellings. J. Green Build. 5, 137-147.

Belanger, C. (2018). Hydro- Québec's technological visions 2035

Bianchini G, Casini M, Vicino A, Zarrilli D. Demand-response in building heating systems: A model predictive control approach. Applied Energy 2016;168: 159-70.

Blum D. H, Arendt K, Rivalin L, Piette M. A, Wetter M, Veje C. T. Practical factors of envelope model setup and their effects on the performance of model predictive control for building heating, ventilating, and air conditioning systems. Applied Energy 2019;236:410-25.

Blum D. H, Xu N, Norford L. K. A novel multi-market optimization problem for commercial heating, ventilation, and air-conditioning systems providing ancillary services using multi-zone inverse comprehensive room transfer functions. Science and Technology for the Built Environment 2016;22:783-97.

Braun J. E, Chaturvedi N. An Inverse Gray-Box Model for Transient Building Load Prediction. HVAC\&R Research 2002;8:73-99.

Buonomano, Annamaria (2016), Code-to-Code Validation and Application of a Dynamic Simulation Tool for the Building Energy Performance Analysis

C. Whitaker, T. Townsend, J. Newmiller, D. King, W. Boyson, J. Kratochvil, D. Collier, and D. Osborn, "Application and Validation of a New PV Performance Characterization Method," 26th IEEE PV Specialists Conference, 1997, pp. 1253-1256. 
Candanedo Ibarra, Luis M. (2010), Modelling and Evaluation of the Performance of BuildingIntegrated Open Loop Air-based Photovoltaic/Thermal Systems

Candanedo J. A, Allard A, Athienitis A. K. Predictive control of radiant floor heating and transmitted irradiance in a room with high solar gains. ASHRAE Transactions 2011;117:65265.

Candanedo J. A, Dehkordi V. R, Saberi-Derakhtenjani A, Athienitis A. K. Near-optimal transition between temperature setpoints for peak load reduction in small buildings. Energy and Buildings 2015;87:123-33.

Candanedo, J., Dehkordi, V. and Lopez, Ph. (2013). A control-oriented simplified building modeling strategy. IBPSA Chambery, France.

Candanedo, J., Dehkordi, V. and Lopez, Ph. (2014). A multi-level architecture to facilitate MPC implementation in commercial buildings: basic principles and case study. esim 2014, Ottawa, Canada.

Cao Y, Du J, Soleymanzadeh E. Model predictive control of commercial buildings in demand response programs in the presence of thermal storage. Journal of Cleaner Production 2019;218:315-27.

Chen, Y., Athienitis, A. K., \& Galal, K. E. (2013). Frequency domain and finite-difference modeling of ventilated concrete slabs and comparison with field measurements: Part 1, modeling methodology. International Journal of Heat and Mass Transfer, 66 (0), 948 - 956.

consumption information. Energy and Buildings, 40 (3), 394-398.

Cutsem O. V, Kayal M, Blum D. H, Pritoni M. Comparison of MPC formulations for building control under commercial time-of-use tariffs. IEEE Powertech Milan 2019.

D. King and P. Eckert, "Characterizing (Rating) Performance of Large PV Arrays for All Operating Conditions,” 25th IEEE PV Specialists Conference, 1996, pp. 1385-1388.

D. King, J. Kratochvil, and W. Boyson, "Field Experience with a New Performance Characterization Procedure for Photovoltaic Arrays," 2nd World Conference on PV Solar Energy Conversion, Vienna, 1998, pp. 1947-1952.

D. King, J. Kratochvil, and W. Boyson, "Measuring Solar Spectral and Angle-of-Incidence Effects on PV Modules and Solar Irradiance Sensors,” 26th IEEE PV Specialists Conference, 1997, pp. 1113-1116. 
D. King, J. Kratochvil, and W. Boyson, "Temperature Coefficients for PV Modules and Arrays: Measurement Methods, Difficulties, and Results," 26th IEEE PV Specialists Conference, 1997, pp. $1183-1186$.

D. King, W. Boyson, and J. Kratochvil, "Analysis of Factors Influencing the Annual Energy Production of Photovoltaic Systems,” 29th IEEE PV Specialists Conference, 2002.

D. L. King, W. E. Boyson, and J. A. Kratochvil, Photovoltaic Array Performance Model, Sandia National Laboratories Report, SAND2004-3535, August 2004. http://www.sandia.gov/pv. D. L. King, G. M. Galbraith, W. E. Boyson, S. Gonzalez, A. T. Murray, J. W. Ginn, and

Date J. A, Candaedo J. A, Athienitis A. K, Lavigne K. Development of reduced-order thermal dynamic models for building load flexibility of an electrically-heated high-temperature thermal storage device. Science and Technology for the Built Environment 2020;26:956-74.

Date J. A, Chen Y, Athienitis A. K, Fournier M. Impact of thermal model resolution on peak heating demand calculation under different setpoint profiles. ASHRAE Transactions 2016;122:278-88.

De Coninck R, Magnusson F, Åkesson J, Helsen L. Toolbox for development and validation of gray-box building models for forecasting and control. Building Performance Simulation 2015; 9(3):288-303.

Deru, M., and Torcellini, P. (2005). Performance Metrics Research Project - Final Report.

Drgona J, Arroyo J, Figueroa I. C, Blum D, Arendt K, Kim D, Olle E. P, Oravec J, Wetter M, Vrabie D. L, Helsen L. All you need to know about model predictive control for buildings. Annual Reviews in Control 2020;50:190-232.

Duun-Henriksen, Anne Katrine (2013), Model Identification Using Stochastic Differential Equation Gray-Box Models in Diabetes

E. Skoplaki and J. A. Palyvos, "On the temperature dependence of photovoltaic module electrical performance: A review of efficiency/power correlations," Solar Energy, to be published.

Eric Hirst, Price-Responsive Demand as Reliability Resources, April 2002

Evans D. L, Florschuetz L. W. Cost studies on terrestrial photovoltaic power systems with sunlight concentration. Solar Energy 1977;19:255-62. 
Evans, D.L., Florschuetz, L.W., 1977. Cost studies on terrestrial photovoltaic power systems with sunlight concentration. Solar Energy 19, 255-262.

Fischer D, Bernhardt J, Madani H, Wittwer C. Comparison of control approaches for variable speed air source heat pumps considering time variable electricity prices and PV. Applied Energy 2017;204:93-105.

Foucquier A, Robert S, Suard F, Stephan L, Jay A. State of the art in building modelling and energy performance prediction: A review. Renewable and Sustainable Energy Reviews 2013;23:272_88.

Foucquier, A., Robert, S., Suard, F., Stephan, L., \& Jay, A. (2013). State of the art in building modeling and energy performance prediction: A review. Renewable and Sustainable Energy Reviews, 23 (0), $272-288$.

Fournier, M., \& Leduc, M.-A. (2014). Study of electrical heating setpoint modulation strategies for residential demand response. In Proceedings of eSim Conference 2014. Ottawa, Ontario.

Gillespie, K. L., Cowan, J. D., Frazell, C. W., Haberl, J. S., Heinemeier, K. H., Kummer, J. P., Culp, C. H., Watson, T. E., Arnold, C. G., Baxter, V. D., Evans, R. a., Hogan, J. F., Kohloss, F. H., \& Montgomery, R. D. (2002). Measurement of Energy and Demand Savings. 8400, 170.

Goyal S, Barooah P. A method for model-reduction of non-linear thermal dynamics of multi-zone buildings. Energy and Buildings 2012;47:332-40.

Goyal, S., \& Barooah, P. (2012). A method for model-reduction of non-linear thermal dynamics of multi-zone buildings. Energy and Buildings, 47 (0), 332 - 340.

Guidebook for Emerging Renewables Program, California Energy Commission, $8^{\text {th }}$ Edition, December 2006,www.consumerenergycenter.org: $\underline{\text { http://www.consumerenergycenter.org/erprebate/equipment.html }}$

H. Fanney, et al., "Short-Term Characterization of Building Integrated Photovoltaic Modules", Proceedings of Solar Forum 2002, Reno, NV, June 15-19, 2002.

H. Neuenstein and A. Schlumberger, PHOTON Puts On-Grid Inverters Through Their Paces, Photon International, January 2007.

Haghighi, M.M. (2013). Controlling Energy-Efficient Buildings in the Context of Smart Grid : A Cyber Physical System Approach. University of California at Berkeley. 
Hart, G.W., Raghuraman, P., 1982. Simulation of thermal aspects of residential photovoltaic systems. MIT Report DOE/ET/20279-202.

Hazyuk I, Ghiaus C, Penhouet D. Optimal temperature control of intermittently heated buildings using model predictive control: Part II-control algorithm. Building and Environment 2012;51:388-94.

Hazyuk, I., Ghiaus, C., \& Penhouet, D. (2012). Optimal temperature control of intermittently heated buildings using model predictive control: Part $\{\mathrm{II}\}-$ control algorithm. Building and Environment, 51 (0), 388 - 394.

Henze G, Dodier R, Krarti M. Development of a predictive optimal controller for thermal energy storage systems. HVAC\&R Research 1997;3:233-64.

Henze G. P, Kalz D. E, Liu S, Felsmann C. Experimental analysis of model-based predictive optimal control for active and passive building thermal storage inventory. HVAC\&R Research 2005;11:189-213.

Henze, G. P., Kalz, D. E., Liu, S., \& Felsmann, C. (2005b). Experimental analysis of model-based predictive optimal control for active and passive building thermal storage inventory. HVAC\&R Research, 11 (2), $189\{213$.

Henze, G., Dodier, R., \& Krarti, M. (1997). Development of a Predictive Optimal Controller for Thermal Energy Storage Systems. HVAC\&R Research, 3 (3) 233 264.

Henze, G., Kalz, D., Liu, S., \& Felsmann, C. (2005a). Experimental Analysis of Model-Based Predictive Optimal Control for Active and Passive Building Thermal Storage Inventory. HVAC\&R Research, 11 (2), 189\{213.

https://en.wikipedia.org/wiki/Finite_difference_method

https://en.wikipedia.org/wiki/Lumped-element_model

https://en.wikipedia.org/wiki/Peak_demand

https://theengineeringmindset.com/heat-pumps-explained/

Huntoon, S. (2016). Battery Storage : Drinking Electric Kool-Aid. Public Util. Fortn. 36.

Hydro- Québec (2013). Rapport annual (annual report) 2013. Available at /http: //www.hydroquebec.com/publications/fr/index.html.

IEA, “Energy Technology Perspectives 2017 - Executive Summary,” Iea, p. 371, 2017. 
John Clauß, Christian Finck, Pierre Vogler-Finck, and Paul Beagon. Control strategies for building energy systems to unlock demand-side flexibility - A review. In $15^{\text {th }}$ International Conference of the International Building Performance Simulation Association (IBPSA), 2017. ISBN 9780521834339

Jorissen F. Toolchain for Optimal Control and Design of Energy Systems in Buildings. KU Leuven, Belgium. Ph.D. Thesis 2018.

Kaplan, S. M. (2009). Smart Grid. Electrical Power Transmission: Background and Policy Issues. The Capital.Net, Government Series. Pp. 1-42

Kintner-Meyer M, Emery A.F. Optimal control of an HVAC System using cold storage and building thermal capacitance. Energy and Buildings 1995;23:19-31.

Klein, K., Kalz, D., and Herkel, S. (2015). Grid Impact of a Net-Zero Energy Building With BIPV Using Different Energy Management Strategies. In CISBAT 2015, (Lausanne, Switzerland), pp. 579-584.

Kuboth S, Heberle F, Konig-Haagen A, Brüggemann D. Economic model predictive control of combined thermal and electric residential building energy systems. Applied Energy 2019;240:372-85.

Kummert M, André P, Argiriou A. A. Comparing control strategies using experimental and simulation results: Methodology and application to heating control of passive solar buildings. HVAC\&R Research 2006;12:715-38.

Kummert, M., Andre, P., \& Argiriou, A. A. (2006). Comparing control strategies using experimental and simulation results: Methodology and application to heating control of passive solar buildings. HVAC and R Research, 12 (3 A), 553 \{575.

Langner, M. R., Henze, G. P., Corbin, C. D., \& Brandemuehl, M. J. (2012).

Le Bel, C., \& Gelinas, S. (2012). All-electric experimental twin houses: The ultimate demand management testing tool. In Proceedings of The IASTED International Symposium on Power and Energy (PE 2013). Marina Del Rey, California.

Le Bel, C., \& Handfield, L. (2008). Cold load pick-up algorithms for line-voltage thermostats in a winter climate. (pp. 199 \{203). Baltimore, MD, United states.

Le Dréau, J. and P. Heiselberg (2016). "Energy flexibility of residential buildings using short term heat storage in the thermal mass." Energy 111: 991-1002 
Lund, P.D., Lindgren, J., Mikkola, J., and Salpakari, J. (2015). Review of energy system flexibility measures to enable high levels of variable renewable electricity. Renew. Sustain. Energy Rev. $45,785-807$.

Luque A, Hegedus S. Handbook of Photovoltaic Science and Engineering. Hoboken, NJ:Wiley 2003:943-51.

M. Vervaart, Test of a Photovoltaic Inverter of a Rated Power of 1100 W INES institute, 2007.

MacDougall P., Ran B., Huitema G., and Deconinck G. (2017). "Performance Assessment of Black Box Capacity Forecasting for Multi-Market Trade Application”. Energies 101673 http://dx.doi.org/10.3390/en10101673.

Maui Solar Energy Software Corporation, Solar Design Studio Ver. 6.0: PV-DesignPro and IVTracer, http://www.mauisolarsoftware.com.

Mavromatidis G, Orehounig K, Carmeliet J . Evaluation of photovoltaic integration potential in a village. Solar Energy 2015;121:152-68.

Michael Ropp and Sigifredo Gonzalez, "Development of a MATLAB/Simulink Model of a SinglePhase Grid-Connected Photovoltaic System,” infoserve.sandia.gov/sand_doc/2007/073290p.pdf.

NASA, "NASA GLOBAL CLIMATE CHANGE," February 2018. [Online]. Available: https://climate.nasa.gov/vital-signs/carbon-dioxide/.

Nise, N.S. (2011). Control Systems Engineering, Wiley.

Oldewurtel F, Ulbig A, Parisio A, Andersson G, Morari M. Reducing peak electricity demand in building climate control using real-time pricing and model predictive control. Decision and control (CDC), 49th IEEE conference 2010, on (pp. 1927-32) IEEE.

ourworldindata.org/world-population-growth

Patteeuw D, Henze G. P, Helsen L. Comparison of load shifting incentives for low-energy buildings with heat pumps to attain grid flexibility benefits. Applied Energy 2016;167:80-92.

Perez-Lombard, L., Ortiz, J., \& Pout, C. (2008). A review on buildings energy

Picard D, Helsen L. MPC performance for hybrid GEOTABS buildings. Purdue conferences-5th international high performance building conference, West Lafayette, IN, USA 2018. Purdue University, West Lafayette, IN, USA 
Prívara S, Vána Z, Záceková E, Cigler J. Building modeling: Selection of the most appropriate model for predictive control. Energy and Building 2012;55:341-50.

R. De Coninck, L. Helsen, (2013). "Bottom-up quantification of the flexibility potential of buildings", Building Simulation, 13th International Conference of the International Building Performance Simulation Association, IBPSA, France

Reddy, T. A. (2006). Literature Review on Calibration of Building Energy Simulation Programs. ASHRAE Transactions, 112 (1), 226-240.

Reynders Glenn. Quantifying the impact of building design on the potential of structural storage for active demand response in residential buildings; 2015

Robert, F. C., Sisodia, G. S., and Gopalan, S. (2018). A Critical Review on the Utilization of Storage and Demand Response for the Implementation of Renewable Energy Microgrids, Sustainable Cities and Society.

Rouchier S, Jimenez, M. J, Castano S. Sequential Monte Carlo for on-line parameter estimation of a lumped building energy model. Energy and Buildings 2019;187: 86-94.

Rui Amaral Lopes, Adriana Chambel, João Neves, Daniel Aelenei, and João Martins. A Literature Review of Methodologies Used to Assess the Energy Flexibility of Buildings 2016. ISSN 18766102. doi: 10.1016/j.egypro.2016.06.274

Rune Grønborg Junker, Armin Ghasem Azar, Rui Amaral Lopes, Karen Byskov Lindberg, Glenn Reynders, Rishi Relan, and Henrik Madsen. Characterizing the energy flexibility of buildings and districts. Applied Energy, 2018. ISSN 03062619. doi: 10.1016/j.apenergy.2018.05.037

Salom, J., Marszal, A.J., Candanedo, J., Widén, J., Lindberg, K.B., and Sartori, I. (2014b). Analysis of load match and grid interaction indicators in net zero energy buildings with highresolution data A report of Subtask A IEA Task 40 / Annex 52 Towards Net Zero Energy Solar Buildings.

Salom, J., Marszal, A.J., Widén, J., Candanedo, J., and Lindberg, K.B. (2014a). Analysis of load match and grid interaction indicators in net zero energy buildings with simulated and monitored data. Appl. Energy 136, 119-131.

Salpakari J, Lund P. Optimal and rule-based control strategies for energy flexibility in buildings with PV. Applied Energy 2016;161:425-36. 
Shi Z, O'Brien W. Sequential state prediction and parameter estimation with constrained dual extended kalman filter for building zone thermal responses. Energy and Buildings 2019;183:538-46.

Shou, J. (1991). A computer technique for heating control analysis and application to radiant heating. Ph.D. thesis, Concordia University, Montreal, Canada.

Søren Østergaard Jensen, Anna Marszał-Pomianowska, Roberto Lollini, Wilmer Pasut, Armin Knotzer, Peter Engelmann, Anne Stafford, and Glenn Reynders. IEA EBC Annex 67 Energy Flexible Buildings. Energy and Buildings, 2017. ISSN 03787788. doi: 10.1016/j.enbuild.2017.08.044

Statistics Canada (2011a). Households and the environment: Energy use. Accessed January 2015. Available at http://www.statcan.gc.ca/pub/11-526-s/11-526-s2013002-eng.htm.

Statistics Canada (2011b). Report of energy supply and demand in Canada. Accessed January 2015. Available at: http://www5.statcan.gc.ca/olc-cel/olc.action?objId=57-003$\underline{X}$ \&objType $=2 \&$ lang $=$ en $\&$ limit $=0$.

Statistics Canada. Households and the Environment: Energy Use 2011; Accessed January 2015: www.statcan.gc.ca

Tarragona J, Fernandez C, de Gracia A. Model predictive control applied to a heating system with PV panels and thermal energy storage. Energy 2020;197:117229.

Teeter, J., \& Chow, M.-Y. (1998). Application of functional link neural network to HVAC thermal dynamic system identification. Industrial Electronics, IEEE Transactions on, 45 (1), 170-176.

The Value of Reliability in Power Systems, MIT Energy Laboratory, June 1999

Toradmal A, Kemmler T, Thomas B. Boosting the share of onsite PV-electricity utilization by optimized scheduling of a heat pump using buildings thermal inertia. Applied Thermal Engineering 2018;137:248-58

Troncoso, R. (1997). A hybrid monitoring-modeling procedure for analyzing the performance of large central chilling plants. vol. 97, (pp. 421-428).

UN DESA, "World Population Prospects The 2017 Revision Key Findings and Advance Tables," World Popul. Prospect. 2017, pp. 1-46, 2017. 
Vanhoudt, D., Geysen, D., Claessens, B., Leemans, F., Jespers, L., and Van Bael, J. (2014). An actively controlled residential heat pump: Potential on peak shaving and maximization of selfconsumption

Vrettos E, Lai K, Oldewurtel F, Andersson G. Predictive control of buildings for demand response with dynamic day-ahead and real-time prices. European Control Conference (ECC), Zurich, Switzerland 2013, on (pp. 2527-34). IEEE.

W. I. Bower, Array Performance Characterization and Modeling for Real-Time Performance Analysis of Photovoltaic Systems, $4^{\text {th }}$ World Conference on PV Energy Conversion, Hawaii, May 2006.

Watson, D.S. (2013). Fast Automated Demand Response to Enable the Integration of Renewable Resources. Lawrence Berkeley National Lab Rep. LBNL5555E.

WBCSD. Transforming the market. Technical report, 2009

William F. Holmgren, Clifford W. Hansen, and Mark A. Mikofski. "pvlib python: a python package for modeling solar energy systems.” Journal of Open Source Software, 3(29), 884, (2018).

Winn R. C, Wins C. B. Optimal control of auxiliary heating of passive-solar-heated buildings. Solar Energy 1985;35:419-27.

Y. Riffonneau, A.Delaille, F.Barruel, and S. Bacha, "System modeling and energy management for grid connected PV systems with storage," in Proc. 24th EU Photovoltaic Solar Energy Conf., Valencia, Spain, 2008.

Yan, Chengchu (2017), A simplified analytical model to evaluate the impact of radiant heat on building cooling load

Zafar, R., Mahmood, A., Razzaq, S., Ali, W., Naeem, U., and Shehzad, K. (2018). Prosumer based energy management and sharing in smart grid. Renewable and Sustainable Energy Reviews, 82(August 2016):1675-1684.

Zakula T, Armstrong P. R, Norford L. Modeling environment for model predictive control of buildings. Energy and Buildings 2014;85:549-59.

Zondag, H.A., 2007. Flat-plate PV-thermal collectors and systems - a review. Renew. Sustain. Energy Rev. doi:10.1016/j.rser.2005.12.012. 


\section{Appendix A: Winter Weather Clustering}

An unsupervised learning with K-means clustering method is performed to classify the coldest days of winter 2019 and the average silhouette test is performed to measure the quality of the clustering. This test investigates intra-class similarity and inter-class dissimilarity and ranges from -1 to +1 , where a high value indicates a good clustering solution. In other words, the optimal number of clusters is the one that maximizes the average silhouette over a range of possible values for $\mathrm{K}$.

Figure AA.1 shows the results of classification based on the outside ambient air temperature. As per the average silhouette test, 2-cluster solution is an optimal answer, where the blue trajectory represents the daily profile of outside ambient air temperature for a typical very cold day, and the red trajectory reflects the daily profile of outside ambient air temperature for a typical cold day.

The results of classification based on the global irradiance are presented in figure AA.2. The average silhouette test based on the vertical irradiance suggests that 3-cluster is an optimal solution, where the red trajectory represents clear sky, the green trajectory represents partly-cloudy sky, and finally, the blue trajectory represents overcast sky.

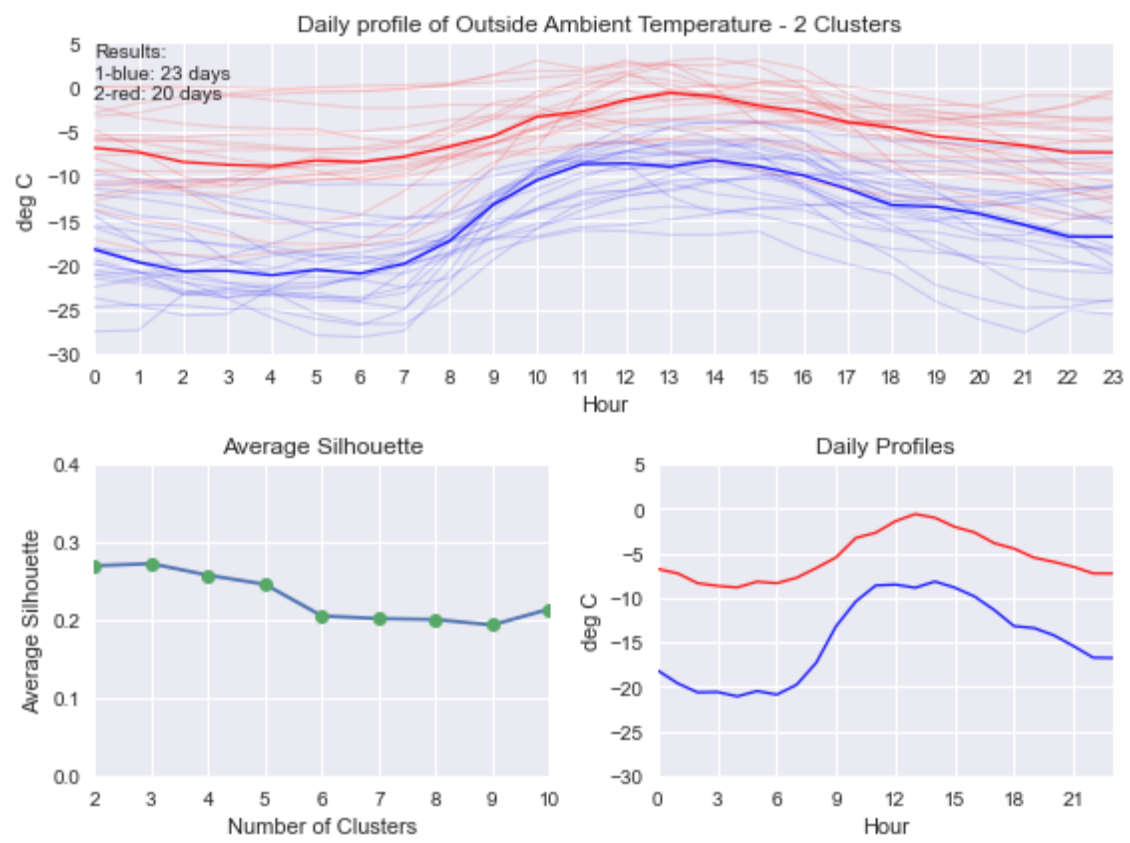

Figure AA.1: Classification of the coldest days of year based on the daily profiles of outside ambient air temperature using K-means method and the associated average silhouette test results 

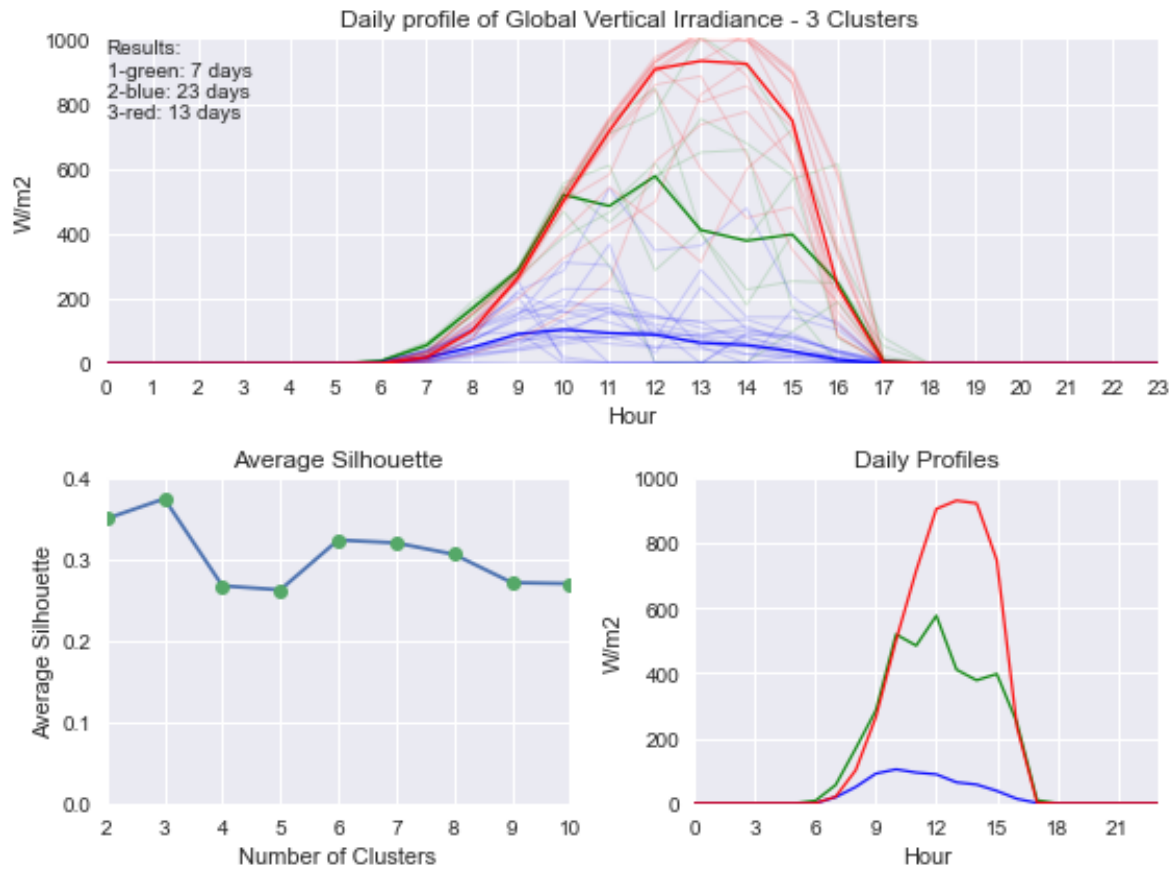

Figure AA.2: Classification of the coldest days of year based on the daily profiles of global irradiance using K-means method and the associated average silhouette test results

K-means clustering is the most commonly used unsupervised machine learning algorithm for partitioning a given data set into a set of $\mathrm{K}$ groups (clusters), where $\mathrm{K}$ represents the number of clusters pre-specified by the analyst. It classifies objects in multiple groups, such that objects within the same cluster are as similar as possible (high intra-class similarity), whereas objects from different clusters are as dissimilar as possible (low inter-class similarity). In K-means clustering, each cluster is represented by its center (centroid) which corresponds to the mean of points assigned to the cluster. 


\section{Appendix B: Photovoltaics System Performance Modelling}

When it comes to grid-connected photovoltaics systems, it is crucial to precisely model

the impact of introducing this intermittent power source to the grid and also to help distribution planners perform the necessary interconnection impact studies.

The time-varying ambient temperature and solar irradiance influence the total photovoltaics system output and ultimately the net power demand of the prosumer. Both accurate data and time series simulations are often required to fully understand the impact of variability on distribution system operations and reliability. There are different approaches to model and simulate the performance of photovoltaics systems.

Assuming the photovoltaics module, the effective cell temperature and the effective irradiance are known, there are two main approaches to output the module's currentvoltage curve:

1. Single-diode circuit approach which is developed by De Soto et al. (2006) and defines the entire curve as a continuous function of inputs

2. Point-value approach which is developed by King et al. (2004) at Sandia National Laboratories and predicts five points on the curve as a function of inputs.

\section{Single-Diode Circuit Approach}

Solar cells and photovoltaics modules can be modeled as a current source in parallel with a diode. A diode is a two-terminal device that allows an electrical current to flow in only one direction. The standard model of a solar cell is called a single-diode model and includes a parallel resistance (shunt resistance $\mathrm{R}_{\text {sh }}$ ) to account for leakage losses and a series resistance $\left(R_{S}\right)$ to account for voltage losses, between the semiconductor and the electrical contacts of the module.

In figure $\mathrm{AB} .1, \mathrm{~V}$ is the solar cell terminal voltage, $\mathrm{I}_{\mathrm{o}}$ is the diode reverse saturation current, $\mathrm{I}_{\mathrm{L}}$ is the so-called light current or photocurrent (the ideal current produced by the panel), $\mathrm{I}_{\text {sh }}$ is the parallel resistor current or shunt current, I is the solar cell terminal current, 
$\mathrm{R}_{\text {sh }}$ is the parallel or shunt resistance, and $\mathrm{R}_{\mathrm{S}}$ is the series resistance. The characteristic equation of the circuit is given by:

$$
I=I-I_{L}-=I_{S h}=I_{L}-I_{o}\left[e^{\frac{V+I R_{S}}{a}}-1\right]-\frac{V+I R_{S}}{R_{S h}}
$$

where the first term corresponds to the photocurrent, the second term represents the current through the diode, and the third term represents the current through the parallel resistor. The electrical power is the product of the current multiplied by the voltage ( $\mathrm{P}=$ I.V).

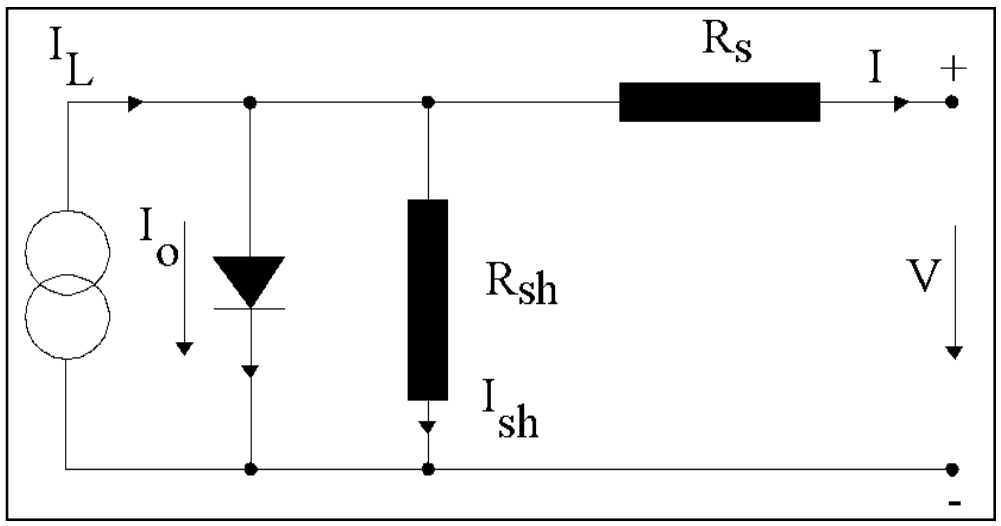

Figure AB1: Single-diode circuit (De Soto, W. et al., 2006)

The parameters $\mathrm{I}_{0}, \mathrm{a}, \mathrm{R}_{\mathrm{S}}$ and $\mathrm{R}_{\mathrm{SH}}$ depend on the photovoltaics technology employed, as well as on the construction of each cell. The physical parameter a depends on the temperature of the panel (De Soto, W. et al., 2006) and is given by:

$$
a=\frac{N_{s} n_{i} k T_{C}}{q}
$$

where $\mathrm{q}$ represents the electron charge, $\mathrm{k}$ is Boltzmann's constant, $\mathrm{n}_{\mathrm{i}}$ is the ideality factor, $\mathrm{N}_{\mathrm{S}}$ is the number of cells in series and $\mathrm{T}_{\mathrm{C}}$ is the cell temperature.

The single-diode circuit approach is simple and suitable as its parameters can be found with typical data provided by the photovoltaics module manufacturer.

\section{Point-Value Approach}

The point-value approach appears as a set of equations which describe the electrical performance of an individual photovoltaics module; however, can be scaled for any series or parallel combination of modules in an array. Assuming that module performance 
parameters and solar resource information are available, equations below are used to calculate the expected power and energy produced by a module:

$$
\begin{aligned}
& I_{s c}=I_{s c o} f_{1}(A M a)\left[\frac{E_{b} f_{2}(A O I)+f_{d} E_{d i f f}}{E_{o}}\right]+\left[1+\alpha I_{s c}\left(T_{c}-T_{o}\right)\right] \\
& I_{m p}=I_{m p o}\left[C_{0} E_{e}+C_{1} E_{e}{ }^{2}\right]\left[1+\alpha I_{m p}\left(T_{c}-T_{o}\right)\right. \\
& V_{o c}=V_{o c o}+N_{s} \delta\left(T_{c}\right) \ln \ln \left(E_{e}\right)+\beta V_{o c}\left(E_{e}\right)\left(T_{c}-T_{o}\right) \\
& V_{m p}=V_{m p o}+C_{2} N_{s} \delta\left(T_{c}\right) \ln \ln \left(E_{e}\right)+C_{3} N_{s}\left[\delta\left(T_{c}\right) \ln \ln \left(E_{e}\right)\right]^{2}+\beta V_{m p}\left(E_{e}\right)\left(T_{c}-T_{o}\right) \\
& P_{m p}=I_{m p} V_{m p} \\
& F F=P_{m p} V_{o c} / I_{s c} \\
& E_{e}=I_{s c} /\left[I_{s c o}\left[1+\alpha I_{s c}\left(T_{c}-T_{o}\right)\right]\right] \\
& \delta\left(T_{c}\right)=n k\left(T_{c}+273.15\right) / q \\
& I_{x}=I_{x o}\left[C_{4} E_{e}+C_{5} E_{e}{ }^{2}\right]\left[1+\alpha I_{s c}\left(T_{c}-T_{o}\right)\right] \\
& I_{x x}=I_{x x o}\left[C_{6} E_{e}+C_{7} E_{e}{ }^{2}\right]\left[1+\alpha I_{m p}\left(T_{c}-T_{o}\right)\right]
\end{aligned}
$$

where:

$\mathrm{I}_{\mathrm{sc}}=$ Short-circuit current $(\mathrm{A})$

$\mathrm{I}_{\mathrm{mp}}=$ Current at the maximum-power point (A)

$\mathrm{I}_{\mathrm{x}}=$ Current at module voltage equal to $0.5 \mathrm{~V}_{\mathrm{oc}}(\mathrm{A})$

$\mathrm{I}_{\mathrm{xx}}=$ Current at module voltage equal to $0.5\left(\mathrm{~V}_{\mathrm{oc}}+\mathrm{V}_{\mathrm{mp}}\right)(\mathrm{A})$

$\mathrm{V}_{\mathrm{oc}}=$ Open-circuit voltage $(\mathrm{V})$

$\mathrm{V}_{\mathrm{mp}}=$ Voltage at maximum-power point $(\mathrm{V})$

$\mathrm{P}_{\mathrm{mp}}=$ Power at maximum-power point $(\mathrm{W})$

$\mathrm{FF}=$ Fill Factor (dimensionless)

$\mathrm{N}_{\mathrm{s}}=$ Number of cells in series in a module's cell-string

$\mathrm{N}_{\mathrm{p}}=$ Number of cell-strings in parallel in module

$\mathrm{k}=$ Boltzmann's constant, 1.38066E-23 (J/K)

$\mathrm{q}=$ Elementary charge, $1.60218 \mathrm{E}-19$ (coulomb)

$\mathrm{T}_{\mathrm{c}}=$ Cell temperature inside module $\left({ }^{\circ} \mathrm{C}\right)$

$\mathrm{T}_{\mathrm{o}}=$ Reference cell temperature, typically $25^{\circ} \mathrm{C}$

$\mathrm{E}_{\mathrm{o}}=$ Reference solar irradiance, typically $1000 \mathrm{~W} / \mathrm{m}^{2}$

$\delta\left(\mathrm{T}_{\mathrm{c}}\right)=$ Thermal voltage per cell at temperature $\mathrm{T}_{\mathrm{c}}$

$\mathrm{E}_{\mathrm{e}}=$ The effective solar irradiance 
$\mathrm{C}_{0}, \mathrm{C}_{1}=$ Empirically determined coefficients relating $\mathrm{I}_{\mathrm{mp}}$ to effective irradiance, $\mathrm{C}_{0}+$ $\mathrm{C}_{1}=1$ (dimensionless)

$\mathrm{C}_{2}, \mathrm{C}_{3}=$ Empirically determined coefficients relating $\mathrm{V}_{\mathrm{mp}}$ to effective irradiance $\left(\mathrm{C}_{2}\right.$ is dimensionless and $\mathrm{C}_{3}$ has units of $1 / \mathrm{V}$ )

$\mathrm{C}_{4}, \mathrm{C}_{5}=$ Empirically determined coefficients relating the current $\mathrm{I}_{\mathrm{x}}$ to effective irradiance, $\mathrm{C}_{4}+\mathrm{C}_{5}=1$ (dimensionless)

$\mathrm{C}_{6}, \mathrm{C}_{7}=$ Empirically determined coefficients relating the current $\mathrm{I}_{\mathrm{xx}}$ to effective irradiance, $\mathrm{C}_{6}+\mathrm{C}_{7}=1$ (dimensionless)

$\mathrm{n}=$ Empirically determined 'diode factor' associated with individual cells in the module, with a value typically near one, (dimensionless)

$\mathrm{T}_{\mathrm{c}}=$ Temperature of cells inside module, typically determined from module back surface temperature measurements, or from a thermal model using solar resource and environmental data $\left({ }^{\circ} \mathrm{C}\right)$

$\mathrm{AMa}=$ Absolute air mass, calculated from sun elevation angle and site altitude and provides a relative measure of the path length the sun must travel through the atmosphere (dimensionless)

$\mathrm{f}_{1}(\mathrm{AMa})=$ Empirically determined polynomial relating the solar spectral influence on Isc to air mass variation over the day, where:

$\mathrm{f}_{1}(\mathrm{AMa})=\mathrm{a}_{0}+\mathrm{a}_{1} \cdot \mathrm{AMa}+\mathrm{a}_{2} \cdot(\mathrm{AMa})^{2}+\mathrm{a}_{3} \cdot(\mathrm{AMa})^{3}+\mathrm{a}_{4} \cdot(\mathrm{AMa})^{4}$

$\mathrm{AOI}=$ Solar angle-of-incidence, the angle between a line perpendicular to the module surface and the beam component of sunlight (degrees)

$\mathrm{f}_{2}(\mathrm{AOI})=$ Empirically determined polynomial relating optical influences on Isc to solar angle-of-incidence (AOI), where:

$f_{2}(A O I)=b_{0}+b_{1} \cdot A O I+b_{2} \cdot(A O I)^{2}+b_{3} \cdot(A O I)^{3}+b_{4} \cdot(A O I)^{4}+b_{5} \cdot(A O I)^{5}$

$\alpha \mathrm{I}_{\mathrm{sc}}=$ Normalized temperature coefficient for $\mathrm{I}_{\mathrm{sc}}\left(1 /{ }^{\circ} \mathrm{C}\right)$

$\alpha \mathrm{I}_{\mathrm{mp}}=$ Normalized temperature coefficient for $\mathrm{I}_{\mathrm{mp}}\left(1 /{ }^{\circ} \mathrm{C}\right)$

$\beta \mathrm{V}_{\text {oc }}\left(\mathrm{E}_{\mathrm{e}}\right)=\beta \mathrm{V}_{\text {oco }}+\mathrm{m} \beta \mathrm{V}_{\text {oc }} \cdot\left(1-\mathrm{E}_{\mathrm{e}}\right)\left(\mathrm{V} /{ }^{\circ} \mathrm{C}\right)$

$\beta \mathrm{V}_{\text {oco }}=$ Temperature coefficient for module $\mathrm{V}_{\text {oc }}$ at a $1000 \mathrm{~W} / \mathrm{m}^{2}$ irradiance level $\left(\mathrm{V} /{ }^{\circ} \mathrm{C}\right)$

$\mathrm{m} \beta \mathrm{V}_{\mathrm{oc}}=$ Coefficient providing the irradiance dependence for the $\mathrm{V}_{\mathrm{oc}}$ temperature coefficient, typically assumed to be zero $\left(\mathrm{V} /{ }^{\circ} \mathrm{C}\right)$ 
$\beta \mathrm{V}_{\mathrm{mp}}\left(\mathrm{E}_{\mathrm{e}}\right)=\beta \mathrm{V}_{\mathrm{mpo}}+\mathrm{m} \beta \mathrm{V}_{\mathrm{mp}} \cdot\left(1-\mathrm{E}_{\mathrm{e}}\right)$, Temperature coefficient for module maximum power-voltage as a function of effective irradiance $\left(\mathrm{V} /{ }^{\circ} \mathrm{C}\right)$

$\beta \mathrm{V}_{\text {mpo }}=$ Temperature coefficient for module $\mathrm{V}_{\mathrm{mp}}$ at a $1000 \mathrm{~W} / \mathrm{m}^{2}$ irradiance level $\left(\mathrm{V} /{ }^{\circ} \mathrm{C}\right)$ $\mathrm{m} \beta \mathrm{V}_{\mathrm{mp}}=$ Coefficient providing the irradiance dependence for the $\mathrm{V}_{\mathrm{mp}}$ temperature coefficient, typically assumed to be zero $\left(\mathrm{V} /{ }^{\circ} \mathrm{C}\right)$

$\mathrm{T}_{\mathrm{o}}=\mathrm{STC}$ Reference cell temperature for rating performance, typically $25^{\circ} \mathrm{C}$

$\mathrm{E}_{\mathrm{o}}=$ STC Reference solar irradiance, typically $1000 \mathrm{~W} / \mathrm{m}^{2}$

$$
\begin{aligned}
& \mathrm{I}_{\mathrm{sco}}=\mathrm{I}_{\mathrm{sc}}\left(\mathrm{E}_{\mathrm{e}}=\mathrm{E}_{\mathrm{o}} \mathrm{W} / \mathrm{m} 2, \mathrm{AMa}=1.5, \mathrm{~T}_{\mathrm{c}}=\mathrm{T}_{\mathrm{o}}{ }^{\circ} \mathrm{C}, \mathrm{AOI}=0^{\circ}\right)(\mathrm{A}) \\
& \mathrm{I}_{\mathrm{mpo}}=\mathrm{I}_{\mathrm{mp}}\left(\mathrm{E}_{\mathrm{e}}=1, \mathrm{~T}_{\mathrm{c}}=\mathrm{T}_{\mathrm{o}}\right)(\mathrm{A}) \\
& \mathrm{V}_{\mathrm{oco}}=\mathrm{V}_{\mathrm{oc}}\left(\mathrm{E}_{\mathrm{e}}=1, \mathrm{~T}_{\mathrm{c}}=\mathrm{T}_{\mathrm{o}}\right)(\mathrm{V}) \\
& \mathrm{V}_{\mathrm{mpo}}=\mathrm{V}_{\mathrm{mp}}\left(\mathrm{E}_{\mathrm{e}}=1, \mathrm{~T}_{\mathrm{c}}=\mathrm{T}_{\mathrm{o}}\right)(\mathrm{V}) \\
& \mathrm{I}_{\mathrm{xo}}=\mathrm{I}_{\mathrm{x}}\left(\mathrm{E}_{\mathrm{e}}=1, \mathrm{~T}_{\mathrm{c}}=\mathrm{T}_{\mathrm{o}}\right)(\mathrm{A}) \\
& \mathrm{I}_{\mathrm{xxo}}=\mathrm{I}_{\mathrm{xx}}\left(\mathrm{E}_{\mathrm{e}}=1, \mathrm{~T}_{\mathrm{c}}=\mathrm{T}_{\mathrm{o}}\right)(\mathrm{A})
\end{aligned}
$$

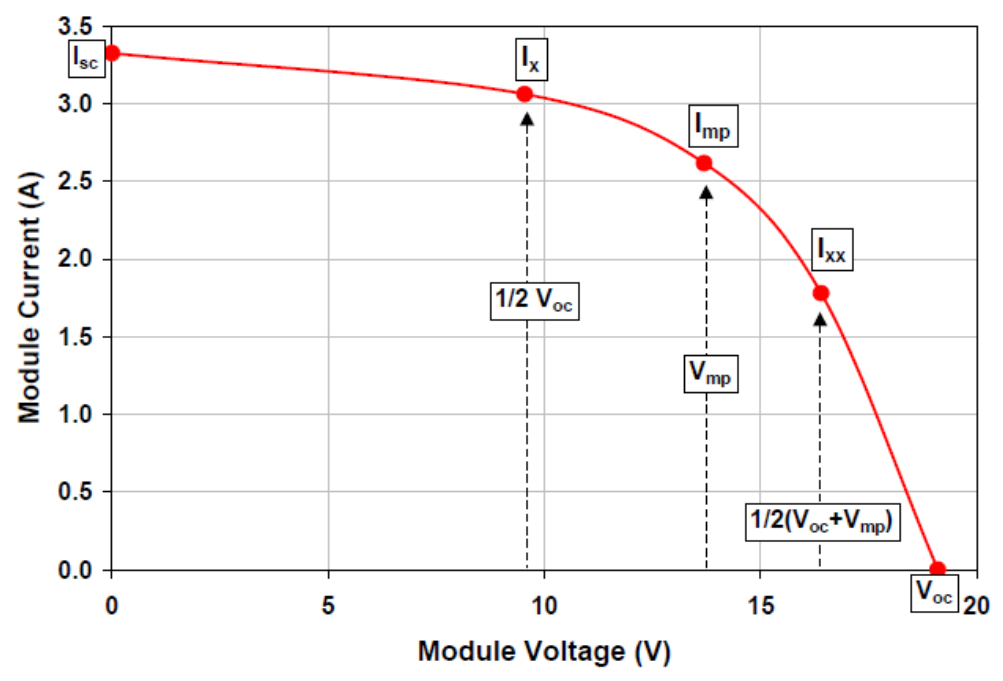

Figure AB.2: Illustration of a module I-V curve showing the five points on the curve that are provided by the Sandia performance model (King et al., 2004)

The inverter performance model presented does not provide an electrical engineering model of circuit characteristics or power conditioning algorithms used in the development of new inverter designs; rather it is an empirical, or phenomenological, model that simply but accurately replicates the power delivery characteristics of the dc-to-ac inversion process. 


$$
\begin{aligned}
& P_{a c}=\left[\left(\frac{P_{a c o}}{A-B}\right)-C(A-B)\right]\left(P_{d c}-B\right)+C\left(P_{d c}-B\right)^{2} \\
& A=P_{d c o}\left[1+C_{1}\left(V_{d c}-V_{d c o}\right)\right] \\
& B=P_{s o}\left[1+C_{2}\left(V_{d c}-V_{d c o}\right)\right] \\
& C=C_{o}\left[1+C_{3}\left(V_{d c}-V_{d c o}\right)\right]
\end{aligned}
$$

where:

$\mathrm{P}_{\mathrm{ac}}=$ ac-power output from inverter based on input power and voltage $(\mathrm{W})$

$\mathrm{P}_{\mathrm{dc}}=\mathrm{dc}$-power input to inverter, typically assumed to be equal to the PV array maximum power (W)

$\mathrm{V}_{\mathrm{d}}=\mathrm{dc}$-voltage input, typically assumed to be equal to the PV array maximum power voltage (V)

$\mathrm{P}_{\mathrm{aco}}=$ maximum ac-power "rating" for inverter at reference or nominal operating condition, assumed to be an upper limit value (W)

$\mathrm{P}_{\mathrm{dco}}=\mathrm{dc}$-power level at which the ac-power rating is achieved at the reference operating condition (W)

$\mathrm{V}_{\mathrm{dco}}=$ dc-voltage level at which the ac-power rating is achieved at the reference operating condition (V)

$\mathrm{P}_{\text {so }}=$ dc-power required to start the inversion process, or self-consumption by inverter, strongly influences inverter efficiency at low power levels (W)

$\mathrm{C}_{\mathrm{o}}=$ parameter defining the curvature (parabolic) of the relationship between ac-power and dc-power at the reference operating condition, default value of zero gives a linear relationship $(1 / \mathrm{W})$

$\mathrm{C}_{1}=$ empirical coefficient allowing $\mathrm{P}_{\mathrm{dco}}$ to vary linearly with dc-voltage input, default value is zero $(1 / \mathrm{V})$

$\mathrm{C}_{2}=$ empirical coefficient allowing $\mathrm{P}_{\text {so }}$ to vary linearly with dc-voltage input, default value is zero $(1 / \mathrm{V})$

$\mathrm{C}_{3}=$ empirical coefficient allowing $\mathrm{C}_{\mathrm{o}}$ to vary linearly with dc-voltage input, default value is zero $(1 / \mathrm{V})$

\section{Linear correlations for maximum power}

Assuming that Fig. AB.3 illustrates the I-V curve of a typical photovoltaics cell, fill factor (FF) is the ratio of the actual maximum obtainable power (dark blue box), to the 
product of short-circuit current and open-circuit voltage (light blue box) and is essentially a measure of the photovoltaics cell's efficiency. The theoretical maximum value of fill factor for a cell mainly depends on its technology; however, deviation from the expected value or changes in fill factor can mean that a fault is present.

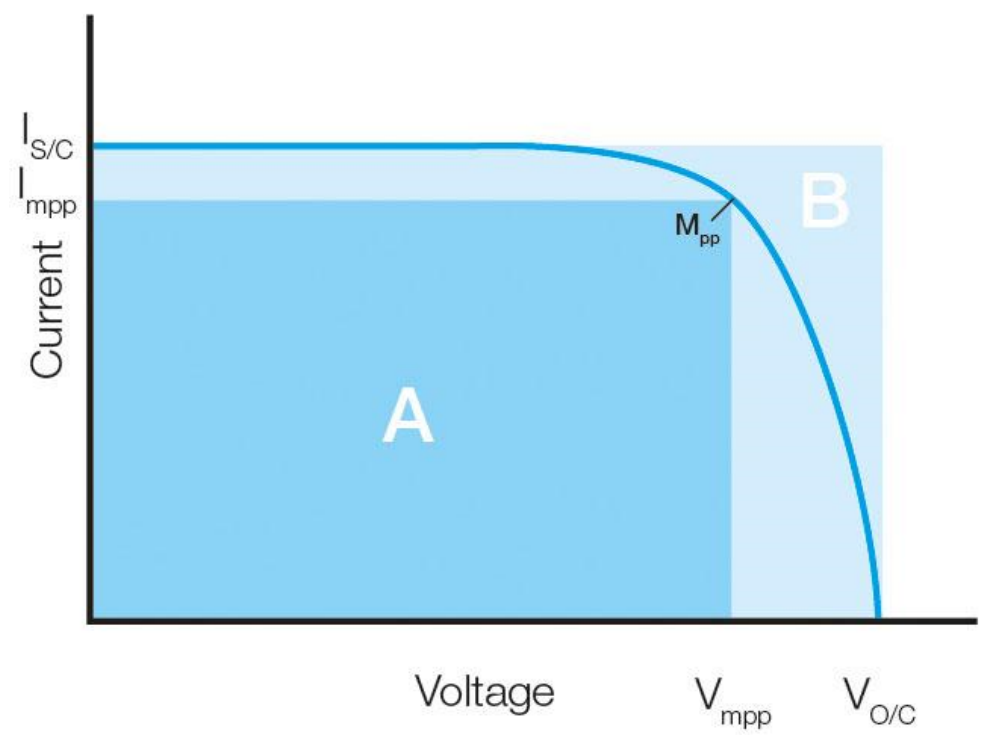

Figure AB.3: Illustration of a module I-V curve and the concept of fill factor (www.seaward.com)

If cell temperature increases, the open-circuit voltage and the fill factor both increase; however, the short-circuit current decreases, but only slightly. The effect of temperature on the electrical efficiency of a cell can be traced to its effect on the current and the voltage as the maximum power is given by:

$$
\begin{aligned}
& P_{m p}=I_{m p} \cdot V_{m p}=F F \cdot V_{o c} / I_{s c} \\
& F F=I_{m p} \cdot V_{m p} \cdot V_{o c} / I_{s c}
\end{aligned}
$$

The latter equation serves as a definition of the fill factor. Evans (1981) developed a linear expression which applies the net effect of temperature and plane of array irradiance to the cell electrical efficiency:

$$
\eta_{c}=\eta_{o} \cdot\left(1-\beta_{r e f} \cdot\left(T_{c}-T_{o}\right)+\gamma \cdot \log _{10} G_{T}\right)
$$

where:

$\eta_{\mathrm{o}}=$ Module's electrical efficiency at the reference temperature

$\mathrm{T}_{\mathrm{o}}=\mathrm{STC}$ Reference cell temperature for rating performance, typically $25^{\circ} \mathrm{C}$ 
$\beta_{\text {ref }}=$ Temperature coefficient for the maximum power point at a $1000 \mathrm{~W} / \mathrm{m}^{2}$ irradiance level $\left(1 /{ }^{\circ} \mathrm{C}\right)$

$\gamma=$ Irradiance coefficient for the maximum power point at $25^{\circ} \mathrm{C}$

If $\gamma$ equals to zero, then the previous equation simplifies to the equation below which represents the well-known Evans-Florschuetz linear correlation for the photovoltaics cell electrical efficiency (Evans and Florschuetz, 1977).

$$
\eta_{c}=\eta_{o} \cdot\left(1-\beta_{\text {ref }} \cdot\left(T_{c}-T_{o}\right)\right)
$$

The quantities $\eta_{o}$ and $\beta_{\text {ref }}$ are normally given by the manufacturer. However, they can be obtained from flash tests in which the cell's electrical output is measured at two different temperatures for a given irradiance. (Hart and Raghuraman, 1982). 


\section{Appendix C: Hydro- Québec EHBE}

\section{Location}

Latitude: $46.56^{\circ} \mathrm{N}$

Longitude: $72.77^{\circ} \mathrm{W}$

Time zone: UTC-5

\section{Orientation}

Twin houses facade is facing south-south-west. House 2 is shifted $1.22 \mathrm{~m}$ back of house 1 to limit shading.

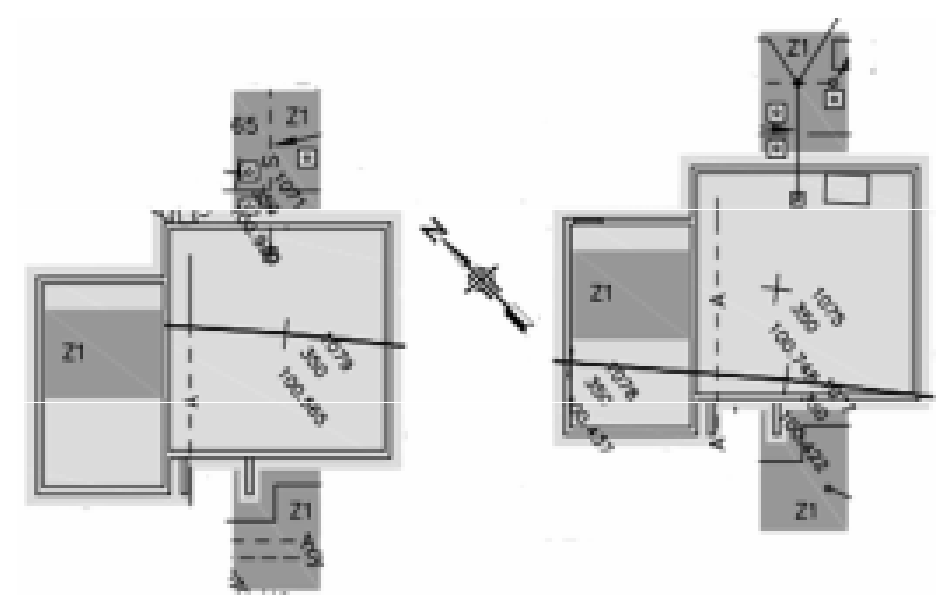

Figure AC.1: Houses shift and orientation

\section{Dimensions}

House zones per floor are given in Table 1. Abbreviated reference to data point names is given for each zone. The entrance hall, living room, bedroom 2 and bedroom 3 comprise the house facade. The kitchen, dining room, bathroom and bedroom 1 comprise the house back. The washroom is adjacent to the entrance hall and garage.

Table AC.1: House zones

\begin{tabular}{|l|l|l|}
\hline Basement & First Floor & Second Floor \\
\hline
\end{tabular}




\begin{tabular}{|c|c|c|}
\hline basement 1(SS) & hall & bedroom 3 (CH3) \\
\hline basement 2 (SS2) & washroom (SE) & bedroom 1 (CH1) \\
\hline other & kitchen (CU) & bedroom 2 (CH2) \\
\hline garage (GA) & living room (SA) & bathroom (SB) \\
\hline attic & dining room (SM) & hall \\
\hline
\end{tabular}

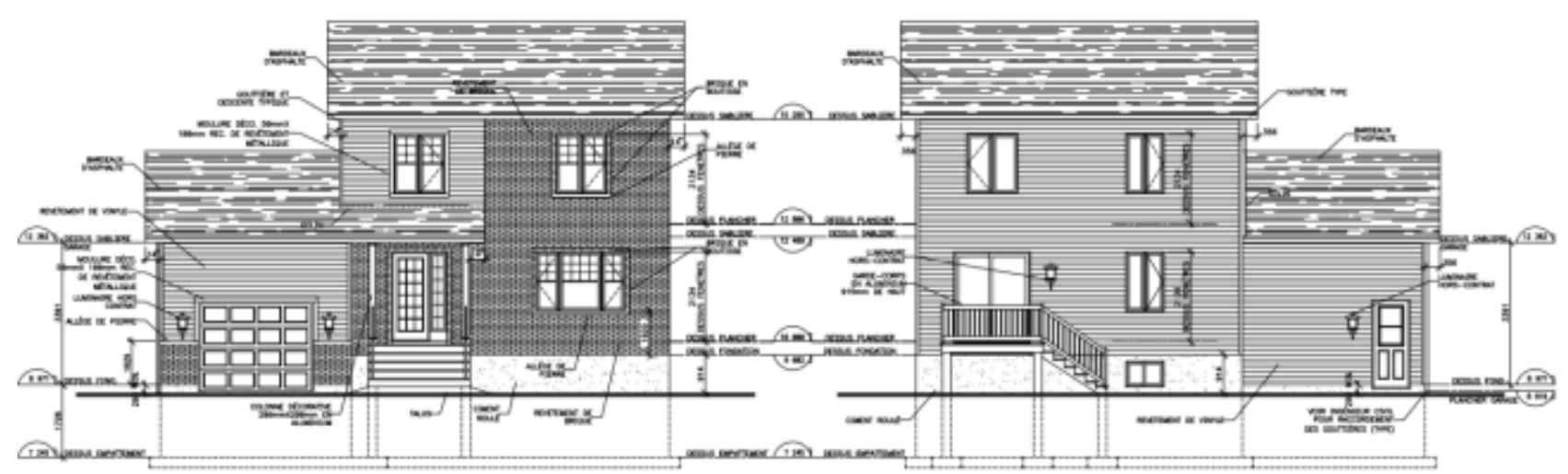

Figure AC.2: Front and back elevations (mm)

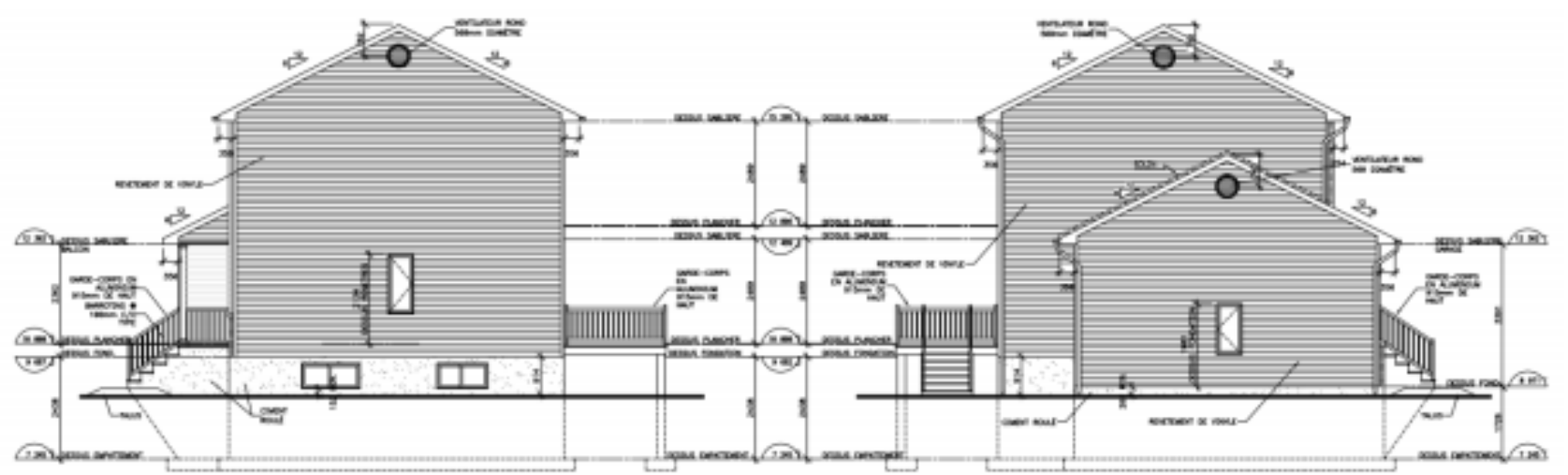

Figure AC.3: Side elevations (mm) 

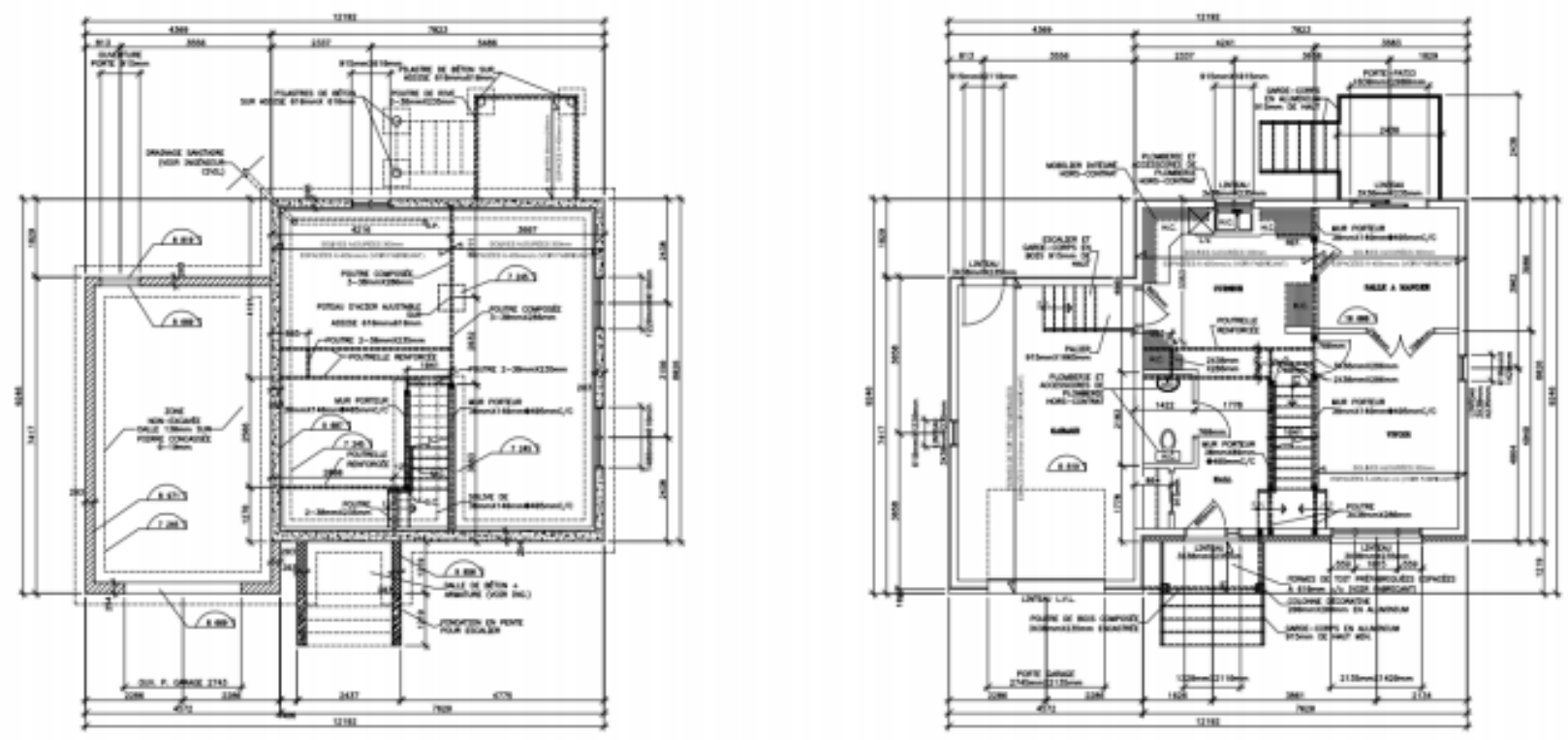

Figure AC.4: Basement and first floor plans (mm)
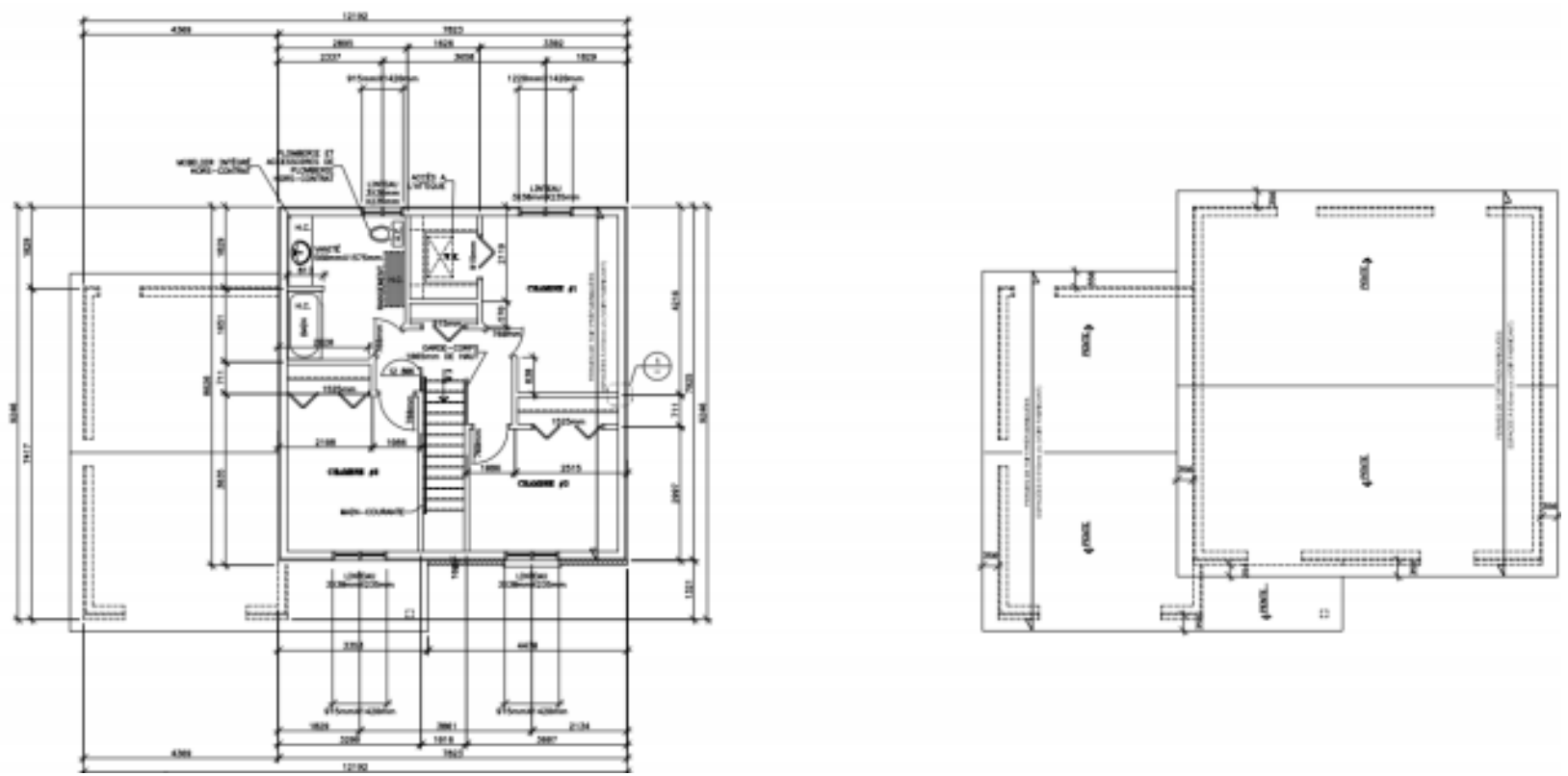

Figure AC.5: Second floor and roof plans (mm)

\section{Constructions}

Measured properties are marked $(*)$. Others are from component specification sheets or from AHSRAE fundamentals (chapter 26, 2009). When air gaps are labeled as effective, conduction, convection and radiation contributions are included using ASHRAE procedure. 
Table AC.2: Foundation walls (outside to inside)

\begin{tabular}{|c|c|c|c|c|c|c|c|}
\hline \multirow[t]{2}{*}{ material } & \multicolumn{3}{|c|}{ wall segment } & \multirow{2}{*}{$\begin{array}{l}\text { thickness } \\
(\mathrm{mm})\end{array}$} & \multirow{2}{*}{$\begin{array}{l}\text { rsi } \\
\left(\mathrm{m}^{2} \mathrm{~K} / \mathrm{W}\right)\end{array}$} & \multirow{2}{*}{$\begin{array}{l}\text { specific } \\
\text { heat } \\
(\mathrm{kJ} / \mathrm{kgK})\end{array}$} & \multirow{2}{*}{$\begin{array}{l}\text { density } \\
\left(\mathrm{kg} / \mathrm{m}^{3}\right)\end{array}$} \\
\hline & $\begin{array}{l}\text { above } \\
\text { soil }\end{array}$ & insulated & $\begin{array}{l}\text { less than } \\
24 \text {-inch } \\
\text { from } \\
\text { footing }\end{array}$ & & & & \\
\hline soil & & $\mathrm{X}$ & $\mathrm{X}$ & - & & & \\
\hline backfill & & X & X & - & & & \\
\hline $\begin{array}{l}\text { drainage } \\
\text { board }\end{array}$ & & X & X & $10(0.4$ '’ $)$ & 0.16 & - & - \\
\hline $\begin{array}{l}\text { bituminous } \\
\text { coating }\end{array}$ & & X & X & - & - & - & - \\
\hline parging & $\mathrm{X}$ & & & $\sim 5$ & 0.070 & 0.84 & 1860 \\
\hline concrete & X & X & X & $\begin{array}{l}\text { others } \\
203\left(8^{\prime \prime}\right) \\
\text { front wall } \\
254\left(10^{\prime \prime}\right)\end{array}$ & $\begin{array}{l}0.078 \text { - } \\
0.156 \\
0.098 \text { - } \\
0.195\end{array}$ & 0.9 & 2200 \\
\hline $\begin{array}{l}\text { insulating } \\
\text { panel }\end{array}$ & X & X & & $50.4(2 ’)$ & $1.76^{*}$ & 1.47 & $25-40$ \\
\hline $\begin{array}{l}\text { polyethylene } \\
\text { film }\end{array}$ & & & & 0.15 & neglected & & \\
\hline
\end{tabular}




\begin{tabular}{|c|c|c|c|c|c|c|c|}
\hline $\begin{array}{l}\text { air } \\
\text { (effective) }\end{array}$ & $X$ & $X$ & $X$ & $\begin{array}{l}\text { other } \\
19(0.75 \text { ') } \\
\text { no } \\
\text { insulation } \\
70(2.75 \text { '”') }\end{array}$ & $\begin{array}{l}0.18 \\
0.19\end{array}$ & & \\
\hline $\begin{array}{l}\text { gypsum } \\
\text { board }\end{array}$ & $X$ & $X$ & $\mathrm{X}$ & $\begin{array}{l}12.7 \\
\left(0.5^{\prime \prime}\right)\end{array}$ & 0.079 & 1.15 & 640 \\
\hline
\end{tabular}

Table AC.3: Slab (inside to outside)

\begin{tabular}{|c|c|c|c|c|c|c|}
\hline material & basement & garage & $\begin{array}{l}\text { thickness } \\
(\mathrm{mm})\end{array}$ & $\begin{array}{l}\text { rsi } \\
\left(\mathrm{m}^{2} \mathrm{~K} / \mathrm{W}\right)\end{array}$ & $\begin{array}{l}\text { specific heat } \\
(\mathrm{kJ} / \mathrm{kgK})\end{array}$ & $\begin{array}{l}\text { density } \\
\left(\mathrm{kg} / \mathrm{m}^{3}\right)\end{array}$ \\
\hline $\begin{array}{l}\text { concrete } \\
\text { with metallic } \\
\text { framework }\end{array}$ & X & $\mathrm{X}$ & $\begin{array}{l}101 \text { (4’’) } \\
152(6, ")\end{array}$ & $\begin{array}{l}0.039- \\
0.078 \\
\\
0.058- \\
0.117\end{array}$ & 0,9 & 2200 \\
\hline $\begin{array}{l}\text { waterproofing } \\
\text { membrane }\end{array}$ & $\mathrm{X}$ & & 3 & & & \\
\hline geotextile & X & & $\sim 1$ & 0.011 & - & - \\
\hline crushed stone & $\mathrm{X}$ & & $\begin{array}{l}350 \\
(13.75, \prime)\end{array}$ & & & \\
\hline stone dust & & X & $152\left(6^{\prime \prime}\right)$ & & & \\
\hline backfill & & X & & & & \\
\hline
\end{tabular}




\begin{tabular}{|l|l|l|l|l|l|l|}
\hline geotextile & $\mathrm{X}$ & & $\sim 1$ & 0.011 & - & - \\
\hline soil & $\mathrm{X}$ & $\mathrm{X}$ & & & & \\
\hline
\end{tabular}

Table AC.4: Exterior walls (outside to inside)

\begin{tabular}{|l|l|l|l|}
\hline material & $\begin{array}{l}\text { thickness } \\
(\mathrm{mm})\end{array}$ & $\begin{array}{l}\text { rsi } \\
\left(\mathrm{m}^{2} \mathrm{~K} / \mathrm{W}\right)\end{array}$ & $\begin{array}{l}\text { density } \\
\left(\mathrm{kg} / \mathrm{m}^{3}\right)\end{array}$ \\
\hline brick or vinyl & $90\left(3.5^{\prime \prime}\right)$ & $0.06-0.07$ & 2474 \\
\hline air (effective) & $19\left(0.75^{\prime \prime}\right)$ & 0.18 & \\
\hline air barrier & $12.7\left(0.5^{\prime \prime}\right)$ & $0.19-0.23$ & \\
\hline fiberboard or \\
plywood (bracing) & $12.7\left(0.5^{\prime \prime}\right)$ & 0.14 & \\
\hline glass wool or & $140\left(5.5^{\prime \prime}\right)$ & $3.52(2.94$ combined $) 1.1-1.3$ & \\
\hline wood studs (2x6") & $140\left(5.5^{\prime \prime}\right)$ & & \\
\hline insulating board & $12.7\left(0.5^{\prime \prime}\right)$ & 0.20 & \\
\hline air (effective) & $19\left(0.75^{\prime \prime}\right)$ & 0.61 & \\
\hline gypsum board & $12.7\left(0.5^{\prime \prime}\right)$ & 0.079 & \\
\hline
\end{tabular}


Table AC.5: Wall adjacent to garage

\begin{tabular}{|c|c|c|}
\hline material & $\begin{array}{l}\text { thickness } \\
(\mathrm{mm})\end{array}$ & $\begin{array}{l}\text { rsi } \\
\left(\mathrm{m}^{2} \mathrm{~K} / \mathrm{W}\right)\end{array}$ \\
\hline gypsum board & $12.7\left(0.5^{\prime \prime}\right)$ & 0.079 \\
\hline air (effective) & $19(0.75, ')$ & 0.18 \\
\hline air barrier & & neglected \\
\hline $\begin{array}{l}\text { fiberboard } \\
\text { or } \\
\text { plywood (bracing) }\end{array}$ & $\begin{array}{l}12.7(0.5 ") \\
12.7\left(0.5^{\prime \prime}\right)\end{array}$ & $\begin{array}{l}0.19-0.23 \\
0.14\end{array}$ \\
\hline $\begin{array}{l}\text { glass wool } \\
\text { or } \\
\text { wood studs (2"x6") }\end{array}$ & $\begin{array}{l}140\left(5.5^{\prime \prime}\right) \\
140\left(5.5^{\prime \prime}\right)\end{array}$ & 3.52 (2.94 combined) $1.1-1.3$ \\
\hline insulating board & $12.7\left(0.5^{\prime \prime}\right)$ & 0.20 \\
\hline air (effective) & $19\left(0.75^{\prime \prime}\right)$ & 0.61 \\
\hline gypsum board & $12.7\left(0.5^{\prime \prime}\right)$ & 0.079 \\
\hline
\end{tabular}

Table AC.6: Garage walls (outside to inside)

\begin{tabular}{|l|l|l|l|}
\hline material & thickness & rsi & density \\
\hline
\end{tabular}




\begin{tabular}{|l|l|l|l|}
\hline & $(\mathrm{mm})$ & $\left(\mathrm{m}^{2} \mathrm{~K} / \mathrm{W}\right)$ & $\left(\mathrm{kg} / \mathrm{m}^{3}\right)$ \\
\hline brick or vinyl & $90\left(\sim 3.5^{\prime \prime}\right)$ & $0.06-0.07$ & 2474 \\
\hline air (effective) & $19\left(0.75^{\prime \prime}\right)$ & 0.18 & \\
\hline air barrier & $12.7\left(0.5^{\prime \prime}\right)$ & $0.19-0.23$ & \\
\hline fiberboard or \\
plywood (bracing) & $12.7\left(0.5^{\prime \prime}\right)$ & 0.14 & \\
\hline glass wool or & $140\left(5.5^{\prime \prime}\right)$ & $3.52(2.94$ combined $) 1.1-1.3$ & \\
wood studs (2x6”) & $140\left(5.5^{\prime \prime}\right)$ & & \\
\hline polyethylene film & 0.15 & neglected & \\
\hline air (effective) & $19\left(0.75^{\prime \prime}\right)$ & 0.18 & \\
\hline gypsum board & $12.7\left(0.5^{\prime \prime}\right)$ & 0.079 & \\
\hline
\end{tabular}

Table AC.7: Exterior wall at joist (outside to inside)

\begin{tabular}{|l|l|l|l|}
\hline material & $\begin{array}{l}\text { thickness } \\
(\mathrm{mm})\end{array}$ & $\begin{array}{l}\mathrm{ri} \\
\left(\mathrm{m}^{2} \mathrm{~K} / \mathrm{W}\right)\end{array}$ & $\begin{array}{l}\text { density } \\
\left(\mathrm{kg} / \mathrm{m}^{3}\right)\end{array}$ \\
\hline brick or vinyl & $90\left(3.5^{\prime \prime}\right)$ & $0.06-0.07$ & 2474 \\
\hline air (effective) & $19\left(0.75^{\prime \prime}\right)$ & 0.18 & \\
\hline
\end{tabular}




\begin{tabular}{|l|l|l|l|}
\hline air barrier & & neglected & \\
\hline $\begin{array}{l}\text { fiberboard or } \\
\text { plywood (bracing) }\end{array}$ & $\begin{array}{l}12.7\left(0.5^{\prime \prime}\right) \\
12.7\left(0.5^{\prime \prime}\right)\end{array}$ & $\begin{array}{l}0.19-0.23 \\
0.14\end{array}$ & \\
\hline air barrier & & neglected & \\
\hline particle board & $12.7\left(0.5^{\prime \prime}\right)$ & 0.14 & \\
\hline glass wool & $140\left(5.5^{\prime \prime}\right)$ & 3.52 & \\
\hline
\end{tabular}

Table AC.8: Plywood covered floors

\begin{tabular}{|l|l|l|l|l|}
\hline material & $1^{\text {st }}$ floor & $2^{\text {nd }}$ floor & $\begin{array}{l}\text { thickness } \\
(\mathrm{mm})\end{array}$ & $\begin{array}{l}\text { rsi } \\
\left(\mathrm{m}^{2} \mathrm{~K} / \mathrm{W}\right)\end{array}$ \\
\hline varnish plywood & $\mathrm{X}$ & $\mathrm{X}$ & $19\left(0.75^{\prime \prime}\right)$ & 0.19 \\
\hline plywood & $\mathrm{X}$ & $\mathrm{X}$ & $15.7\left(0.625^{\prime \prime}\right)$ & 0.15 \\
\hline air/floor joists & $\mathrm{X}$ & $\mathrm{X}$ & $300\left(11.75^{\prime \prime}\right)$ & \\
\hline air & & $\mathrm{X}$ & $19\left(0.75^{\prime \prime}\right)$ & \\
\hline gypsum board & & $\mathrm{X}$ & $12.7\left(0.5^{\prime \prime}\right)$ & \multirow{2}{*}{0.079} \\
\hline
\end{tabular}


Table AC.9: Ceramic covered floors

\begin{tabular}{|l|l|l|l|l|l|}
\hline material & washroom & kitchen & bathroom & $\begin{array}{l}\text { thickness } \\
(\mathrm{mm})\end{array}$ & $\begin{array}{l}\text { rsi } \\
\left(\mathrm{m}^{2} \mathrm{~K} / \mathrm{W}\right)\end{array}$ \\
\hline ceramic & $\mathrm{X}$ & $\mathrm{X}$ & $\mathrm{X}$ & $\begin{array}{l}9.5 \\
\left(0.375^{\prime \prime}\right)\end{array}$ & $0.116 \pm 0.006^{*}$ \\
\hline $\begin{array}{l}\text { heating wired and self } \\
\text { levelling cement }\end{array}$ & & $\mathrm{X}$ & $\mathrm{X}$ & $\begin{array}{l}9.5 \\
\left(0.375^{\prime \prime}\right)\end{array}$ & 0.12 \\
\hline plywood & $\mathrm{X}$ & & & $\begin{array}{l}9.5 \\
\left(0.375^{\prime \prime}\right)\end{array}$ & 0.08 \\
\hline plywood & $\mathrm{X}$ & $\mathrm{X}$ & $\mathrm{X}$ & $\begin{array}{l}15.7 \\
\left(0.625^{\prime \prime}\right)\end{array}$ & 0.15 \\
\hline air/floor joists & $\mathrm{X}$ & $\mathrm{X}$ & $\mathrm{X}$ & $\begin{array}{l}300 \\
\left(11.75^{\prime \prime}\right)\end{array}$ & 0.079 \\
\hline air & & & $\mathrm{X}$ & $19\left(0.75^{\prime \prime}\right)$ & \\
\hline gypsum board & & $\mathrm{X}$ & $12.7\left(0.5^{\prime \prime}\right)$ & 0.079 \\
\hline
\end{tabular}

Table AC.10: Roof - attic - ceiling (outside to inside)

\begin{tabular}{|l|l|l|l|l|}
\hline Material & house & garage & thickness (mm) & rsi (m2K/W) \\
\hline asphalt shingles & $\mathrm{X}$ & $\mathrm{X}$ & & 0.078 \\
\hline
\end{tabular}




\begin{tabular}{|l|l|l|l|l|}
\hline felt paper & $\mathrm{X}$ & $\mathrm{X}$ & & \\
\hline waterproofing membrane & $\mathrm{X}$ & $\mathrm{X}$ & & to $915 \mathrm{~mm}$ of roof edge \\
\hline plywood & $\mathrm{X}$ & $\mathrm{X}$ & $12.7\left(0.5^{\prime \prime}\right)$ & 0.14 \\
\hline air & $\mathrm{X}$ & $\mathrm{X}$ & - & \\
\hline batt insulation and & $\mathrm{X}$ & $\mathrm{X}$ & $240\left(9.5^{\prime \prime}\right)$ & $5.28(5.11$ combined $)$ \\
wood studs & & & $90\left(3.5^{\prime \prime}\right)$ & 0.90 \\
\hline insulating board & $\mathrm{X}$ & & $12.7\left(0.5^{\prime \prime}\right)$ & 0.20 \\
\hline polyethylene film & & $\mathrm{X}$ & 0.15 & neglected \\
\hline air (effective) & $\mathrm{X}$ & $\mathrm{X}$ & $19\left(0.75^{\prime \prime}\right)$ & 0.61 \\
\hline gypsum board & $\mathrm{X}$ & $\mathrm{X}$ & $12.7\left(0.5^{\prime \prime}\right)$ & 0.079 \\
\hline
\end{tabular}

Table AC.11: Outside doors

\begin{tabular}{|c|c|c|c|}
\hline location & width (mm) & height $(\mathrm{mm})$ & comment \\
\hline house & 1321 & 2105 & two clear glass panels \\
& & & $559 \times 1220 \mathrm{~mm}$ \\
& & & $203 \times 1220 \mathrm{~mm}$ \\
\hline
\end{tabular}




\begin{tabular}{|c|c|c|c|}
\hline garage & 920 & 2105 & $\begin{array}{c}\text { clear glass slider panel } \\
585 \times 940 \mathrm{~mm}\end{array}$ \\
\hline house-garage & 920 & 2105 & no panel \\
\hline
\end{tabular}

Table AC.12: Window dimensions

\begin{tabular}{|l|l|l|}
\hline location & width (mm) & height (mm) \\
\hline living room façade & 2135 & 1420 \\
\hline living room side & 610 & 1420 \\
\hline bedrooms 2 and 3 & 915 & 1420 \\
\hline kitchen & 915 & 1015 \\
\hline bathroom & 915 & 1420 \\
\hline bedroom 1 & 1220 & 1420 \\
\hline garage & 610 & 1220 \\
\hline basement back & 914 & 610 \\
\hline basement side close to back & 1220 & 610 \\
\hline basement side close to facade & 1400 & 610 \\
\hline
\end{tabular}


For better access, the basement ceiling is unfinished. Floors are finished with varnished plywood to emulate hardwood flooring. The aluminium framed casement windows are double glazed clear glass with a thermoplastic divider. Facade windows glazed section is $30 \mathrm{~mm}$ thick with $6 \mathrm{~mm}$ thick glass while others glazed section is $22.2 \mathrm{~mm}$ thick.

The kitchen sliding glass door has an aluminium-pvc frame with double clear glass 3 $\mathrm{mm}$ thick. Other outside doors are foam insulated, steel finished wood doors. Interior room and wardrobe doors are made of MDF.

\section{HVAC}

The twin houses are heated by electric baseboards controlled by line-voltage electronic programmable thermostats.

Table AC.13: Baseboard power per zone

\begin{tabular}{|l|l|}
\hline zone & power (W) \\
\hline garage (GA) & 2000 \\
\hline basement 1 (SS) & 2000 \\
\hline basement 2 (SS2) & 2000 \\
\hline washroom (SE) & 500 \\
\hline kitchen (CU) & 1500 \\
\hline living room (SA) & 1500 \\
\hline dining room (SM) & 1250 \\
\hline
\end{tabular}




\begin{tabular}{|c|l|}
\hline bedroom 2 (CH2) & 1250 \\
\hline bathroom (SB) & 1000 \\
\hline bedroom 3 (CH3) & 1250 \\
\hline bedroom 1 (CH1) & 1250 \\
\hline
\end{tabular}

Electric heating wires embedded in cement and covered by ceramic tiles are installed in the kitchen $\left(9 \mathrm{~W} / \mathrm{pi}^{2}\right)$ and bathroom $\left(12 \mathrm{~W} / \mathrm{pi}^{2}\right)$. Each heated floor is controlled by his electronic programmable thermostat offering three operation modes (air, floor, both). Heated floors are activated only for dedicated experiments.

Although not used, pulse air ducts are installed. Inlet and outlet plenums are in the basement. Air diffusion grilles are located below windows of every room on the first and second floors. In the basement, they are located in the ceiling above windows. The first and second floor halls each have an air return. No central heating/cooling system is present.

A heat recuperating ventilator of $35 \mathrm{l} / \mathrm{s}$ nominal capacity in installed in the basement. Air inlets are in the three bedrooms, while outlets are in the bathroom and first floor hall. The controller has three speeds and three operation modes (recirculation, intermittent, continuous). The heat recuperating ventilator is activated only for dedicated experiments.

The washroom and bathroom ventilation fans nominal capacities respectively are 42.5 $l / s$ and $51.9 \mathrm{l} / \mathrm{s}$. The kitchen exhaust hood has four speeds and a nominal capacity of 306.8 $l / s$. As usual, there is a dryer exhaust vent. These exhausts are unsealed only for dedicated experiments. In addition, soffit and louvers insure attic natural ventilation.

Appliances (electric water heater, washing machine, dryer, oven and refrigerator) are powered only for dedicated experiments. 


\section{Appendix D: Python Code Samples}

\section{Parameter Identification}

The following piece of code corresponds to the training of the $3 \mathrm{C} 7 \mathrm{R}$ network model using the Sequential Least Squares Programming (SLSQP) solver from the SciPy.optimize package:

Tout, Tgrd, P_pv, Q_bb1, Q_bb2, Q_bb3, Q_hp, Q_sol, T_int1, T_int2, T_int3 = df_assign(df_train)

$\mathrm{n}=$ len(df_train.index) \#length of dataset

$\mathrm{t}=(\mathrm{np}$.arānge $(\mathrm{n})+1) * \mathrm{dt}$ \#time array

T_int1_hat, T_int2_hat, T_int3_hat $=n p \cdot \operatorname{zeros}(\operatorname{len}(t)), n p \cdot \operatorname{zeros}(\operatorname{len}(t))$, np.zeros(len(t)) \#temperature arrays

T_int1_hat[0], T_int2_hat[0], T_int3_hat[0] = df_train.T_int1[0], df_train.T_int2[0], df_train.T_int3[0] \#temperature arrays initialization

diff__1, diff__2, diff_3 =np.zeros(len(t)), np.zeros $(\operatorname{len}(t)), n p \cdot \operatorname{zeros}(\operatorname{len}(t))$

w1, $\mathrm{w} 2, \mathrm{w} 3=1,1,1$ \#zonal weights

init_train $=[0.015,0.015,0.019,0.002,0.014,0.014,0.036,6.6 \mathrm{e}, 6.4 \mathrm{e} 6,7.45 \mathrm{e} 6$, $0.6,0.3,0.05]$ \#initial values

bnds_train $=$ so.Bounds $([0.0001,0.0001,0.0001,0.0001,0.0001,0.0001,0.0001$, $0.0001,0.0001,0.0001,0.0001,0.0001,0.0001]$,

\#boundaries

$[1,1,1,1,1,1,1,1 \mathrm{e} 10,1 \mathrm{e} 10,1 \mathrm{e} 10,0.5,0.5,0.5])$

lincons_train $=$ so. LinearConstraint $([0,0,0,0,0,0,0,0,0,0,1,1,1]],[0]$, [1]) \#linear constraints

def calib_train(param): \#minimization

for $i, v$ in enumerate(param):

if $\operatorname{abs}(v)>1 e 15: \operatorname{param}[i]=$ init_train[i]

R1, R2, R3, R4, R5, R6, R7, C1, C2, C3, alpha1, alpha2, alpha3 = param

for $i$ in range(len(t)-1):

T_int1_hat $[i+1]=(d t / C 1) *\left(a l p h a 1 * Q \_s o l[i]+Q\right.$ bb1 $[i]+Q$ hp $[i] / 3+$

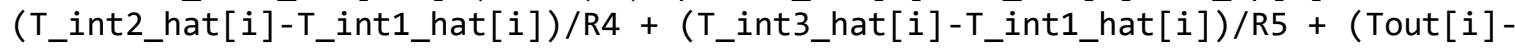

T_int1_hat $[i]) / R \overline{1})+\bar{T}_{-}$int1_hat $[i]$

T_int2_hat $[i+1]=(d t / C 2) *\left(a l p h a 2 * Q \_s o l[i]+Q \_b b 2[i]+Q\right.$ hp $[i] / 3+$

(T_int1_hat [i]-T_int2_hat[i])/R4 + (T_int3_hat[i]-T_int2_hat[i])/R6 + (Tout[i]T_int2_hat $[i]) / R \overline{2})+\bar{T}$ int2_hat $[i]$

T_int3_hat $[i+1]=(d t / C 3) *\left(a l p h a 3 * Q \_s o l[i]+Q\right.$ bb3 $[i]+Q$ hp $[i] / 3+$

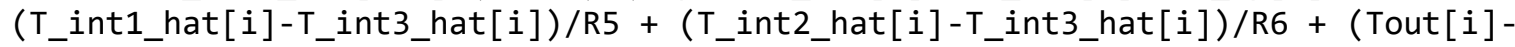

T_int3_hat $\left.[i]) / R \overline{3}+\left(\bar{T} g r d[i]-T \_i n t 3 \_h a t[i]\right) / R 7\right)+T$ int3_hat $[i]$

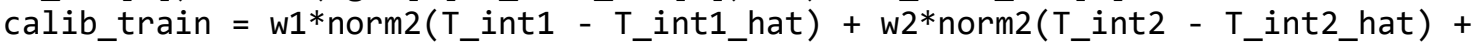

w3*norm2 (T_int3 - T_int3_hat)

return calib_train

opt_train = so.minimize(calib_train, init_train, bounds=bnds_train,

constraints=lincons_train, method=' SLSQP' )

param_trained = opt_train.x 


\section{MPC}

The following piece of code corresponds to the predictive control based on the $3 \mathrm{C} 7 \mathrm{R}$ network model using the ECOS solver from the CVXPY package:

ph. \# define the prediction horizon

ct= 1 \# time step where to start optimization $\{>0\}$

$x=c p$.Variable $((n x, p h))$

$\mathrm{u}=\mathrm{cp}$.Variable $((\mathrm{nu}, \mathrm{ph}))$

$c=n p$.ones $((n u, p h)) \#$ unit cost

constraints $=$ cons $=[]$

cons. append $(x[0,0]==18.3$,

cons. append $(x[1,0]==17.9$,

cons. append $(x[2,0]==17$,

\#NOTE: the comfort violation penalty is not considered if there is hard constraint on temperature

\#cons.append $(x[0,:]>=$ comfort_min, $)$

\#cons.append $(x[0,:]<=$ comfort_max, $)$

cons.append $(x[3,:]>=$ soe_min, $)$

cons.append $(x[3,:]<=$ soe_max, $)$

cons.append $(u[0,:]>=$ heating_min, $)$

cons.append $(u[0,:]<=$ heating_max, $)$

cons.append $(u[1,:]>=$ heating_min, $)$

cons.append $(u[1,:]<=$ heating_max, $)$

cons.append $(u[2,:]>=$ heating_min, $)$

cons.append $(u[2,:]<=$ heating_max, $)$

cons.append $(u[3,:]>=$ battery_min, $)$

cons.append $(u[3,:]<=$ battery_max, $)$

cons.append $\left(d[0,:]==d f \_s i m[' T o u t '][s t: s t+p h],\right)$ \#ambient air temperature

cons.append $\left(d[1,:]==d f \_s i m\left[' P \_p v '\right][s t: s t+p h],\right)$ \#PV generation

cons.append $\left(d[2,:]==d f \_s i m\left[' Q \_s o l '\right][s t: s t+p h],\right)$ \#solar gains

cons.append $\left(d[3,:]==d f \_s i m[' T g r d '][s t: s t+p h],\right)$ \#ground temperature

cost $=0$ \#cost initialization

cons.append $\left(x\left[3, c h^{*} j\right]==\right.$ soe_min, $)$ \#initialization of battery soe

for $k$ in range $((c h * j)+1, c h *(\bar{j}+1))$ : \#step loop cons.append $(x[0, k]==x[0, k-1]+(d t / C 1) *(u[0, k]+$ alpha1*d $[2, k]+(d[0, k]-x[0, k-$

$1]) / R 1+(x[1, k-1]-x[0, k-1]) / R 4+(x[2, k-1]-x[0, k-1]) / R 5)$,$) \#state estimator 0$ cons.append $(x[1, k]==x[1, k-1]+(d t / C 2) *(u[1, k]+$ alpha2*d $[2, k]+(d[0, k]-x[1, k-$

$1]) / R 2+(x[0, k-1]-x[1, k-1]) / R 4+(x[2, k-1]-x[1, k-1]) / R 6)$,$) \#state estimator 1$ cons.append $(x[2, k]==x[2, k-1]+(d t / C 3) *(u[2, k]+$ alpha3*d $[2, k]+(d[0, k]-x[2, k-$

$1]) / R 3+(x[0, k-1]-x[2, k-1]) / R 5+(x[1, k-1]-x[2, k-1]) / R 6+(d[3, k]-x[2, k-1]) / R 7)$,

\#state estimator 2 cons.append $(x[3, k]==x[3, k-1]+(u[3, k] * d t) /$ cap_bat, $)$ \#state estimator 3 cost $+=(u[0, k]+u[1, k]+u[2, k]+u[3, k]-d[1, k]) *$ price $[k] \#$ \#inimize

electricity bill based on rate flex-D cost $+=c p \cdot \operatorname{norm} 2(u[0, k]+u[1, k]+u[2, k]+u[3, k]-d[1, k])$ \#maximize selfconsumtion

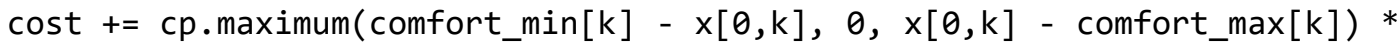

penalty[k] \#penalize comfort violation

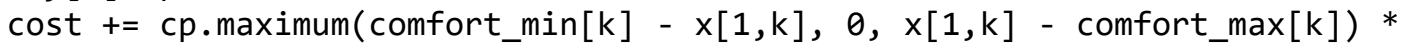
penalty $[k]$ cost $+=$ cp.maximum(comfort_base_min $[k]-x[2, k], 0, x[2, k]-$ comfort_base_max $[k]$ ) * penalty_base[k] cost $+=\operatorname{cp} . \operatorname{norm} 2(\mathrm{u}[0, \mathrm{k}]-\mathrm{u}[0, \mathrm{k}-1])$ \#penalize high slew rate 


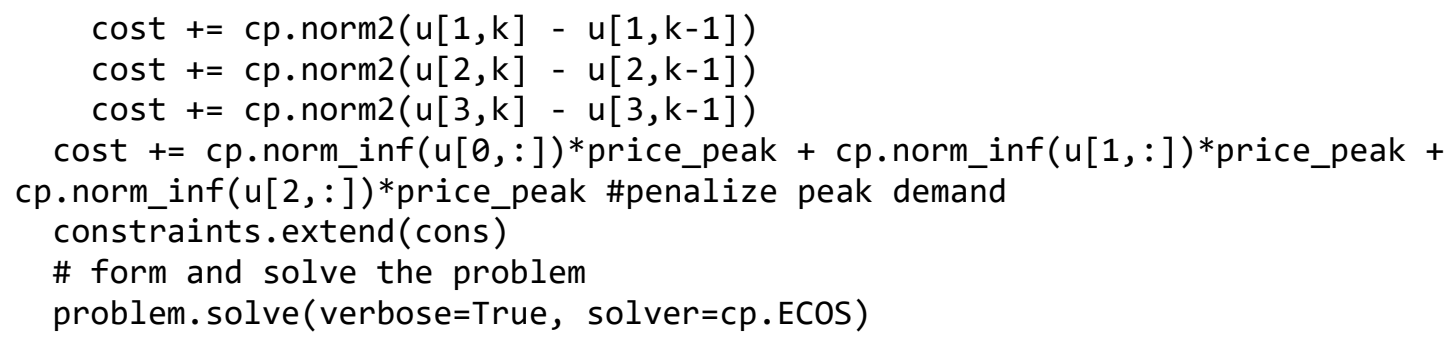




\section{Appendix E: Model Selection and Over- Parameterization}

Low-order thermal RC networks involve parameters that are not (or cannot be) directly observed and must be identified using the observed characteristics of a building or group of buildings. Parameter identification in these networks is an inverse problem, as the parameters that are used to form the model are selected according to the available observations and/or the purpose of study. Practically, the observations and the predictions are two vectors and by minimizing the Euclidean distance between them, the involved parameters are identified. The sum of Euclidean distances between the observations and the predictions for each of the zones over the training period can serve as a useful objective function to be minimized. Different weights can be assigned to each term based on their importance in the overall characteristics of the building, the available training data and the framework of the study.

As these networks grow in complexity, the number of parameters used to form the model may increase to the point where overparameterization can result in overfitting and deterioration in prediction accuracy.

The number of parameters in a $3^{\text {rd }}$ order model tend to be relatively higher, when compared to a $1^{\text {st }}$ order model, as there are more heterogeneous zones and more predominant heat transfer paths in a $3^{\text {rd }}$ order model compared to a $1^{\text {st }}$ order model. This means in such model there are greater number of parameters to be identified and it is a common view that identifying a great number of parameters simultaneously may cause overparameterization and overfitting. Therefore, it is highly desirable to cut the number of parameters that are being identified at the same time in the identification process. Assuming that some parameters of the model are fixed and are not subject to the optimization algorithm helps to reduce the complexity of the calibration; however, this has to be done carefully and needs strong reasoning.

Overfitting refers to the production of an analysis that corresponds too closely or exactly to a particular set of data and may therefore fail to fit additional data or predict future observations reliably. An overfitted model contains more parameters than can be identified 
by the available training data. Overfitting is to unknowingly extract some of the residual variation as if it represents underlying model structure. In other words, overfitting refers to the circumstance where the model starts fitting the existing noise in the training data, as well as the actual observations. The result of an overfitted model is minimal error for the available training data, but larger errors in validation and prediction with other data sets. A model saturates statistically when it has as many parameters as the number of available observations (data points) by which one tries to estimate. In fact, a saturated model is a model that is overparameterized to the point that it is just interpolating the data. Saturated models lead to extremely high-variance predictors that are being pushed around by the noise more than the actual data. Naturally, these models provide a perfect fit to the available training data because they just interpolate or iterate the data.

Calibrating too many parameters simultaneously makes it more likely that overparameterization occurs; however, this definition is independent from the number of parameters. The issue of overparameterization must be solved before sensitivity and uncertainty analysis take place. In an overparameterized model the mean and the standard deviation (if applicable) estimates for the parameters are unreliable. A nonoverparameterized calibrated model is a necessary condition for sensitivity and uncertainty analysis.
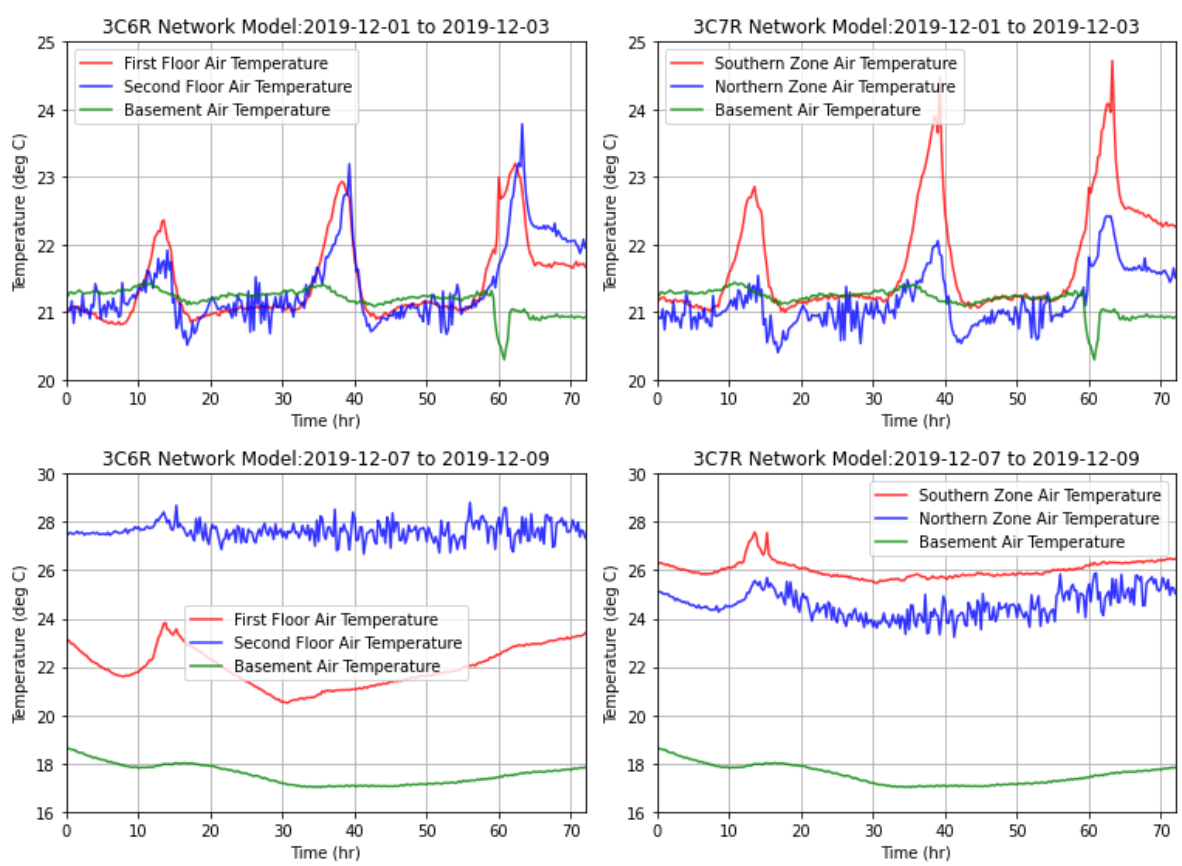

Figure AE.1: Effect of the model resolution on describing the embedded information in the data 